INTER NATIONAL MONETARY FUND
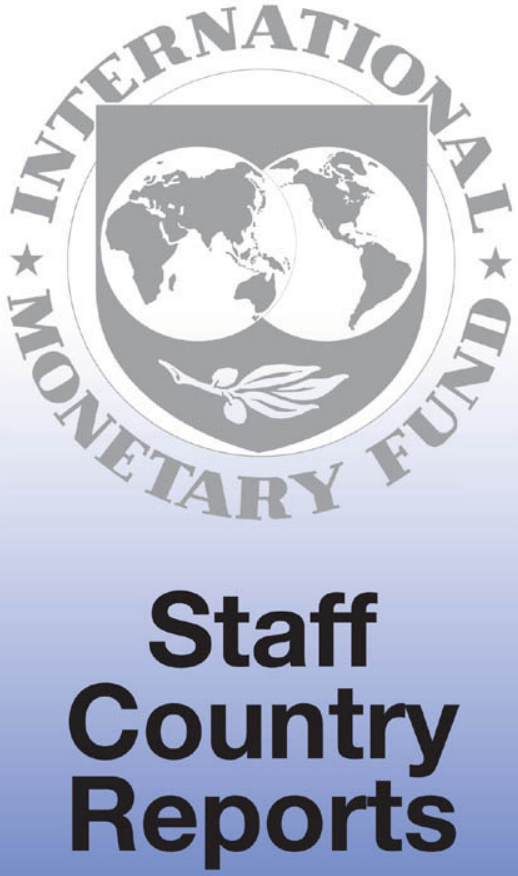


\section{Republic of Mozambique: Poverty Reduction Strategy Paper Progress Report (Review of the Economic and Social Plan for 2003)}

Poverty Reduction Strategy Papers (PRSPs) are prepared by member countries in broad consultation with stakeholders and development partners, including the staffs of the World Bank and the IMF. Updated every three years with annual progress reports, they describe the country's macroeconomic, structural, and social policies in support of growth and poverty reduction, as well as associated external financing needs and major sources of financing. This country document for the Republic of Mozambique, dated March 2004, is being made available on the IMF website by agreement with the member country as a service to users of the IMF website.

To assist the IMF in evaluating the publication policy, reader comments are invited and may be sent by e-mail to publicationpolicy@imf.org.

Copies of this report are available to the public from

International Monetary Fund • Publication Services

$70019^{\text {th }}$ Street, N.W. • Washington, D.C. 20431

Telephone: (202) 623-7430 • Telefax: (202) 623-7201

E-mail: publications@imf.org •Internet: http://www.imf.org

Price: $\$ 15.00$ a copy

\section{International Monetary Fund Washington, D.C.}


This page intentionally left blank

CInternational Monetary Fund. Not for Redistribution 


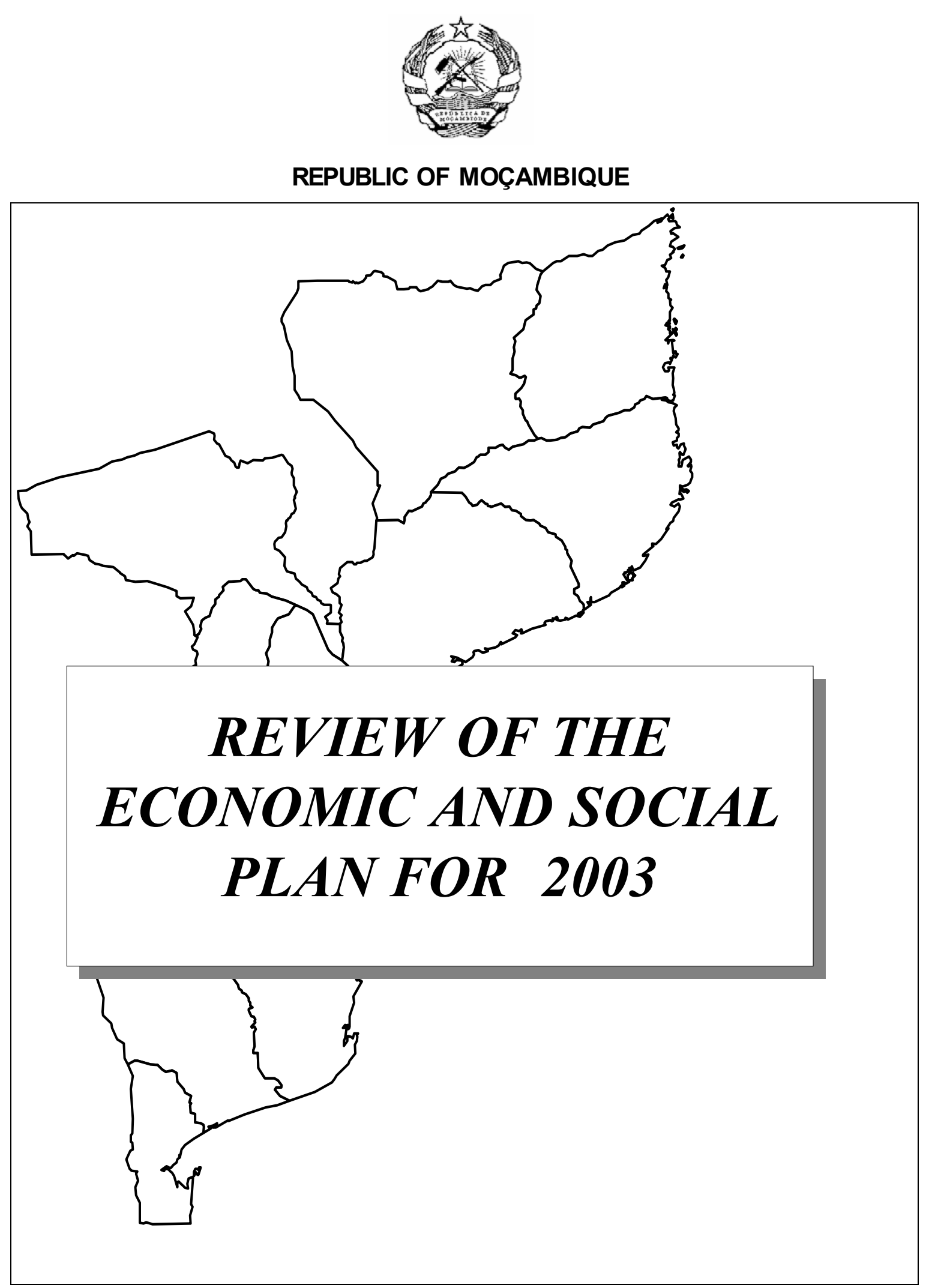

MARCH 2004

CInternational Monetary Fund. Not for Redistribution 


\section{CONTENTS}

I. INTRODUCTORY NOTE

II. IMPROVEMENTS IN THE PLANNING AND MONITORING SYSTEMS \& THE CONSULTATION PROCESS

II.1. IMPROVEMENTS IN PUBLIC PLANNING

II.2. MONITORING AND EVALUATION DEVELOPMENTS

II.3. THE CONSULTATION PROCESS.

III. INTERNATIONAL CONTEXT.

IV. SOCIAL AND DEMOGRAPHIC PROFILE

IV.1. IAF RESULTS ...

IV.2. MILLENIUM DEVELOPMENT GOALS (MDGS).

IV.3. PROJECTIONS OF DEMOGRAPHIC AND MACRO-ECONOMIC IMPACT OF HIVAIDS

V. MACRO-ECONOMIC PROFILE..

\section{MACRO-ECONOMIC PROFILE}

V.1. PRINCIPAL MACRO-ECONOMIC RESULTS

V.2. GLOBAL AND SECTORAL PRODUCTION

V.3. MONETARY AND FOREIGN EXCHANGE SECTORS

V.4. INFLATION

V.5. BALANCE OF PAYMENTS

V.6. MACRO-ECONOMIC OUTLOOK.

VI. MAIN DEVELOPMENTS BY SECTOR .................................................................................... 5

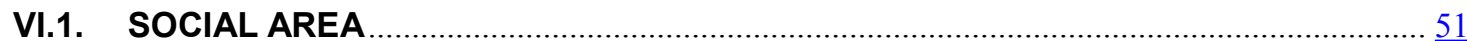

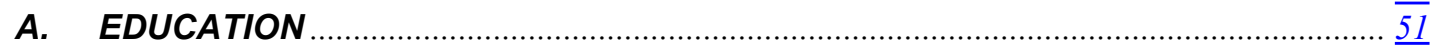

B. SCIENCE, TECHNOLOGY AND HIGHER EDUCATION ......................................

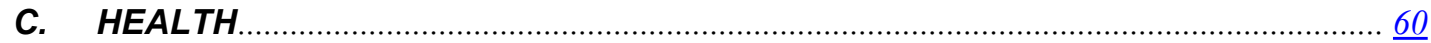

D. LABOUR

E. WOMEN AND SOCIAL WELFARE

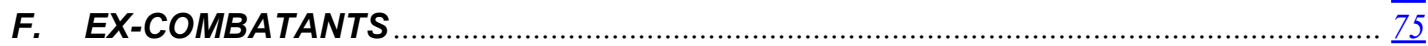

G. CULTURE

$H$. YOUTH AND SPORTS.

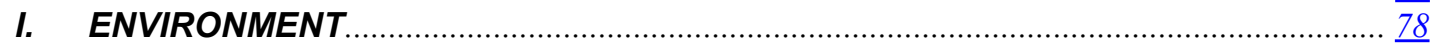

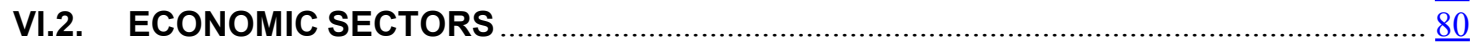

A. AGRICULTURE

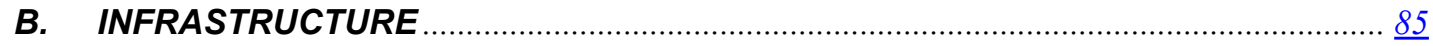

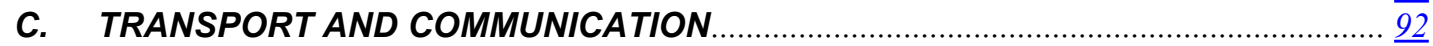

D. PRIVATE SECTOR DEVELOPMENT ASSISTANCE ........................................ $\frac{93}{94}$

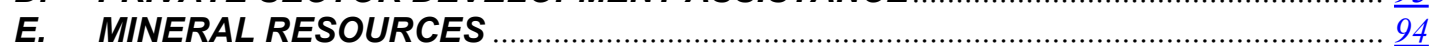

F. FISHERIES

G. MANUFACTURING AND INDUSTRIAL PRODUCTION ....................................... $\frac{98}{98}$

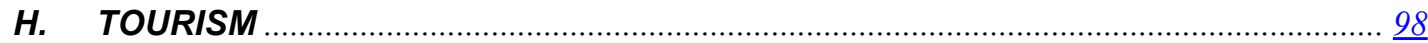

VI.3. GOOD GOVERNANCE, LEGAL SYSTEM, DECENTRALISATION \&

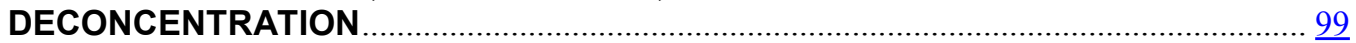

A. PUBLIC SECTOR REFORM, DECENTRALISATION AND DECONCENTRATION $\underline{100}$

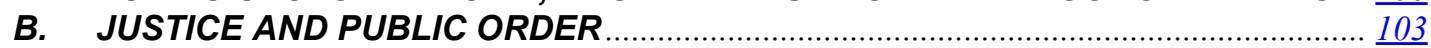

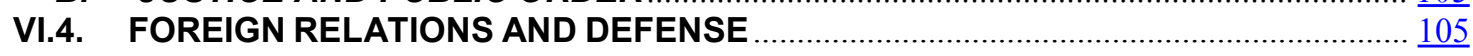

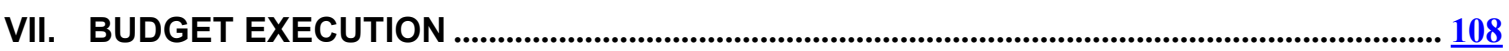


VII.1. REVENUE COLLECTION

VII.2. CURRENT EXPENDITURE

VIII. FINAL CONSIDERATIONS. 


\section{INTRODUCTORY NOTE}

Both the Economic and Social Plan ("PES") and this Review constitute core government planning and monitoring instruments. Given their importance, there is a need for constant improvement of these instruments in order to respond to new challenges that arise.

In this Review of the 2003 Economic and Social Plan a new structure has been adopted. This has resulted in a wider content so as (i) to provide greater consistency and coherence in the operation and harmonization of the different planning instruments; and (ii) to be used for monitoring and assessing the PARPA, an important instrument in the Government's strategy for the reduction of absolute poverty.

This development demonstrates the materialization of the government's commitment to follow up and assess the execution of PARPA through the PES. The expectation is for better visualization of the implementation of Government programmes and their impact in the reduction of absolute poverty in Mozambique.

The document is structured as follows: Chapter II presents the actions that have been taken to improve the current planning instrument, the consultations which took place and issues relating to the improvement of Monitoring and Evaluation of the PARPA; Chapter III presents the international economic context in which Mozambique's performance must be seen; Chapter IV, outlines the social and demographic profile of Mozambique and reviews the extent to which the current strategy for the reduction of absolute poverty in the country is meeting its aims. Results are presented in terms of changes in the welfare indicators (available from the 2002-2003 Household Survey), and the extent to which Mozambique is on course to achieve the Millennium Development Goals (MDG's). This Chapter also deals with the demographic and macro-economic impacts of HIV-Aids epidemic. In Chapter V the macro-economic results are detailed. Chapter VI deals with the Government's performance in the social and economic areas with emphasis on the extent to which the PARPA objectives have been achieved. Trends in key indicators in the main sectors are compared against the planned targets. In addition a discussion of the main activities undertaken in the areas of good governance, legal and justice sectors and support to the development of the private sector is given. In Chapter VII the use of public resources is assessed together with an evaluation of the extent to which the main measures of fiscal policy have been implemented. To this effect the annual planning and budget execution data is compared against the commitments undertaken in this area, especially in the context of PARPA. The final part of the document contains the main conclusions related with each of the issues discussed.

\section{IMPROVEMENTS IN THE PLANNING AND MONITORING SYSTEMS \& THE CONSULTATION PROCESS}


The Government of Mozambique in continuing with its efforts to improve the implementation of its strategies, policies and programmes remains focused on the fundamental goal of reducing absolute poverty through the promotion of social and economic development. In 2001, the Action Plan for the Reduction of Absolute Poverty - PARPA (2001-2005) was adopted as a medium term rolling instrument, incorporated into the public planning system. The central challenge concerns the effectiveness and efficiency to which this medium-term plan can be implemented and this depends on: (i) better integrating the planning instruments, so as to allow for the effective translation of goals and actions identified in the medium and long term into targets and actions incorporated in the annual Economic and Social Plan and the State Budget; (ii) mobilization of adequate stable resources (domestic and foreign) supporting the planned levels of activities; and (iii) improvement of a consistent system of monitoring and evaluation. The domestic and foreign partners must be involved in evaluation of the Government's strategy execution through consultation processes. This chapter is aimed at presenting the most recent developments in these areas.

\section{II.1. IMPROVEMENTS IN PUBLIC PLANNING}

The poverty reduction strategy is managed through the public planning system, which has the Five Year Government Programme at the top, currently referring to the period 2000-2004 which is subordinated by two main bands of instruments, namely:

- Medium term planning instruments. This group, apart from PARPA, includes the sectoral and provincial strategic plans and the medium term expenditure framework (MTEF).

- Annual operation instruments, the Economic and Social Plan (PES) and the State Budget (OE).

These instruments interact for the deepening and improvement of their contents. For each year, the Economic and Social Plan (PES) must operationalise the targets and actions in line with the propositions contained on the medium term instruments. The State Budget (OE), in light with the specific restrictions of resources in each year, determines the level of funded activity, thus to be executed.

The evaluation of the government strategy execution highlights the need for additional efforts towards a greater consistency in the actions aimed at bringing higher effectiveness and efficiency to public institutions. In this context there is consensus within the Government institutions, which is extended to its internal and foreign partners, that it is crucial to have effective improvements in the integration of the Government's Planning instruments, with due emphasis on the Economic and Social Plan, supported by the State Budget. The Economic and Social Plan is the critical link in relation to which measures to achieve the following are required:

- Improvement in the interaction among Government institutions resulting in a more consistent and detailed annual planning hence reflecting the targets and 
actions to be carried out in the year, on PES, in accordance with the main goals of the Five Year Government's Programme and medium term subordinated instruments, especially PARPA.

- Improvement on the implementation management of PES and OE.

- Improvement of monitoring and review processes of PES and related reports, eliminating ad-hoc reports not provided for in the planning system.

The perception and creation of consensus on the need for effective integration of the planning instruments, as mentioned above, were strengthened during the process of designing the current Review of PES, as well as in the Reviews of PES and OE of 2001/2002, in the ad-hoc report of the evaluation of the implementation of PARPA in 2001-2002, in the preparation and execution of the 1st Session of Poverty Observatory (April 2003), and in the Joint Donor Review (May 2003, involving mainly the key partners who directly support the budget).

In 2003 important steps were taken in the desired direction, with emphasis to a study to assess the implications of decentralization and deconcentration on the planning and budgeting system, the preparation of an analysis of pre-requisites for the introduction of budgeting by programmes and the production of a deep study on the experience with the Medium Term Expenditure Framework in Mozambique which includes recommendations for strengthening and greater integration of this instrument with PES and OE. Apart from these initiatives, the Government was engaged in a process of producing an expanded matrix of government action, the identification of a reduced matrix of actions/indicators through which the monitoring by foreign partners will take place. These processes are described in detail in the following sections.

\section{Production of an expanded and multi-sectoral matrix of government action for 2003-2006}

The exercise had as a presupposition, the recognition of the existence of a set of plans, programmes and actions (for medium/long and short terms) generated by the planning system and also commitments already made between the Government and its partners. The exercise consisted mainly of the following:

(a) Verification of the consistency between the propositions of the above set of directives with the content of 2003 PES. Selection of a feasible set (taking into consideration available resources until the end of the year) of subjects/actions, which were eventually, not reflected on the 2003 PES and their adoption for complementary implementation still in the concerned year.

(b) Identification of a sub-set (relatively wide) of actions, programmes and/or subjects to be dealt with and which need to be planned for implementation, on a yearly basis, until 2006. The basic characteristics used for the identification of these actions are their relevance and feasibility, depending on the availability of resources. For each year, these 
actions will be the starting point of the planning exercise for the designing of PES. Adjustments and innovations are expected in this process.

The current matrix was produced with focus on the main areas of action identified in PARPA, namely: Education; health; Infrastructure; agriculture and rural development; good governance; legality and justice; macro-economic and financial policies. As a first exercise on these areas, it was not possible to cover the sub-areas or subjects discussed in the more comprehensive documents on policies and programmes. This is a limitation, which should be overcome in the subsequent exercises. By its nature and as a support document for the annual operational planning, the current matrix has a revolving nature, and requires annual updating and extension. Thus, its timeframe and the incorporation of new data resulting from a better understanding of reality and of the advances in the planning system will be maintained.

The exercise of designing this matrix was integrated on the preparation cycle of 2004 PES. For the next years, this practice will be maintained and integrated on the designing cycle of PES for each subsequent year.

From the institutional point of view, the exercise meant the introduction of a systematic process of interaction between Government institutions that constitute the key areas, under the leadership of the Ministry of Planning and Finance, which is the coordinating institution for the planning process. The practice that was followed showed that the interaction between these institutions is a vital link in the planning process, which must be maintained and extended to the control, monitoring and evaluation of the implementation of the adopted options, objectives, and targets. The effectiveness and efficiency of the Government's action depend on the functioning of this link.

The following are the abridged key elements included in the matrixes, which were produced by sector to be implemented annually between 2003 and 2006:

\section{Education}

Education, a sector with a relatively advanced strategic planning, presents as an essential element the maintenance of an adequate pace of implementation of the strategic plan, which involves the review thereof during the period under consideration. Improvements to be introduced in the planning of the sector include improvement of the monitoring and evaluation system of indicators, the strategic development planning at district level, and the alignment of budget expenditure with the planned programmes and activities.

The increase on the efficiency and quality of education is a central objective, which is associated to actions for the introduction of the new curriculum in the primary education, the inclusion of teachers in the training process currently taking place. 
The elevation of expenditure effectiveness in the sector creates the need for an innovation on the type of schools to be built, with a reduction on the unit price by classroom. In line with the efforts to minimize the costs, a programme will be finalised and adopted for the construction of primary education schools by the communities.

The actions planned for the education sector contribute for the pursuit of specific targets of gross and net admissions to EP1 (Standard 1 to 5), increase in the percentage of girls at EP1, the introduction of the new curricula at national level in 2004 and 2005, the increase in the completion rate at EP1 level and success rate at grade 5 and the reduction in the repetition rate at EP1 level.

\section{Health}

Like education sector, in the Health sector the key issue is around the pursuit of an adequate pace of implementation of the strategic plan for the sector, involving some one-off review in 2005 . The actions that contribute for the improvement of basic indicators in the priority areas of primary health care, health care for the fight against major epidemics and in the fight against HIV/Aids, were identified. The above mentioned indicators include, inter alia: intra-hospital maternal mortality rate, the coverage of institutional child deliveries; infant mortality; vaccination coverage against polio; tuberculosis, DPT and hepatitis; low weight rate at intra-hospital deliveries; hospital mortality rate as a result of malaria; rate of people who stopped tuberculosis treatment before the end of the period; cure rate of new detected cases of tuberculosis; percentage of new cases of leprosy which were cured and/or of those who completed the whole course of treatment; percentage of blood units that tested HIV positive; rate of HIV infections in adults.

Concerning the fight against HIV/Aids, programmes of action are being adopted for prevention and to ensure treatment of STD's, control in blood transfusion an increase in counseling and voluntary testing. Other plans are: review of the National AIDS's Council Country Strategic Plan; expansion of the intervention in campaigns against HIV/Aids in the public and private sectors as well as in the civil society, with the designing and approval of the concerned plans and related funding; in the education sector, the following specific actions are expected: incorporation in the Basic Education of HIV/Aids related themes, sexual and reproductive health, and build the capacity of teachers to teach these components of the curriculum.

The expansion of the sanitary network, furnishing thereof and, the training and placement of staff are important elements to increase access and improve the quality of services provided. 
The efforts to improve planning and management in the health sector lead to the adoption of actions for the development of strategic provincial plans and reinforcement of technical capacity of the Health Provincial Directorates.

\section{Infrastructure}

Concerning roads, the paper makes a detailed identification of the monitoring indicators of road conditions and the efficiency of work execution and improvement of procurement in line with the project's budget. The main works are clearly identified in terms of rehabilitation, periodic maintenance and routine maintenance of tertiary, secondary and main roads.

Under the water and sanitation sector the access indicators for the rural and urban population as well as for the whole population have been clearly identified. The main works for the water network and for sanitation have also been clearly identified, in accordance with the indicators above. The actions identified include important elements of the action plan for the areas of hydro resources management (as a down-stream Country) and institutional development.

\section{Agriculture and Rural Development}

This important area identifies the prospects for the evolution of production covering: cereals (by main crops and totals); other basic food crops including cassava and beans, cash and export crops including cashew nuts, cotton and sugar, cattle breeding including bovine cattle, caprine, swine and poultry. For food crops a distinction is made as to the origin of the expected results between family sector and business sector. As a contribution to the expected results, the following were identified: key indicators of the expansion of access by the farmers to agricultural services of pulverization and vaccination; indicators of the total number of farmers who received assistance from the outreach services, including the provision of public networks and outsourcing; indicators showing the expansion in the use of fertilizers, pesticides, certified seeds, animal traction and watering; expansion in the number of micro-credit clients and the percentage of agricultural farms selling food or cash crops, expansion of the number of agricultural explorations with right of land use and benefit. In the areas of forestry and wildlife the expected evolution in the expansion of community management initiatives, has been determined.

Various process indicators (quantitative) have been determined, including: number of farmers trained in improved technologies; vaccination of cattle and poultry; local seed production; cashew plants produced and distributed; families receiving planting material of cassava and sweet potatoes; animals distributed per year; encouragement campaigns; 
phytosanitarian interventions; identification of areas for and, the execution of rehabilitation and construction works of irrigation Infrastructure.

\section{Good Governance and the Legal System}

The actions included in the matrix related with this area cover the following areas: public sector reform and fight against corruption; justice and legality; creation of a favorable environment which promotes employment and development of the private sector.

In the area of public sector reform the following aspects are highlighted: the elaboration and approval of the State Local Organs Legislation; the execution of a functional analysis of ministries and the consequent restructuring of key ministries, including Education, Health, Agriculture and Rural Development, State Administration and Planning and Finance; completion of the design and implementation of the public sector salary reform. The action related with local organs, together with the actions planned on macro-economic and financial policies, including the expansion of the district participative planning and the suitability of district budgets is critical for the effective impulse of the required deconcentration and decentralization process of the Public Administration. The functional analysis and restructuring of ministries supported by a salary reform aims at contributing to the required increase in efficiency and effectiveness of the public sector, in particular of central agencies.

The extension of anti-corruption units to the provinces and the holding of governance, corruption and service provision surveys, as a support mechanism to the design and adoption of a consistent and wide-covering an action plan which, are important actions that were selected with a view to proceeding and reinforcing the fight against corruption.

The improvement of the planning system in the area of justice has the relevant attention in the actions contained in the matrix. The approval of the integrated strategic plan and the respective operational plan is complemented with the introduction of a revolving planning and budgeting system which does the relevant annual planning integrated in the Economic and Social Plan. This planning highlights the importance of improving the system of indicators on the provision of public services by the justice and legality sector. Emphasis also goes to the creation of an internal performance control system within the attorney general office and courts, which will sustain the increase on the quality of the annual programmes for the judicial inspection services and the General Prosecutors Office. The selected actions aim at also stressing in PES the component of service provision to the public, in a sustainable manner.

A comprehensive package of legal reform is considered, contemplating: the review of the Community Courts Law- Lei 4/92; review of the Family 
and Succession Law; Review of the Criminal Code, Code of Civil Law, of Public Notary and Civil Registration. These reviews will input to simplify the proceedings of court cases, contributing to the flexible and faster provision of justice.

With the aim of expanding and improving the quality of judicial assistance to the poorer people, actions for regulating and reviewing the organic status of the Institute for Legal Assistance (Instituto de Patrocínio e Assistência Jurídica) are contemplated. Judges and attorneys in the provincial capitals and Maputo City working on shifts will be instituted with the aim of ending with the situation where people under preventive arrest stay longer than the period stated in the law without being formerly and officially charged. This programme is associated with the campaign for trials and legalization of the cases of those citizens whose rights in terms of deadlines were not respected. On the other hand, with the aim of providing the required speed in the resolution of commercial disputes, there is a plan for the creation of civil sections planned to deal specifically with issues of commercial nature in the Judicial Courts of Maputo City and of Sofala and Nampula Provinces. These are the courts dealing with most of the cases of this nature.

The actions planned for the justice and legality sector include, improvement of Infrastructure consisting on the continued rehabilitation and construction of: courts, houses to accommodate judges; state prosecutors offices and houses to accommodate state prosecutors; Civil Registration Offices facilities in the districts, and prison Infrastructure.

In order to cater for the creation of a favorable environment to the promotion of employment actions are considered for the review of the following legislation: Labour Law and its regulations, regulations on licensing of commercial and industrial activities (Decrees 43/98 and 44/98); regulations on the inspection of commercial and industrial activities. In association with the review of inspection regulations actions to build the capacity of inspectors are included.

\section{Macro-Economic and Financial Policies}

Reference has already been made to the actions in this area linked to District Participative Planning and bringing District Budgets in line with the Law of State Local Organs. Other relevant aspects related with the improvement of the planning system were also largely dealt with. It is maybe worth highlighting that, the effort for integrating the planning instruments, whereby the key link is to associate PES to the OE, carries with it the concrete effort of respecting the option contained in PARPA (sustained by the Medium Term Expenditure Framework) to allocate about $67 \%$ of the public expenditure to fundamental areas of action. An activity which is worth mentioning is related with the introduction of budgeting through programmes. 
The sustainability of meeting the planned levels of public expenditure requires a progressive effort of increasing the collection of budget revenue. This effort requires the support of an extensive programme of tax reform, with the aim of achieving the planned increase on the collection of budget revenue, based on a system that observes the principles of tax equity and justice and which is supported by an efficient and effective tax administration. Thus, the reform programme includes, inter alia, the following:

- Design, approval and implementation of income tax codes; regulation of tax on vehicles; regulation of tax retention at source of the IRPS, income and pensions of people employed by others; regulation on the General Regime on Fiscal Crimes;

- Design and submission for approval of the General Tax Law proposal;

- Reform of customs legislation, including: introduction of Decree $36 / 2002$ which reduces the maximum import duties to $25 \%$; approval of the Judicial System for Fiscal and Customs Breaches;

- Preparation of the conditions for the introduction of payments of import / export duties through banks;

- Approval and implementation of the programme for the creation and installation of the Central Revenue Authority;

- Preparation and submission of the proposal for Fiscal Courts Law and installation of Fiscal Courts;

The increase in the efficiency of management of available funds and state resources is another critical factor to induce the necessary savings in face of the shortage of available means. Hence, various actions were selected that are related to the introduction of the SISTAFE - Public Financial Management System, and reform of public procurement system. These actions include: adoption of a system for automatic transfer on a daily basis of the collected revenue to the Treasury, by the fiscal administration, both at central level or in the provinces; introduction a Single Treasury Account; elimination of Titles as a means of payment and the adoption of means of payment provided for by the banking system; updating of the register and inventory and, production of a data base of the funding agreements, including off-budgets, as a means of support for the management of off-budgets, with the aim of including those under the control of government into the $\mathrm{OE}$; progressive introduction of eSISTAFFE covering Ministries and Provinces; design (through a participative approach) and adoption of a legal diploma on contracting for Public Works and procurement of goods and services.

The financial sector also deserved special attention and a number of actions were included in the matrix aimed mainly at the reinforcement of 
bank supervision and improvement of the management of monetary policy. The actions include: Design and submission for approval of the new version of the Law for Credit Institutions and Financial Corporations; Review of the law on bankruptcy and liquidation of Credit Institutions and Financial Corporations; development and implementation in the Central Bank of Mozambique of the Bank Supervision Application (IT application for bank supervision within SADC); design and implementation of a programme for the reinforcement of the institutional capacity in the Department of Bank Supervision within Bank of Mozambique; contracting of an independent firm to carry out bank expertise inspection in Banco Austral; implementation of the recommendations of the bank expertise inspection at BIM; contracting of consultants for the assessment of 4 major commercial banks within the IAS scope and training of personnel in the Department of Bank Supervision; design and raising of funding for a project for the reinforcement of institutional capacity of the Bank of Mozambique, including technical assistance and covering the bank supervision areas, payment systems and management of monetary policies

In the financial component actions are also expected in the following areas: implementation of the plans to recover the bad debts associated with the privatisation of Banco Austral and the adoption of BIM's Business Plan; continuation in the process of reducing state's participation (public administration) as a shareholder in the commercial banks. These measures are aimed at reducing possible processes of moral-hazard in the management and contracting of credit due to the involvement of the State.

\section{Identification of a summary matrix of actions/indicators, to assist monitoring by foreign partners}

As previously indicated, convergence between the Government and its foreign partners has been created on the fact that this matrix must include a limited number of actions/indicators, extracted/derived from the Matrix referred to in the previous section. The aim is to create focus on the monitoring of a sub-set of manageable actions, which are in line with the wider set of normal activities planned by the Government. The selection of a limited number of actions, deriving from normal activities, reflects an effort in the maximisation of the lesson learning which occurred in the management of conditionalities in the course of social and economic reforms which led the country to its acknowledged good performance.

The identification process of this matrix consisted of the following:

(a) Selection of proposals for some eligible actions/indicators for inclusion in the reduced matrix for foreign monitoring, during the process of designing the matrix referred to in the previous section. 
(b) Acceptance of the foreign partners' counterproposal for the version of the short monitoring matrix.

(c) Discussion between Government teams and foreign partners for the elimination of possible differences and completion of the design of the intended matrix.

The conclusion of this specific matrix was very much facilitated by the fact that, in this first exercise, the government involved foreign partners in a systematic dialogue process, for the assessment of the overall process of efforts to improve the planning system. This dialogue took place simultaneously with the preparation of the wider matrix, mentioned in the previous section.

The selection of a reduced matrix for foreign monitoring is based in a process of reinforcing trust between the parties. First it became clear that the Government's commitment is to render relevant services to its citizens whose demands are not limited to a reduced number of actions/indicators. In terms of consistence, the Government's actions are vast and are controlled by a wide range of actions/indicators, which the planning system cannot overlook. Therefore, there is no danger of reducing the Government's activity deriving from the selection of a reduce matrix for foreign monitoring. Secondly the reduced matrix is part of a wider set of actions, therefore relevant for the overall action aimed at achieving more complex objectives and goals.

\section{Linkage between medium term sector plans and annual planning}

The process embarked on with the aim of improving the planning system and process, at this stage, emphasized on the need to increase effectiveness on the PES critical linkage nature, as an annual instrument that must increasingly incorporate the propositions of the medium term planning. In this process a key issue was raised on the linkage between medium term sector planning and the annual operational planning, which deserves special attention since it will result on the improvement of the effectiveness of the whole system. Despite its limitations, the sector strategic planning has advanced considerably in various sectors including health, education, roads and water, agriculture and more recently the judicial sector. The sector strategic planning has had the merit of identifying the critical aspects to be prioritized, with the aim of meeting certain targets, which would lead the country to a situation where it would overcome the chronic structural problems, bringing the respective basic indicators close to international relevant averages. This process also identifies the level of required resources for the materialization of the identified programmes and projects. Due to shortage of available resources, the annual planning systematically reduces the targets identified at the medium term planning to significantly low levels. Undoubtedly, this undermines substantial progress on the necessary changes and improvement of indicators. Reiteration of this situation will weaken the effort to improve the planning.

Just to illustrate the content of the previous paragraph it can be mentioned that although acknowledging the importance of Infrastructure, especially roads and 
bridges, and despite the excellent project planning and design system, it has not been enough to identify the adequate funding solutions for an acceptable and necessary pace of recovery and maintenance of the existing network. More recently the judicial sector made efforts during its medium term strategic planning and now with the annual plan, there is a substantial reduction on the planned level of its basic Infrastructure refurbishment, due to lack of means. The identification of an adequate financial engineering for these cases is a challenge to be faced which has not had appropriate solutions, so far.

\section{II.2. MONITORING AND EVALUATION DEVELOPMENTS}

In terms of PARPA monitoring and evaluation, an evaluation Report on the implementation of PARPA in the period 2001-2002 was developed. It contained information on the Government's performance as well as the budget execution for the priority areas. The Report, together with the PES Review and the Report on the State Budget Execution, was presented in April 2003 to national and international partners during Poverty Observatory I.

The report was of extraordinary nature since the Government Monitoring and Evaluation Strategy gives privilege to the use of existing Government action monitoring instruments to supervise and control the execution of PARPA. In this context, efforts are made, namely through greater internal and inter-sector coordination, to ensure that this Report on PES Review includes the relevant information for the monitoring of PARPA as well as the priority activities selected in the reduced matrix of actions and indicators through which the monitoring by foreign partners will take place. This exercise is not limited only to monitoring the processes but also it attempts to equally assess the impact of public policies in the levels of welfare established by the survey on Household Survey (IAF 20022003). On the other hand, in order to reinforce the component of monitoring the qualitative impact, a new methodology involving partners from the civil society was tested in Sofala

In the context of resources monitoring, work has been done in order to harmonize and integrate the information from State Budget Execution Reports and from PES Review. Additionally, analyses of Public Expenditure were done in the areas Education, Health and Agriculture. The communication of the results of the first two analysis was of made through brochures. The Health brochure also includes information on the results from the Survey on Funding, management and rendering of Service at Health Primary Level.

Although there were important advances in the quantity of information due to a more intense dialogue between MPF and the sectors, the quality of information is yet not enough, requiring bigger efforts for the validation of the received data. It is therefore imperative to strengthen the capacity to monitor and assess at all levels (provinces, sectors, MPF).

\section{II.3.THE CONSULTATION PROCESS}


The Government is aware of the need to involve all its partners in the process of monitoring the action for the reduction of poverty. It is in this context that in 2003 the Poverty Observatory was instituted. This forum brings together government players, civil society organizations, including representatives from various religions, business leaders, Trade Unions, NGOs and international cooperation partners. This Review, as the main Government monitoring product, will be submitted for analysis and discussion in the Poverty Observatory, which will take place in the first half of 2004.

On the other hand, the different sectors have institutionalized the principle of consultation and participation of partners involved in the implementation of the relevant strategic plans. The Agriculture sector also used a process of consultation for the designing of the second phase of its integrated programmes referred to in section VI.2. Next, as an example, more details are given in the cases of Education and Waters.

In the case of Education, in 2003 the most important events that took place were the National Meeting for Planning, the Coordination Meeting of MinEd (Conselho Coordenador do MinEd) and the Annual Meeting for the Review of the Strategic Plan for Education. The Coordinating Council, in particular, apart from the effective members of the group, it had as invitees the district directors for Education, representatives from NGOs, Teachers Trade Union, religious groups and foreign partners. The annual meeting for the Review of the Strategic Plan for Education was the highest point in terms of the mechanisms established for consultation and participation in planning Education. The following attended the event: MinEd at all levels as well as other government's sectors (MAE and MPF), representatives from national and foreign NGOs and bilateral and multilateral partners.

The participation of our partners in the planning and implementation of programmes in the Water Sector is a crucial factor for better hydro resources management. To accommodate this need of greater involvement and structuring of the active actors in the Sector, the National Council for Waters (CNA) under the Water Law was created. Other initiatives taking place with the aim of allowing for greater integration and participation of the community sectors include the work sub-group dealing with Water Supply and Sanitation, the sub-group working on the integrated management of hydro resources, and the sub-group responsible for the institutional capacity building and Human Resources Management. The Core group, which coordinates the activities of the above mentioned three sub-groups met twice during 2003. Another meeting of the Wider Working Group for the coordination and supervision of processes for the formulation of the National Strategy for the Integrated Management of hydro resources, which also involves Government's partners, also took place.

\section{INTERNATIONAL CONTEXT}


The recovery of the world economy in 2003 was progressive and with a great variation amongst economies. Predictions indicate that growth in the developed economies will be below the long-term trends. For 2004, a possible recovery is expected in terms of growth above long-term trends. However, an aspect that deserves special attention in 2003 , and with an effect for the following years is the level of fiscal deficits of the more advanced economies, which might affect potential flows of resources to developing economies, and for Africa in particular.

According to recent estimations made by the International Monetary Fund [IMF] and by the OCDE, the world economy in 2003 grew by close to $3 \%$. For 2004 , the world GDP is expected to grow by about $4 \%$.

Growth in developing countries is estimated to have been of $5 \%$ in developing countries in 2003, and will remain within the same levels in 2004 . In relation to Africa, it is expected to have reached $4 \%$ of growth in 2003 and will reach $4.8 \%$, in 2004.

The global international trade grew at about $3 \%$ in 2003, and is expected to grow by $6 \%$ in 2004. Imports and exports, for 2003 and 2004, both for advanced economies and developing economies, show growth rates higher than they experienced in 2002 
Selected Growth Rates in \%

\begin{tabular}{|c|c|c|c|}
\hline & 2002 & 2003 & 2004 \\
\hline $\begin{array}{l}\text { World GDP Growth Rates } \\
\text { USA } \\
\text { Japan } \\
\text { Euro Zone } \\
\text { Advanced Economies } \\
\text { Developing Countries } \\
\text { Africa } \\
\text { South Africa }\end{array}$ & $\begin{array}{l}2,4 \\
2,4 \\
0,2 \\
0,9 \\
1,5 \\
4,2 \\
3,1 \\
3,6\end{array}$ & $\begin{array}{l}3,0 \\
2,9 \\
2,6 \\
0,5 \\
2,2 \\
5,0 \\
4,0 \\
1,9\end{array}$ & $\begin{array}{r}4,0 \\
4,2 \\
2,0 \\
1,7 \\
2.5 / 3 \\
5,0 \\
4,0 \\
2 / 3\end{array}$ \\
\hline $\begin{array}{l}\text { International Trade } \\
\text { Imports }\end{array}$ & 2,1 & 2,9 & 5 \\
\hline $\begin{array}{l}\text { Advanced Economies } \\
\text { Developing Countries }\end{array}$ & $\begin{array}{l}1,2 \\
3,2\end{array}$ & $\begin{array}{l}2,9 \\
5,3\end{array}$ & $\begin{array}{l}4,8 \\
6,5\end{array}$ \\
\hline $\begin{array}{l}\text { Exports } \\
\text { Advanced Economies } \\
\text { Developing countries }\end{array}$ & $\begin{array}{l}1,7 \\
3,8\end{array}$ & $\begin{array}{l}1,1 \\
5,0\end{array}$ & $\begin{array}{l}4,8 \\
6,0\end{array}$ \\
\hline
\end{tabular}

Source: IMF World Economic Outlook (September 2003), OECD (June and December 2003), The Economist (various).

According to data published recently, the economy of the United States of America grew by $2.4 \%$ in 2002 and it is estimated to have grown by around $2.9 \%$ in 2003. The Federal Reserve Bank reduced its interest rates (federal-funds) to $1 \%$, the lowest level in the last years, being this sign to support the recovery of the economy. By November 2003, industrial production grew by $1.6 \&$ in relation to the same period of 2002 , and the retail sales, by October, grew by $7.8 \%$ in relation to the same period of the previous year, consumption has been responding strongly and helping to the recovery of the economy. The Gross Formation of Fixed Capital 'Formação Bruta de Capital Fixo (FBCF)' in 2003, is estimated to have grown about $3 \%$, with emphasis to housing investments. Exports recovered in 2003. Unemployment level in December 2003 was about $6 \%$

In Japan growth stalled in the second half of 2002 as a result of a reduction in the exports. Although domestic demand continues to be weak, the recovery of international trade during the second half of 2003, whereas exports might grow about $7 \%$, strengthening the FBCF growth, may contribute for a mild growth which is expected to have reached $2.6 \%$ in 2003 and $2 \%$ in 2004 .

In the European Union, Euro zone, after a GDP growth of $0.4 \%$ during the 1 st half of 2003, it is estimated that growth was around $0.5 \%$ in 2003 and should be $1.7 \%$ in 2004 . The unemployment rate was $8.9 \%$ in July 2003, higher than experienced during the same period of the previous year $(8.4 \%)$ and in October it was at $8,8 \%$. In relation to inflation, it was at $2 \%$ during the first half of 2003 and is estimated to have been at about $2 \%$ and will be $1.3 \%$ in 2004 . In 2003 , neither exports nor FBCF had a positive performance.

In South Africa, the GDP growth rate for 2003 was 1.9\%, and the South African economy grew by $3.6 \%$ in 2002 . The sectors that gave major positive 
contribution for the growth in 2003 were Transport and Communications, Financial and Corporate Services and gross and retail Trade, hotels and restaurants. However, Agriculture, Forestry and Fishery and the Manufacturing sector are those, which gave a negative contribution for growth. In Agriculture, a note must be made to the low harvests of maize and vegetables. Concerning the Manufacturing sector, the areas that contributed for the weak performance are equipment and transports, food, tobacco and beverages, electronic equipment, textiles, clothes and leather (hide). For 2004 expectations indicate a growth rate of between 2 and 3\%. Inflation was 5.8\% in 2003, against $9.2 \%$ during the previous year. The Rand (SA Currency) at late 2003 was rated at about 6.7 Rand for a Dollar, while it was rated 9 during the same period of the previous year, an appreciation of about 25\%. In 2001 and 2003, the Rand experienced an accumulated appreciation of about $45 \%$ in relation to the Dollar. Metical (Mozambican currency) depreciated in relation to the Rand during the period 2002 and 2003 (end of period variation) by $22 \%$ and $28,7 \%$, respectively. The average of Mozambicans imports from South Africa corresponds to $45 \%$ of the total of imports. This performance of the last two years has an impact on the real volume of imports originating from this neighbouring country, which might also influence the prices and costs of Mozambicans companies. From that structure of imports $40 \%$ are chemical and related products, $30 \%$ are various machinery and vehicles and about $12 \%$ are metallic and non-metallic products.

Zimbabwe experienced a growth rate of $11 \%$ in 2003, and in 2002 it was $13 \%$. The accumulated GDP fall in this Country between 1999 and 2003 was about $33 \%$. In 2002, inflation was around $140 \%$ and for 2003 it was $500 \%$. This performance has big impacts on the economic activity in the Centre of Mozambique, namely on the ports and rail and utilisation of the pipeline.

As to the rest of SADC economies, excluding Mozambique, South Africa and Zimbabwe, growth was around $3 \%$ in 2003 , having been about $4 \%$ in 2002 . The countries with a relatively high rate for the average above are Angola, Lesotho, Malawi and Tanzania. The countries with relatively lower rates are Seychelles e Swaziland. The level of inflation in the SADC economies is around $8-10 \%$, for the period 2002 and 2003, excluding Angola, Democratic Republic of Congo and Zimbabwe, which represent inflation rates much higher than the average. However, there is a trend for the reduction of the levels of inflation in these countries, in general.

The trading terms for the more advanced economies experienced stagnation during the period 2003-2004.

The table below shows the growth rate of the Consumer Price Index for 20032004. In the advanced economies there will be a trend to price stability to relatively lower levels, while in developing economies and in Africa, the inflation rates will vary between $6 \%$ and $10 \%$. It is estimated that the interest rates in the more developed economies will continue at the levels experienced in 2002, despite showing a trend for a light increase. 


\section{(Percentages)}

\begin{tabular}{l|r|r|r|}
\hline & 2002 & 2003 & 2004 \\
\hline Trade Terms & & & \\
Advanced Economies & 0,2 & 0,0 & 0,0 \\
Developing Countries & $-0,2$ & 0,2 & 0 \\
& & & \\
Prices in Dollars & & & \\
Manufactured Products & 2,6 & 4,5 & 1,5 \\
Oil & 0,5 & 7,8 & $-4,0$ \\
Commodities & 4,2 & 5,6 & 3,1 \\
& & & \\
Inflation & & & \\
USA & 1,6 & 2,1 & 1,3 \\
Euro Zone & 2,1 & 1,8 & 1,3 \\
Advanced Economies & 1,4 & 1,9 & 1,6 \\
Developing Countries & 5,6 & 6,0 & 6,0 \\
Africa & 9,6 & 9,0 & 9,0 \\
\hline
\end{tabular}

\section{(Percentages)}

\begin{tabular}{|l|l|l|l|}
\hline & 2002 & 2003 & 2004 \\
\hline Short Term Exchange Rates & \multicolumn{4}{|l}{} \\
USA & 1,8 & 1,6 & 3,4 \\
United Kingdom & 4,0 & 4,2 & 5,0 \\
Euro Zone & 3,3 & 3,0 & 3,6 \\
Japan & 0,1 & 0,0 & 0,0
\end{tabular}

Unemployment

\begin{tabular}{llll} 
USA & 5,8 & 6,0 & 5,8 \\
Japan & 5,5 & 5,6 & 5,6 \\
Euro Zone & 8,3 & 8,5 & 8,3 \\
Advanced Economies & 6,8 & 6,9 & 6.7 \\
\hline
\end{tabular}

Source: IMF World Economic Outlook (September 2003), OECD (June and December 2003), The Economist (various)

For 2004, it is expected that unemployment rates in more advanced economies remain at the same levels as during 2003. This is an indicator that the recovery of the world economy was and will continue to be slow in 2004.

By the end of 2003, the performance of some products at the international market showed the following trend: i) gold had a variation of about $21 \%$ in relation to the same period of 2002 , having reached $\$ 416,4$ per ounce; ii) crude price (West Texas Intermediate) experienced an increase of $8 \%$ in relation to the same period of 2002, having been rated at $\$ 33$ a barrel; iii) food products experienced an increase of about $10 \%$; iv) industrial products experienced an increase of $33,6 \%$.

For 2004, the IMF expects the prices of manufactured products to grow by $1.5 \%$, and for the rest of the commodities to increase by $3.1 \%$. The Fund and the OCDE estimate that crude price will fall by $4 \%$ in 2004 . 
These predictions point to a scenario of the international economy for the period 2003-2004, with still a slow recovery of the advanced economies. In 2003 some of those more advanced economies had to take some measures in terms of fiscal policies to face the slowing down of their economies, and many of them today present relatively high fiscal deficits in comparison with the last years. These predictions indicate to a scenario of the international economy with yet many risks, as the slow recovery of the more advanced economies will pose some difficulties for the less developed e dependent from the more developed. The interest rates may increase lightly during 2004 . Finally, crude price is still an incognito depending on the international momentum and particularly on the Middle East. 


\section{SOCIAL AND DEMOGRAPHIC PROFILE}

\section{IV.1. IAF RESULTS}

Between 1996 and 1997 the first survey on the households consumption (IAF I) was conducted basing on an approach of "cost of the basic needs"; this survey was representative at the national level. The outcome of the survey, show a poverty incidence of about $69,4 \%$ at the national level, and also showed that poverty was more acute in the rural areas that in the urban areas.

A second survey on the consumption of households (IAF II) was conducted between 2002 and 2003. Using the same approach of "cost of the basic needs", the outcome of IAF II showed a poverty incidence of $54,1 \%$ (Table below), suggesting that poverty incidence at the national level has decreased by $15.3 \%$ during the six-year period between the two surveys.1 As on the first IAF, IAF II shows that poverty is more acute in the rural areas in comparison with the urban areas, however, between the two periods, poverty reductions has been higher in the rural areas than in the urban areas. Further to that, IAF II outcome indicate major reductions of poverty in the central region, which is after all, the region with more inhabitants. Despite not being that fast, poverty reduction in the northern region was generally also strong with a variation of $11 \%$.

Table: Poverty Incidence from 1996/97 and 2002/3

\begin{tabular}{|r|c|c|c|}
\hline \multirow{2}{*}{} & \multicolumn{3}{|c|}{ Estimations of Poverty Incidence } \\
\cline { 2 - 4 } & $1996-97$ & $2002-03$ & Difference \\
\hline \hline National & 69,4 & 54,1 & $-15,3$ \\
Urban & 62,0 & 51,5 & $-10,5$ \\
Rural & 71,3 & 55,3 & $-16,0$ \\
\hline
\end{tabular}

More specifically, of the 11 elements represented on the survey (ten provinces plus Maputo City as a separate element), eight experienced a reduction on the poverty incidence. The Provinces that experienced a poverty reduction higher than the national average are: Niassa, Nampula, Zambezia, Tete, Manica and Sofala (Chart below).

Chart: Changes of Poverty Incidence $1996-97$ by Province

\footnotetext{
${ }^{1}$ For more information on the methodology and outcomes in general see the report: Poverty and Welfare in Mozambique: The Second National Evaluation (MPF, 2004).
} 


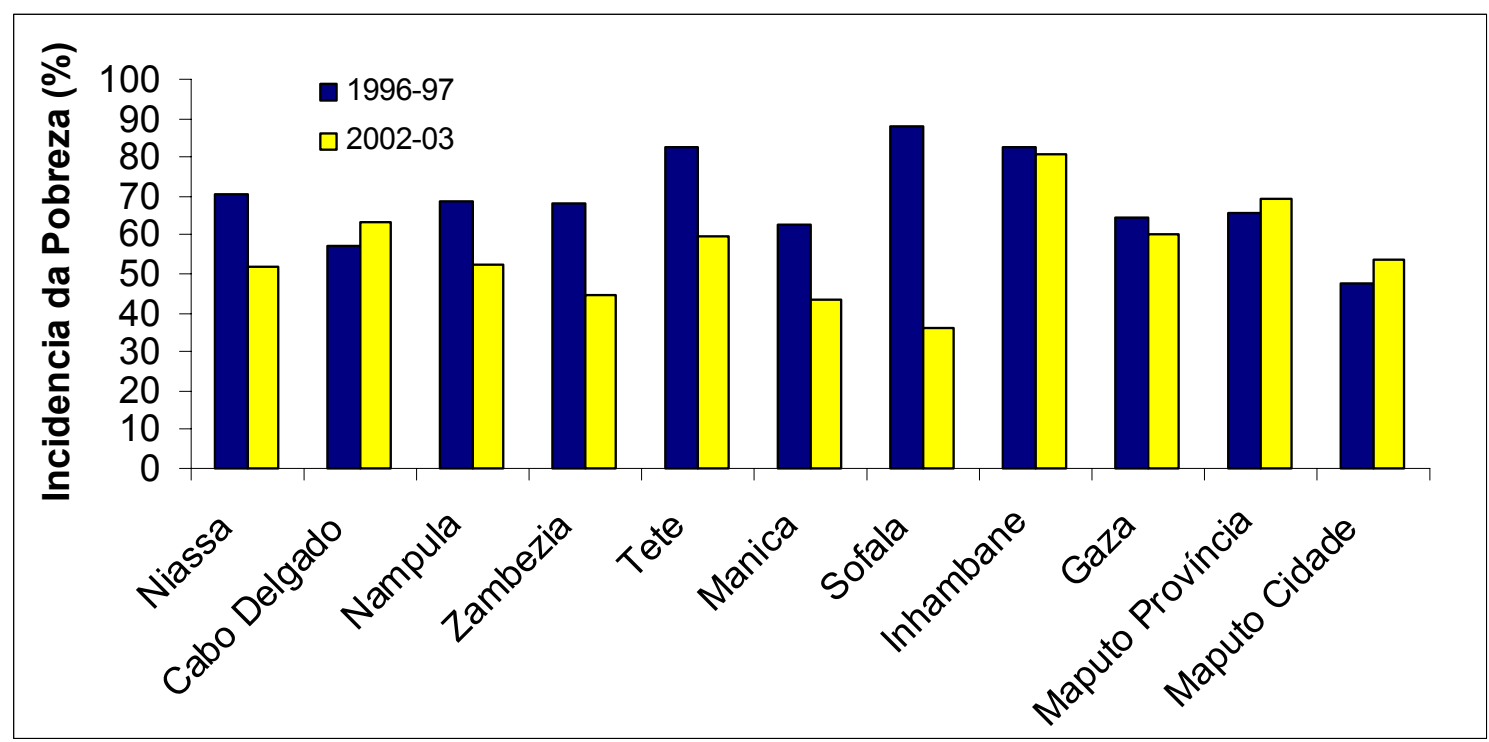

Three factors might have had an influence on the results from various provinces, especially Sofala. The two first ones are related to the special circumstances under which the first IAF was conducted. First the local floods in the Province in 1996 and 1997 resulting in particularly low households income (especially in agriculture) while forcing the soaring of prices at local markets. Second, on the IAF 1996-97, 70\% of the urban households in Sofala were interviewed in January and February 1997 - "famine season" - when the prices were higher. The third factor is related with the fact that Sofala, as well as the whole central region, was extremely affected by the war. Thus it is very probable that the effects of the war continued to make the living standards to be very low in 1996-97. Consequently, the reduction of poverty incidence recorded by the IAF 2002/03 appears to be very high in the Central region.

In contrast, Cabo Delgado and Maputo (including Maputo City) experienced an opposite trend to the other provinces during that period.

The rapid appreciation of the Rand against the o Metical (40\% between January 2002 and June 2003) is one of the factors that explain the increase on the incidence of poverty in Maputo (province and city). Given that Maputo depends strongly on importing food and non-food products from South Africa, the rapid appreciation of the Rand had substantial implications on the basic cost of living during the period when the household survey was conducted.

The global results, at the national level, of the household survey (IAF) are highly consistent with the information from other sources of data. In order to monitor changes on the living standards at reduced costs and more frequently, INE implemented the Welfare Basic Indicators Questionnaire (QUIBB) in 2000-01 and in 2002-03 (simultaneously with IAF 2002-3). When living standards improve, households accumulate more assets. For example, the percentage of households that own bicycles has increased to the double between IAF 1996-7 and QUIBB 2000-01 and increased modestly between the later and e IAF 2002- 
3. Owning a radio also shows this growing trend between the two surveys. On IAF $2002-3,45.2 \%$ of households own a radio, compared with only $28.9 \%$ of households during the period referring to IAF 1996-97.

The changes that occurred on the housing and sanitation conditions are other indicators of improvement of living standards. Comparisons of IAFs 1996-7 and 2002-3 show an evident improvement in these areas. For example the percentage of households with houses covered with grass has decreased by about $8 \%$, while the percentage of households with latrines increased from $31 \%$ to $41 \%$.

Schooling is another useful indicator in the living standards and it is possible to note the efforts made by the Government, in the scope of the strategy to reduce poverty and social and regional unbalances, where it has been implementing, with remarkable results, a program of expanding education to all levels. The results on schooling are explanatory of an increase of children that were enrolled, from less than half to close to two thirds between the two surveys. Once again growth has been faster in the rural areas. Despite the fact of differences in terms of schooling between the rural and urban areas has a tendency to decrease, it still persists and on a large scale.

Like wise, data of the Food Security Early Warning System (FEWS) shows a growth on the production of grains per capita of about $14 \%$ in the period between 1996-2002. The rural survey on the rural households income (TIA) was also conducted in 1996 and 2002. Using the food baskets developed by IAF of 199697 and 2002-03 to generate comparisons of real income, the real of the medium net income of the production per capita increased between 1996 and 2002 in about $26 \%$ between 1996 and 2002.

\section{Linkages with the growth on the economy}

It should be noted that reduction of the poverty incidence has occurred during a period of high economic growth in Mozambique. Between 1996 and 2002 the real GDP increased by $62 \%$. Despite being slighter, the growth of real consumption per capita still experienced an impressive increase of $50 \%$. Given the related restrictions on the distribution of income at the large scale, economy growth is a critical condition for the poverty reduction. The official data show that this condition was minimally met. However, for poverty reduction, growth only is not sufficient. The pattern of growth is also important. Concentration of growth benefits on classes with major income would obviously reduce the impact of growth on poverty reduction. While the evolution of income distribution continues to be a topic for future investigations, the results of IAF provide a global level confirmation of the rapid growth on the consumption and indicate a considerable accumulated sharing of benefits to the lower income elements of the population.

\section{IV.2. MILLENIUM DEVELOPMENT GOALS (MDGs)}


The PES Review provides a good opportunity to assess the extent to which Mozambique is on course to meet the Millennium Development Goals - MDGs. These goals are a set of objectives for human development established by the Millennium Declaration that was signed in September 2000 by 147 countries. The following MDGs are to be met by 2015 :

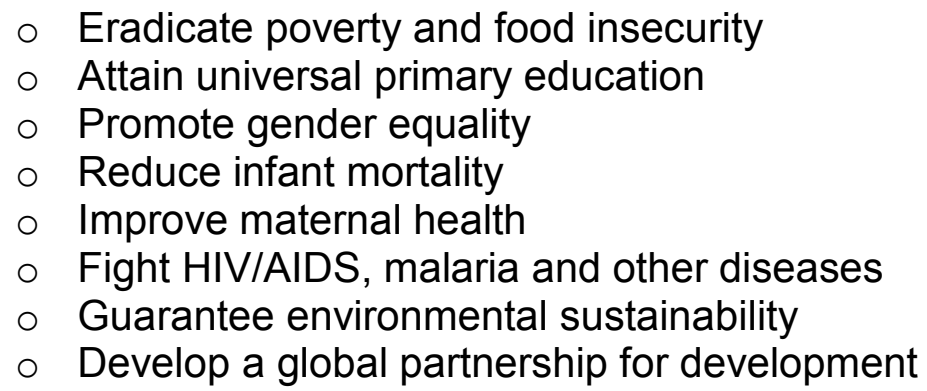

For each objective the United Nations designed concrete monitorable goals measured by quantitative indicators. However, in some cases it is necessary to adjust these goals to the national context. For example, the indicators suggested by the United Nations are not always possible to gather on an annual basis. In such cases therefore proxy indicators, developed for PARPA monitoring, are more relevant. The following section, presents each of the goals together with a brief discussion of the status of Mozambique in terms of the MDGs' challenge. However, chapter VI covers the activities developed to meet those objectives.

\section{Reduction of Extreme Poverty and Food Insecurity}

A global ("MDG") goal, aimed at reducing the percentage of people living in extreme poverty or suffering from famine to half between 1990 and 2015. The results of the IAF indicate that Mozambique is on the right track to meet this goal. After all, it can be said that the PARPA central objective of reducing poverty incidence to less than $60 \%$ of the population by 2005 had already been met. Likewise the results of the Food Security Early Warning System (FEWS) and of TIA show positive results. However, as there is no reliable information concerning poverty incidence in 1990 , it is difficult to establish precisely which is the target for the 2015 MDG. Nevertheless, the targets established on the PARPA are, in general, consistent with the MDG targets.

Despite that these trends are favorable, the poverty levels remain high. From a population estimated at 18.3 million of inhabitants, almost 10 million are still poor. In future, while the poverty measured by the consumption is an integral component of a multi-dimensional poverty concept, some attention should be directed to aspects of poverty, such as access to public services that are not directly measured through households surveys based on consumption.

\section{Fighting HIVIAIDS}


One of the objectives of the Millennium Development is to stop and start reducing, by 2015, the spreading of HIVIAIDS. In order to know the real dimension and geographic distribution of the HIVIAIDS, there have been studies on the demographic and macro-economic prevalence and impact of this pandemic, as detailed under section IV.3 below. It is too soon to indicate the real impact of the National Strategic Plan for the Fighting of HIVIAIDS. This program has many different components including a big awareness and HIVIAIDS mitigation programme and free distribution of condoms. Specific actions in 2003 were developed involving the civil society in actions of fighting AIDS, giving responsibility to Ministries per area of action, promoting a concrete multi-sector response and giving priority to geographic areas of economic corridors in the Centre, South and North.

\section{Basic Commodities}

One of the objectives of the Millennium Development is to half the proportion of people without access to potable water by 2015. In 1992 according to statistics of the Public Works and Housing sector, $10 \%$ of rural households had access to potable water, while in 2003 they were $39.4 \%$ households. In the urban areas the rate of increase was slower, from $29 \%$ in 1991 to $33.3 \%$ in 2003. An important factor associated to this situation is the rapid migration thus, although the absolute number of people in the urban areas who have access to potable water has increased considerably as a percentage of the urban population, the coverage increased more slowly. However, as a result of the new urban water and sanitation project in various cities, this number should increase rapidly.

\section{Universal Primary Education}

One of the objectives of the Millennium Development is to meet the universal access to primary education by 2015 . The universal primary education continues to represent a great challenge for Mozambique. The strong growth in the admission rates in Primary Education (EP1) shows the efforts by the government to improve the situation in terms of primary education, yet there are still various challenges. In the first place, the recent evaluation of the education expenses suggests that current expenditure is still insufficient. Secondly, as suggested by the high repetition rates, the quality of primary education remains low. Thirdly, the enrollment rates for upper primary education (EP2) continue to be disappointing. The two latter problems are being tackled through various efforts, including training of teachers and the introduction of a new curriculum to merge EP1 and EP2.

\section{Gender Equality}

One of the objectives of the Millennium Development is to eliminate gender unbalances within the primary and secondary education, preferably by 2005 , and at all levels of education by 2015 , the latest. In recent years, gender unbalance 
within the primary education decreased remarkably. The Education Sector Strategic Plan aims to increase access to education, giving particular emphasis to girls' education. Further to that, there are programs such as Food Rations to Girls, which make a great effort so that there are more female teachers. Should the present trends persist, it is probable that the objective of meeting gender parity in education will be met on the first grade education by 2005 , or a bit later.

\section{Reduce child mortality}

Another objective of the Millennium Development is to reduce the mortality of children under the age of 5 years of age by two thirds by 2015. In order to meet this MDG Mozambique needs to reduce the mortality rate of children under 5 from $277 / 1000$ living births in 1994 to $82 / 1000$ living births in 2015 . The mortality rate of children under 5 in 2002 was 135/1000. This shows that it is possible to meet the MDG by 2015. Part of Government efforts in this area is the Wide Vaccinations Programme. The objective of PARPA - 2005 of $98 \%$ of coverage of BCG (against Tuberculosis) seems to have been met in 2003 but a lot of effort is still necessary to raise the coverage rate of DTP (3) vaccination.

\section{Improve the maternal health}

BY 2015 the reducing by three quarters the ratio of maternal mortality is another Millennium Development Goal. A central component in the Health Sector Strategic Plan and of the PARPA is the Maternal-Child Health Programme and Family Planning (SMI/PF). In 2003 the main components of the Maternal-Child health continued to keep the trend of growing that they have been experiencing since 1999. With exception to institutional child deliveries, the indicators of women's' health are above the predicted targets on the PARPA. The target of PARPA to reduce the intra-hospital maternal mortality from 175 to 100,000 in 2000 to 160 in 2005 can be met.

\section{Fight against malaria}

One of the objectives of the Millennium Development is to stop, by 2015, and starts to regress the incidence of malaria and other notorious diseases. In 2003 $4,478,215$ cases of malaria were notified and 3,212 deaths, which represents a reduction from $1.6 \%$ to $23 \%$ on the number of cases and deaths respectively in relation to 2002. The prevention programs are common and effective treatment at the hospital is still being followed closely.

\section{Environmental sustainability}

One additional objective of the Millennium Development is to integrate the principles of sustainable development in the programs and policies of the Country and regress the loss of environmental resources. There is a high level political commitment for the promotion of this objective. The creation, in 2001, of the Commission for Sustainable Development aims to meet this objective and also ensure that the sustainability issues are being disseminated. 


\section{IV.3. PROJECTIONS OF DEMOGRAPHIC AND MACRO-ECONOMIC IMPACT OF HIV-AIDS}

AIDS is the pandemic with enormous challenges for its control at present in Mozambique. Mozambique is within the most affected group of countries in the world. The national prevalence rate of HIV in 2002 was 13,6\%. For 2003 the national prevalence was estimated at $14 \%$.

Knowing exactly the dimension and geographical spread of HIV/Aids in our country facilitates the decisions and policy design, which are more realistic and integrated for the control of the epidemic.

It was in this context that the Government, in 1998, adopted a multi sectoral approach with the aim of involving each sector of the society in the fight against AIDS, at the level of its areas of influence. In the context of this multi-sectoral approach a Technical Group was set up in 1999 for support in the fight against HIV/Aids. Currently there are eight institutions: Ministry of Health, Ministry of Planning and Finance, Statistics National Institute, Centre for the Study of Populations (UEM), Faculty of Medicine (UEM), Ministry of Agriculture and Rural Development, Ministry of Education and the National Council for the Fight Against HIV/Aids. This group has, as its main mandate, the elaboration and publication of data on the prevalence projections and demographic impact of HIV/Aids in Mozambique.

Based on recent information, from the 2002 epidemiological survey, the Technical Group compiled the data on demographic Impact of HIV/Aids in Mozambique between 2003 until 2010. The study presents HIV/Aids prevalence projections in adults and the demographic Impact of HIV/Aids in terms of the number of people living with HIV/Aids, new cases, death and life expectancy of the populations. The results from the study are the following.

The chart below presents the national HIV prevalence amongst the adult population between 15-49 years of age. If the historic trend is followed without an immediate and efficient intervention it is expected to reach $16,8 \%$ by 2010 . 


\section{Chart : National HIV Prevalence in Adults (15 - 49 years of age)}
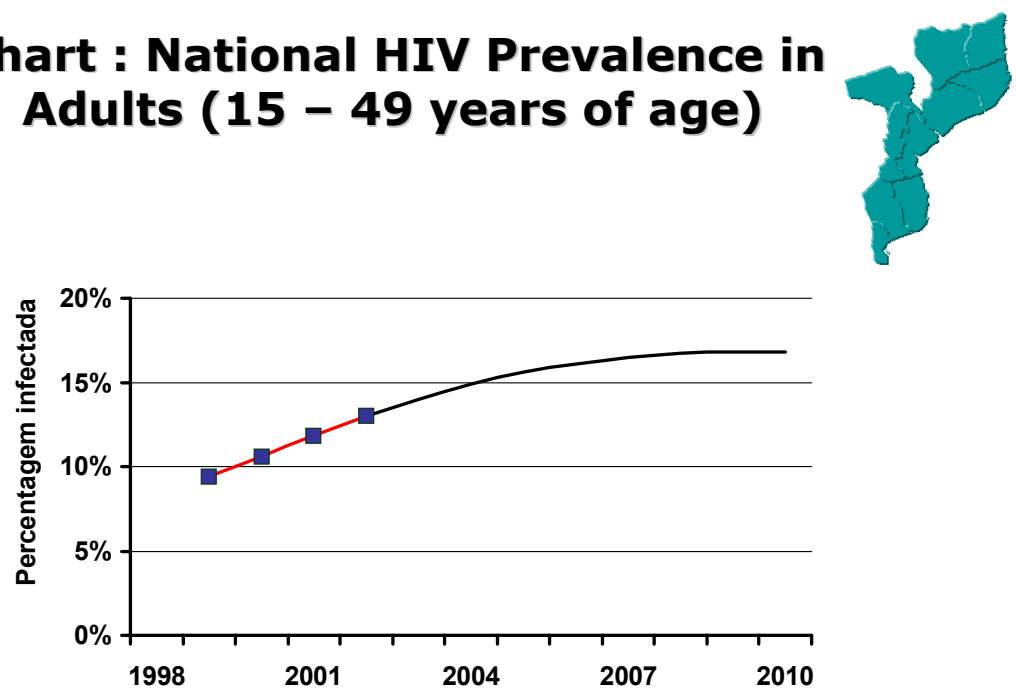

Table: HIVIAIDS Prevalence in Adults (15-49 years of age), at national and regional levels

\begin{tabular}{|l|l|l|l|l|}
\cline { 2 - 5 } \multicolumn{1}{c|}{} & \multicolumn{3}{l|}{ Both Sexes } \\
\cline { 2 - 5 } \multicolumn{1}{c|}{} & South & Centre & North & National \\
\hline $\mathbf{1 9 9 8}$ & $8.2 \%$ & $12.2 \%$ & $3.2 \%$ & $8.2 \%$ \\
$\mathbf{1 9 9 9}$ & $9.9 \%$ & $13.3 \%$ & $4.1 \%$ & $9.4 \%$ \\
$\mathbf{2 0 0 0}$ & $11.6 \%$ & $14.2 \%$ & $5.3 \%$ & $10.6 \%$ \\
$\mathbf{2 0 0 1}$ & $13.2 \%$ & $15.0 \%$ & $6.8 \%$ & $11.8 \%$ \\
$\mathbf{2 0 0 2}$ & $14.5 \%$ & $15.7 \%$ & $8.4 \%$ & $13.0 \%$ \\
$\mathbf{2 0 0 3}$ & $15.6 \%$ & $16.2 \%$ & $10.0 \%$ & $14.0 \%$ \\
$\mathbf{2 0 0 4}$ & $16.4 \%$ & $16.7 \%$ & $11.5 \%$ & $14.9 \%$ \\
$\mathbf{2 0 0 5}$ & $16.9 \%$ & $17.0 \%$ & $12.8 \%$ & $15.6 \%$ \\
$\mathbf{2 0 0 6}$ & $17.2 \%$ & $17.3 \%$ & $13.8 \%$ & $16.1 \%$ \\
$\mathbf{2 0 0 7}$ & $17.3 \%$ & $17.5 \%$ & $14.6 \%$ & $16.5 \%$ \\
$\mathbf{2 0 0 8}$ & $17.3 \%$ & $17.6 \%$ & $15.1 \%$ & $16.7 \%$ \\
$\mathbf{2 0 0 9}$ & $17.2 \%$ & $17.7 \%$ & $15.4 \%$ & $16.8 \%$ \\
$\mathbf{2 0 1 0}$ & $17.1 \%$ & $17.7 \%$ & $15.5 \%$ & $16.8 \%$ \\
\hline
\end{tabular}

In the South the lowest prevalence rate is in Inhambane Province (8,6\%). There are no big differences in the prevalence for Maputo Province $(17,4 \%)$, Maputo City $(17,3 \%)$ and Gaza province $(16,4 \%)$. In the central region Sofala Province presents the highest prevalence $(26,5 \%)$ followed by Manica with $19 \%$, Tete with $14,2 \%$ AND Zambezia with $12,5 \%$. In the northern Niassa province $(11,1 \%)$ has the highest prevalence followed by Nampula $(8,1 \%)$ and Cabo Delgado $(7,5 \%)$.

In the context of projections of demographic impact in terms of number of people living with HIVIAids in Mozambique, it is estimated that 1,3 million people were 
infected by the virus in 2003. Of this number 74,000 are children and 511,000 are men and 740,000 are women.

\section{Projection of number of people living with HIVIAIDS}

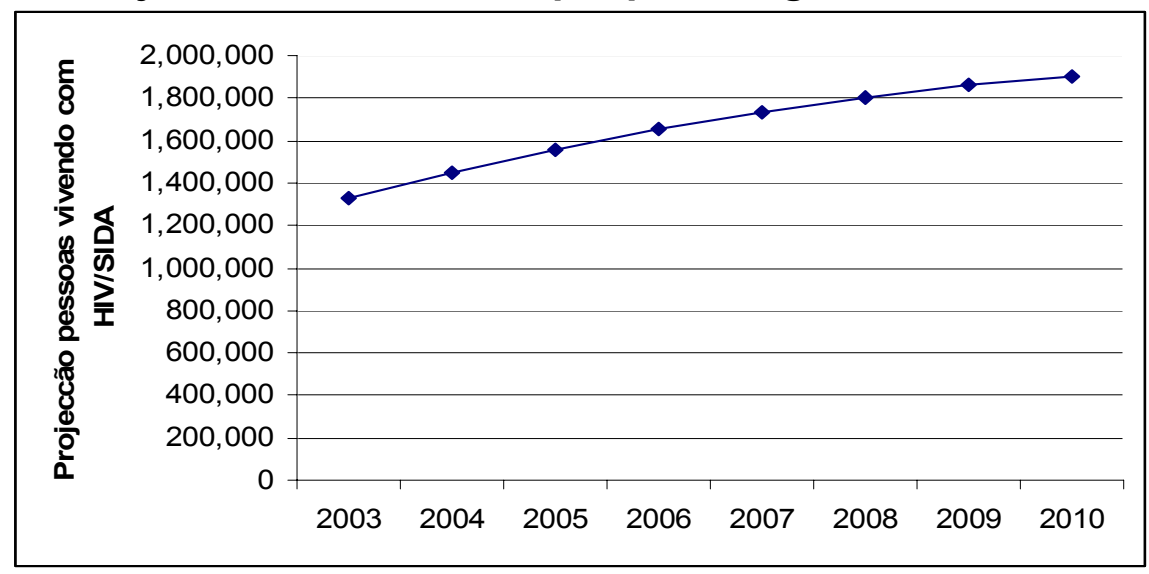

For the calculation of the projections of new cases of AIDS it is necessary to take into account that the period from the infection with HIV until the disease with AIDS varies according to age. Normally this period is shorter for children than in adults. The average is 1 to 8 respectively. In 2003 it is estimated that there were 95,000 new cases of AIDS. For 2004 it is estimated that in Mozambique around 109,000 new cases of AIDS will occur. Two years from now this number will have increased to 135,000 and will continue to increase from year to year. The majority of new cases will be amongst the people who are currently HIV positive. According to the projections, the number of new cases of AIDS may reach 178,000 in 2010 if efficient interventions do not take place.

\section{Chart: New Cases of AIDS - 1999-2010}

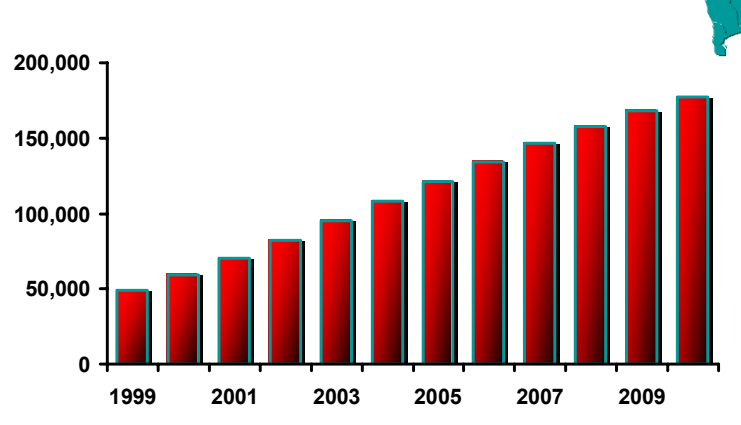

In a short period of time AIDS became in one of the key causes of mortality in Mozambique. The chart below illustrates the accumulated deaths due to AIDS. It shows that in only 5 years, from 1999 to 2003, 300,000 people died of AIDS. The number of deaths estimated for 2003 is 84,000 people. It is important to 
highlight that this mortality is different from region to region. Around $58 \%$ of the deaths occurred in the central region of Mozambique. This fact can be explained by factors such bigger population and the early beginning of the epidemic. In the next 7 years it is estimated that the number of deaths due to AIDS will triplicate, even with the expansion of ARV therapy.

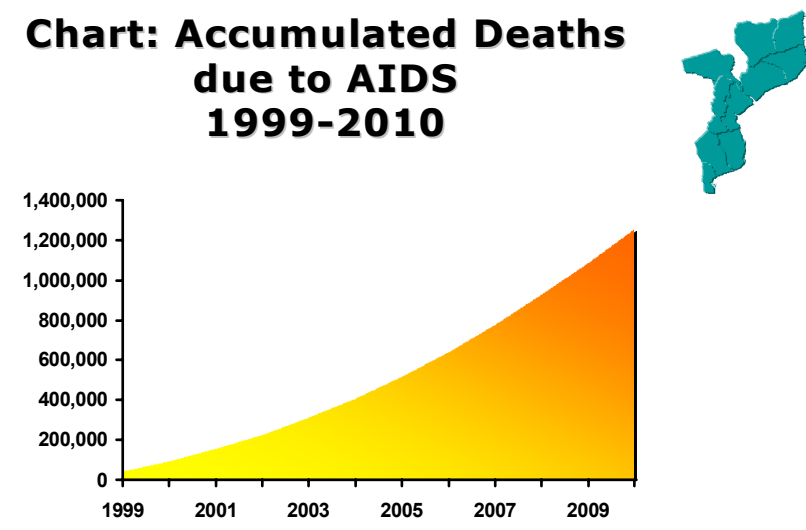

\section{Projection of number of deaths due to HIVIAIDS}

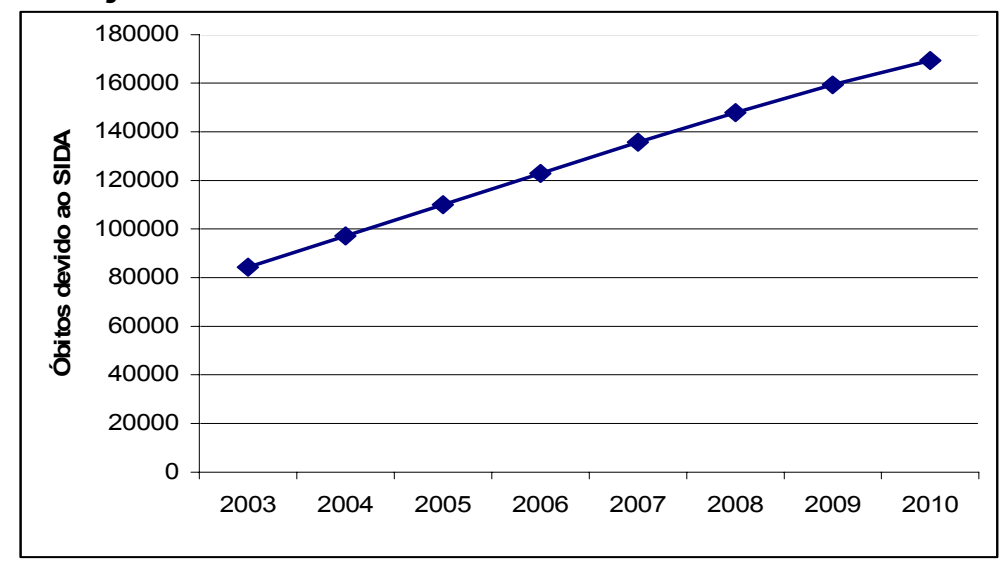

The chart below shows the number of children on the ages of 0 to 17 whose mothers died due to AIDS and other causes. A comparative analysis between the number of orphans whose mothers died of AIDS and those whose mothers died due to other reasons shows a big difference. We observed that maternal orphans due to AIDS have the tendency of increasing while the orphans whose mothers died of other causes have the tendency of slightly reducing. It is estimated that the number of maternal orphans due to AIDS increase from around 187,000 in 2003 to around 228,000 maternal orphans in 2004. The estimations indicate that 
until the end of 2004 , around $28 \%$ of the total maternal orphans in the Country will be a result of AIDS.

With time the proportion of these AIDS related orphans would tend to increase. In 2010 , if there are no efficient interventions, it is estimated that more than 500,000 maternal orphans (approximately $48 \%$ of all maternal orphans) will result from AIDS. It is important to highlight that although the mothers died of AIDS not all these orphans are HIV positive. In reality, most of these orphans are HIV negative, either because they were born before the mother was infected or because the vertical transmission did not occur.

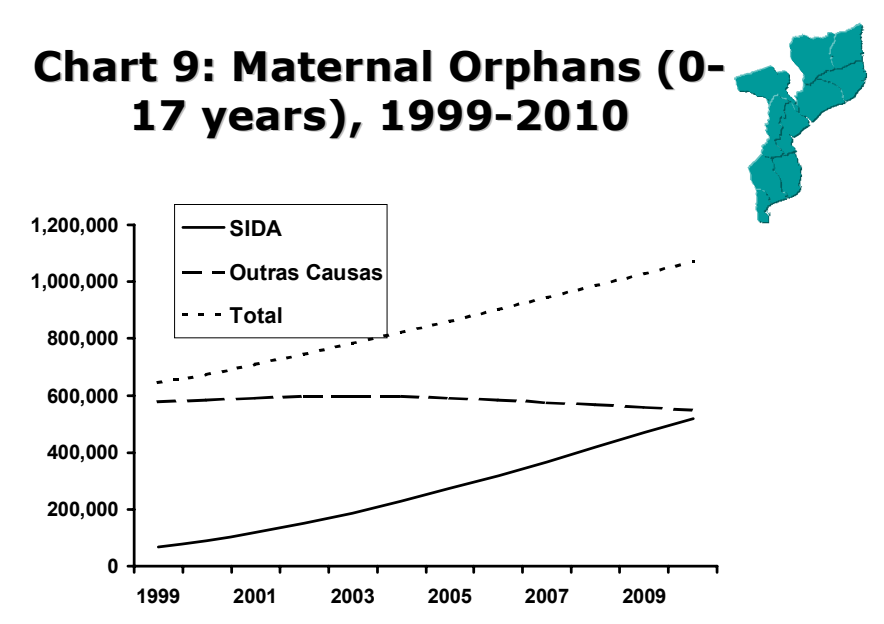

Another consequence of AIDS is the reduction in life expectancy of population longevity, as shown in the chart below. In a scenario where AIDS does not exist it is estimated that life expectancy at birth would be approximately 44 years in 1999 and around 50 years in 2010. When taking into account the effects of the epidemic the longevity of Mozambicans may be less in the future. For 2010 it is estimated that this deficit increases to more than 14 years, should there be no efficient interventions. 


\section{Chart : Life Expectancy}

1999-2010
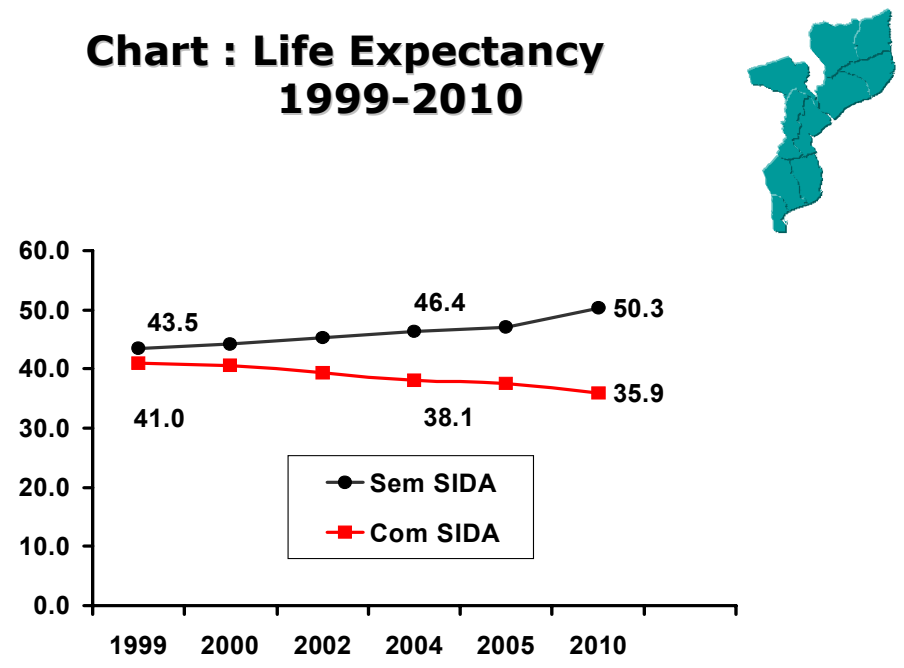

This study shows the relevant information for the design of actions against HIVIAIDS. The data analysis for 2002 reinforces the hypothesis that the central region reached the mature phase of evolution of the epidemic, except Zambézia where the epidemic is growing. In the southern region, with the epidemic growing slowly, it is within the intermediary evolution phase of the epidemic. In the North region the epidemic seems to be at a stage of growth. The most vulnerable group are the youth, especially the girls. The mortality caused by AIDS is changing the population structure due to the sudden decrease in the number of adults above 30 years. This fact will have negative socio-economic effects in the country.

\section{Macro-Economic Impacts of HIV-AIDS}

Literature on HIVIAIDS and economic growth is far from drawing final conclusions in relation with the magnitude of the impact and to the relative importance of the various channels through which this impact may occur. However, some key indications are drawn from the analysis, which have been made so far. For example, the official projections of the demographic impact of HIVIAIDS in Mozambique assume an interval of 9 years between infection and death. Given the long period of separation between infection and death, the death projections by AIDS until 2013 are programmed within the system. This occurs because the majority of the population, who, according to estimations will die in this decade and early next decade, is currently infected by HIVIAIDS. Given that the pandemic will continue, there will be accumulation over time of small impact areas in the growth elements (such as technical progress, the physical capital, and the human capital), with substantial implications in the economy.

Recently, special attention was given to the accumulation of human capital. With HIVIAIDS it is expected that the school population decrease, reducing that part of the population in school age who attend school and weakening the educative system capacity of meeting its mandate. All these factors indicate a reduction in the ratio of human capital accumulation. If, as it is believed, people with 
education tend to be productive and innovative, low rates of human capital accumulation due to a deteriorated educational system will reduce the growth rates of the economy, possibly during a considerable period of time.

The analysis of HIVIAIDS implication in growth using the general computational equilibrium model for Mozambique, which was done in 2001-2002, indicates that AIDS cases and deaths may have great impact on the economic growth. The analysis indicate that the annual rates of economic growth of GDP (Gross Domestic Product) per capita would be between $0,3 \%$ to $1,0 \%$ lower that in a fictitious scenario without AIDS, during the period between 1997 and 2010, with stronger effects in the period between 2005 and 2010. The biggest sources of reduction in growth are: (1) reduced productivity growth rate, (2) reduced population growth rate and human capital accumulation, and (3) reduced rate of physical capital ratio. Each of these three effects is important.

Given that the pandemic of HIVIAIDS will probably last over a long period of time, the said impacts will accumulate resulting in greater impacts at long term in the economy. Consequently the successful initiatives in the prevention of HIV infections and in the fight against disturbances to the economy due to deaths by AIDS, whilst maintaining at the same time the basic conditions for development, will probably have greater return.

Maintaining the basic conditions for growth is also important. PARPA estimates a GDP growth of approximately 8 per cent and a GDP per capita of 5 per cent per year, levels of growth that were achieved in the last decade. In terms of growth per capita, AIDS projected impacts in the economic growth represent a fraction of the target. For the period 2005-2010 this fraction must be in the interval between 10 and 50 per cent of the targeted growth rate per capita of 5 per cent. Therefore, the mitigation of the pandemic and the maintaining of the basic conditions for economic growth are both important for a continued economic growth and for poverty reduction, although the second element (maintaining the basic conditions for economic growth) is probably the most important. 


\section{MACRO-ECONOMIC PROFILE}

\section{V.1.PRINCIPAL MACRO-ECONOMIC RESULTS}

The Government's Programme and the poverty reduction strategy outlined in the PARPA are based on the premise that accelerated economic growth, which is both comprehensive and sustainable is essential for the reduction of poverty.

According to these principles, the Social and Economic Plan for 2003 had the following main macro-economic objectives:

- Achieve Gross Domestic Product growth of around 7\%.

- Contain the annual average inflation rate at around $7 \%$.

- Achieve growth in the export of goods, excluding those from the bigger projects, at around $7 \%$.

- Proceed with the creation of conditions which will make Mozambique an attractive place for investment, safeguarding, however, a proper management of the environment;

- Expand and improve the quality of public services in the areas of health, education and justice as well as developing the basic Infrastructure for the supply of water, roads and sanitation.

The review presented reveals that most of these objectives were met:

- Gross Domestic Product (GDP) growth was 7.1\%.

- Average annual inflation rate was $13.45 \%$.

- A review of investment legisaltion continued which will stimulate an increased inflow of investment to the country and greater involvement of the private sector

- An expansion and improvement of public services was recorded.

In the following sections more details are provided on the sectoral contributions to economic growth. The main developments in monetary and foreign exchange indicators are presented, as well the monetary policy itself (including financial sector supervision).

Once the analysis of the current situation in the country is presented in real and monetary terms, chapter VI deals with the activities carried out by the State in its role as public services provider and as regulator of the economic activity and guardian of order and justice.

\section{V.2.GLOBAL AND SECTORAL PRODUCTION}


The review of global and sectoral production indicates growth of $4,8 \%$; a performance which is slightly below what was planned for the year, as mentioned in the Social and Economic Plan document for 2003. Excluding the production of aluminium the overall production grew by $2,3 \%$. The strong contribution by the production of aluminium is explained by the starting of operation of Mozal Phase II. Construction expenditure of mega-projects namely Mozal II and Temane decreased in 2003 because they were in their final stage. Without including the mega-projects (under construction and already operational), production grew by $7.4 \%$. This result is explained essentially by the significant performance of the Agricultural sector and Transformation Industry.

\begin{tabular}{|l|r|r|r|}
\hline \multicolumn{3}{|l|}{ PRODUCTION - GROWTH RATES IN VOLUMES (\%) } \\
\hline Designation & $\mathbf{2 0 0 1}$ & $\mathbf{2 0 0 2}$ & $\mathbf{2 0 0 3}$ \\
\hline AGRICULTURE, CATTLE & & & \\
BREEDING AND SYVICULTURE & 12.3 & 10.0 & 8.6 \\
Agriculture & 12.6 & 7.3 & 9.8 \\
Cattle Breeding & 14.9 & 23.3 & 17.4 \\
Sylviculture \& Forest Exploration & 9.4 & 18.3 & -8.7 \\
FISHERIES & 3.3 & -4.6 & 11.1 \\
MINERAL EXTRACTION INDUSTR & -2.0 & 52.1 & 31.6 \\
TRANSFORMATION INDUSTRY & 24.3 & 3.9 & 14.9 \\
ELECTRICITY AND WATER & 21.7 & 10.2 & -12.6 \\
CONSTRUCTION & 4.2 & 104.6 & -7.6 \\
TRADE & 16.6 & 1.1 & 5.3 \\
REPAIR SERVICES & 1.6 & 3.9 & 1.9 \\
RESTAURANTS AND HOTELS & 3.8 & -1.6 & 8.6 \\
TRANSPORT AND & & & \\
COMMUNICATIONS & 13.6 & -8.1 & 8.6 \\
FINANCIAL SERVICES & 6.4 & 1.7 & 0.9 \\
REAL ESTATE RENTALS & 6.3 & 2.5 & 2.4 \\
SERVICES RENDERED TO & & & \\
COMPANIES & 0.0 & 12.0 & 2.0 \\
GOVERNMENT SERVICES & 16.4 & 1.5 & 6.3 \\
OTHER SERVICES & 4.0 & 7.1 & 9.7 \\
\hline TOTAL PRODUCTION & $\mathbf{1 3 . 8}$ & $\mathbf{1 6 . 7}$ & $\mathbf{4 . 8}$ \\
\hline PRODUCTION without ALUMINIUM & 7.6 & 17.1 & 2.3 \\
\hline PRODUCTION without MEGA- & & & \\
PROJECTS & 7.6 & 4.9 & 7.4 \\
\hline
\end{tabular}

An analysis of the production figures shows that apart from the negative performance in the construction sector as a whole $(-7.6 \%)$, there was also a negative performance in the Energy and Water sector given the reduction of levels of production and 3 exporting to South .9 Africa and Zimbabwe 8.6 from Cahora Bassa.

8.6 The agricultural and .9 cattle production grew ,4 more than the average growth recorded in the whole of the economy. 3 This activity was dependent on the adverse weather conditions that the country faces since the 2001/2002 campaigns. The launch of the 2002/2003 campaigns was characterised by the irregularity of rainfall and this resulted in a delay in the beginning of the seeding period. In the central and south regions seeding started in the third decade of October. In some provinces in the central region the seeding went until December whilst in the north region of Mozambique the seeding started in the second decade of December. 
From January, due to 'El Ninõ' together with other atmospheric factors, there were low and irregular rainfalls. This has a negative impact in the normal development of some food crops. Some provinces in the north had problems with excessive rains associated with the inter-tropical convergence zone and lowering of atmospheric pressure.

Due to adverse weather factors, mainly drought, more than 237 thousand ha of sown land were lost and this is equivalent to $6 \%$ of the total area that was sown, affecting around 237 thousand families.

\section{A. AGRICULTURE, CATTLE BREEDING AND FOREST EXPLORATION}

The Agriculture, Cattle Breeding and Forest Exploration sector, despite having suffered the effects of the drought that was felt in the south and centre affecting to a great extent the populations and the production. The production indexes as a

\begin{tabular}{|c|c|c|c|}
\hline $\begin{array}{l}\text { AGRICULTURAL PF } \\
\text { Growth Taxes (\%) }\end{array}$ & 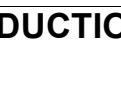 & $\mathbf{N}-$ & lur \\
\hline Designation & 2001 & 2002 & 2003 \\
\hline TOTAL & 12.6 & 7.3 & 9.8 \\
\hline BUSINESS & -22.9 & 57.2 & 109.3 \\
\hline HOUSEHOLD TOTAL & 14.8 & 5.2 & 3.4 \\
\hline HOUSEHOLD & 8.1 & 9.5 & 4.3 \\
\hline COMMERCIALISED & & & \\
\hline SELF CONSUMPTION & 18.7 & 2.9 & 2.8 \\
\hline
\end{tabular}

whole were positive with the expansion of areas of cultivation and increase in productivity, as illustrated in the table below.

cultivation of maize and vegetables. In the south and centre regions the distributed seeds were sufficient except in some districts of Zambézia and Maputo provinces. However, there is still low participation of the private sector in the market of agricultural inputs and this is a constraint for the significant increase of productivity. 
Most of the seeds for the current campaign come from self-production. However, it is worth mentioning the distribution of seeds that occurred after the emergency situation created by the Low Atmospheric Pressure named Delfina in the provinces of Cabo Delgado and Nampula.

The agricultural production recorded a growth of $9.8 \%$ as a whole and the business sector had a significant growth of $109 \%$. This performance underlines

BUSINESS SECTOR PRODUCTION AND MARKETING BY FAMILY SECTOR

GROWTH RATES IN VOLUME

\begin{tabular}{|c|c|c|c|}
\hline & 2001 & 2002 & 2003 \\
\hline EXPORT PRODUCTS & 21.5 & 17.3 & -4.4 \\
\hline Cashew & 41.6 & -6.4 & 27.2 \\
\hline Cotton & 100.9 & 16.8 & -34.8 \\
\hline Copra & -7.6 & -5.9 & 14.7 \\
\hline Sugar Cane & -15.8 & 127.8 & 21.9 \\
\hline Citrus & -86.9 & 80.4 & 5.0 \\
\hline Tea Leaves & -19.4 & 39.3 & 0.9 \\
\hline BASIC FOOD PRODUCTS & -3.9 & 4.8 & 13.6 \\
\hline Maize & 17.1 & 8.3 & 7.9 \\
\hline Rice & 2.6 & 1.6 & 8.5 \\
\hline Mapira & 21.8 & 0.2 & -0.4 \\
\hline Cassava & -9.1 & -0.5 & 4.2 \\
\hline Peeled Peanuts & -6.6 & 0.7 & 0.1 \\
\hline Beans & 1.8 & 14.9 & 1.7 \\
\hline Horticulture & 2.4 & 7.2 & 60.5 \\
\hline Onion & -28.1 & 45.3 & 105.6 \\
\hline PRODUCTS FOR INDUSTRY & 48.2 & 98.5 & 80.5 \\
\hline Tobacco & 163.4 & 58.3 & 73.2 \\
\hline Tomato & -2.6 & 148.3 & 86.5 \\
\hline The Agricultural products for industrial use & 5.9 & 0.0 & 0,0 \\
\hline Other non-industrial agricultural products & 4.6 & 1.4 & 1.4 \\
\hline TOTAL & 3.4 & 14.9 & 20.5 \\
\hline
\end{tabular}
the dynamics of marketing agricultural products in the different markets.

The expansion of business sector production results from the significant increase recorded in some food products and of products for he industry with emphasis on vegetables, onion, tobacco and tomato.

Despite this growth, the family sector continues to provide the biggest contribution in the global agricultural sector structure. Around $90 \%$ of agricultural production and $75 \%$ of the marketed production comes from the family sector. $60 \%$ of the family sector production is related with food crops, and this elucidates the role of food crops in the absolute poverty reduction taking into account its traditional role in the framework of food security and in the generation of income for the rural families; it also reveals that a sustainable and efficient agricultural growth for the fight against poverty has, as its underlining support, the increase in the levels of production of food crops.

The business sector production and family commercialisation recorded a growth of $20.5 \%$. 4 products, namely vegetables $(60.5 \%)$, onion $(105.6 \%)$, tobacco $(73.2 \%)$ and tomato $(86.5 \%)$ essentially explain this growth. 
In the group of products for export a decrease of $4.4 \%$ was recorded. This is explained by the fall in the levels of business sector and family production of cotton (-34.8). Apart from the adverse agro-climatic conditions other conditions contributed to this reduction such as market conditions where replacement of cotton by food crops and products for industry (especially tobacco) due to the fact that these offer more commercial advantages to farmers. In this case, SODAN and SONAM (cotton companies) embarked in the production of food crops.

For the basic food products group a growth of approximately $13.6 \%$ was recorded. Significant increases in vegetables and onion were also recorded. These 2 products explain around $50 \%$ of growth recorded in commercialisation of food products. However, they represent less than $20 \%$ of the food products which were marketed as cassava and maize represent the food products which COMERCIALIZATION BY FAMILY SECTOR GROWTH RATES BY VOLUME (\%)

\begin{tabular}{|c|c|c|c|}
\hline & 2001 & 2002 & 2003 \\
\hline EXPORT PRODUCTS & 64.4 & -1.3 & -4.7 \\
\hline Cashew & 41.6 & -6.4 & 27.2 \\
\hline Cotton & 173.2 & -0.1 & -27.1 \\
\hline Sugar cane & -23.1 & 1.4 & 1.4 \\
\hline Citrus & 113.3 & 66.7 & 0.0 \\
\hline BASIC FOOD PRODUCTS & -4.2 & 4.1 & 5.4 \\
\hline Maize & 12.0 & 8.1 & 1.0 \\
\hline Rice & 2.6 & 0.6 & 19.0 \\
\hline 'Mapira' & 22.7 & 0.1 & 0.3 \\
\hline Cassava & -9.5 & -0.8 & 3.8 \\
\hline Peeled peanuts & -6.6 & 0.8 & 0.0 \\
\hline Beans & 2.2 & 15.1 & 1.7 \\
\hline Horticulture & 2.4 & 5.6 & 7.4 \\
\hline Onion & 2.4 & 41.0 & 55.6 \\
\hline PRODUCTS FOR THE INDUSTRY & 121.5 & 74.6 & 8.7 \\
\hline Tobacco & 1081.2 & 56.7 & 40.9 \\
\hline Tomato & -1.6 & 102.1 & -29.7 \\
\hline $\begin{array}{l}\text { Other agricultural products for industrial } \\
\text { use }\end{array}$ & -90.1 & 5.4 & 0,0 \\
\hline Other non-industrial agricultural products & 4.6 & 1.4 & 1.4 \\
\hline TOTAL & 8.0 & 9.5 & 4.3 \\
\hline
\end{tabular}
are more marketed in the Mozambican economy (around $60 \%$ of the total).

The products for industry recorded significant growth and in the last years they have been an important source of income for the business agricultural sector. The growth recorded in the production of tomato is explained amongst other factors by the prioritisation of products of short cycles in the Gaza Province in order to maximize production in an environment of uncertainty in terms of rainfall and by the use of tomato varieties of high return (around 20 to 30 tons by ha).

The family commercialisation achieved a growth rate of $4.3 \%$. It is worth highlighting that this increase did not jeopardise food stocks (security) according to evolution data of self-consumption (2.8\%). An analysis done to the evolution of self consumption and of the rural population shows some signs of improvement in the process of commercialisation of family products in 2003, since the additional self 
consumption was at levels of what was required to satisfy the growth in rural population.

The programme of cattle breeding promotion implemented by the Government is having positive results with the animal production recording growth of $17.9 \%$.

\begin{tabular}{|l|r|r|r|r|r|r|}
\hline ANIMAL PRODUCTION-Growth Rates by Volume \\
\hline \multirow{2}{*}{ Designation } & \multicolumn{2}{|c|}{$\mathbf{2 0 0 1}$} & \multicolumn{2}{|c|}{$\mathbf{2 0 0 2}$} & \multicolumn{2}{|c|}{$\mathbf{2 0 0 3}$} \\
\cline { 2 - 8 } & Bus Sect & Household Sec & Bus Sect & Household Sec & Bus Sect & Household Sect \\
\hline Cattle & 13.8 & 36.4 & 19.6 & 14.8 & 36.8 & 27.0 \\
\hline Swine & 0.0 & 69.5 & 0.0 & 108.8 & 0.0 & 5.8 \\
\hline Live poultry & -33.4 & 2.5 & 0.0 & 0.0 & 31.9 & 0.2 \\
\hline Fresh Eggs & -32.5 & 2.5 & 0.0 & 0.0 & 784.3 & 242.8 \\
\hline Other animals & 0.0 & 7.6 & 0.0 & 0.0 & 0.0 & 0.3 \\
\hline & & & & & & \\
\hline TOTAL & -32.7 & 19.3 & 4.0 & 24.3 & 36.7 & 16.6 \\
\hline
\end{tabular}

This programme during the first 6 months distributed 592 cattle in Magude (Maputo), 297 cattle and 12 caprines in Tete and 100 caprines in Mecanhelas (Niassa); this last distribution was done by an NGO.

The Sylviculture sector and forest exploration recorded a fall (-8.7) in the production levels compared with 2002.

\section{B. FISHERIES}

The fishery production in 2003 increased by $11 \%$, inverting the fall tendency recorded in 2002 and in the first 6 months of 2003. This positive result is explained by the performance of the non-industrial and semi-industrial sector since these two still maintain the same tendency.

The Industrial and semi-industrial fishing recorded a fall of $8,5 \%$ whilst the nonindustrial sector grew significantly by $41,5 \%$. The recorded fall for industrial

\begin{tabular}{|l|r|r|r|}
\hline $\begin{array}{l}\text { FISHING PRODUCTION } \\
\text { Volume (\%) }\end{array}$ & \multicolumn{3}{l}{ Growth Rates by } \\
\hline Designation & \multicolumn{1}{|c|}{$\mathbf{2 0 0 1}$} & \multicolumn{1}{c|}{$\mathbf{2 0 0 2}$} & $\mathbf{2 0 0 3}$ \\
\hline TOTAL & 3.3 & -4.6 & 11.1 \\
\hline BUSINESS & 9.4 & -6.5 & -8.5 \\
\hline FAMILY TOTAL & -5.5 & -1.4 & 41.5 \\
\hline - FAMILY - MARKETED & -19.0 & 0.6 & 53.8 \\
\hline - SELF-CONSUMPTION & 10.2 & -3.0 & 30.7 \\
\hline
\end{tabular}

fishing is explained by the performance in the production of prawns (including aquaculture) and of opossum, products with more than $90 \%$ weight in the business fishing production structure. 


\begin{tabular}{|l|r|r|r|}
\hline \multicolumn{4}{|c|}{ INDUSTRIAL FISHING - Growth Rates in Volumes (\%) } \\
\hline Designation & $\mathbf{2 0 0 1}$ & \multicolumn{1}{c|}{$\mathbf{2 0 0 2}$} & \multicolumn{1}{c|}{$\mathbf{2 0 0 3}$} \\
\cline { 2 - 4 } & \multicolumn{1}{|c|}{$\%$} & \multicolumn{1}{c|}{$\%$} \\
\hline Lobster & -91.3 & 25.0 & -80.0 \\
\hline Crab & 43.0 & -50.0 & 60.0 \\
\hline Opossum and & -0.4 & -10.0 & -9.7 \\
\hline $\begin{array}{l}\text { Fresh } \\
\text { Refrigerated Fish }\end{array}$ & 4.8 & -52.9 & 82.7 \\
\hline 'Kapenta' & -8.7 & 46.9 & 16.2 \\
\hline Accompanying & 5.6 & 16.5 & 0.6 \\
Fauna & & & -17.7 \\
\hline Prawns & 0.7 & 4.9 & 37.5 \\
\hline Small Lobster & 87.5 & -11.1 & 86.7 \\
\hline Calamari \& Octopus & -75.5 & -36.8 & \\
\hline
\end{tabular}

\begin{tabular}{|c|c|c|c|}
\hline \multicolumn{4}{|c|}{$\begin{array}{l}\text { NON-INDUSTRIAL FISHING - Growth rates in Volumes } \\
(\%)\end{array}$} \\
\hline \multirow[t]{2}{*}{ Designation } & 2001 & 2002 & 2003 \\
\hline & $\%$ & $\%$ & $\%$ \\
\hline Lobster & 69.8 & -5.0 & 10.0 \\
\hline Crab & 43.7 & 18.1 & -55.6 \\
\hline Opossum & 0.0 & 0.0 & 0.0 \\
\hline $\begin{array}{l}\text { Fresh and } \\
\text { Refrigerated Fish }\end{array}$ & 26.0 & 0.3 & 66.7 \\
\hline 'Kapenta' & 0.0 & 0.0 & 0.0 \\
\hline $\begin{array}{l}\text { Accompanying } \\
\text { Fauna }\end{array}$ & 0.0 & 0.0 & 0.0 \\
\hline Prawns & 18.0 & -10.2 & -8.3 \\
\hline Small Lobster & 0.0 & 0.0 & 0.0 \\
\hline Calamari \& Octopus & 424.6 & -6.5 & -38.4 \\
\hline
\end{tabular}

The levels recorded in the capturing of opossum result from the reduction in number of fishing ships. With the implementation of the fishing agreement between Mozambique and the European Union improvements in the levels of catches are expected because quotas for the fishing of opossum to European Union ships will be granted.

The recorded reduction in prawn aquaculture results from the interruption that occurred in one of its main producers for the expansion work on area of cultivation. Substantial improvements are expected in this area with the approval and implementation of project "Indian Ocean" in Cabo Delgado.

The performance recorded in the non-industrial fishing sector results from increases in fish capturing $(66,7 \%)$, product with considerable weight in the nonindustrial production structure.

Overall in 2003 fishery production was in the region of 34,814 tons, of which $35 \%$ went to the international market.

\section{PRIMARY INDUSTRIES}

The production of minerals in 2003 recorded an overall growth of $31.6 \%$ compared with 2002. This expressive level is sustained by the extraction of products such as limestone, sand for construction, clay, tantalite, aquamarine, refuse and riolite. The extraction of limestone represents about $40 \%$ of the global mineral production. The current structure may change significantly when the Pande Gas project starts operating from this year.

The production of coal decreased by $15.6 \%$ due to equipment being old for its extraction. The equipment was down in most of the first six months. This problem was only solved in the third quarter when new equipment from South Africa was imported and installed in the 'Chipanga' mine Lda. 
RECURSOS MINERAIS - Growth Rates in Volume (\%)

\begin{tabular}{|l|r|r|r|}
\hline Designation & \multicolumn{1}{|c|}{$\mathbf{2 0 0 1}$} & \multicolumn{1}{|c|}{$\mathbf{2 0 0 2}$} & \multicolumn{1}{c|}{$\mathbf{2 0 0 3}$} \\
\hline Coal & 71.3 & 56.7 & -15.6 \\
\hline Bauxite & 16.5 & 6.1 & 29.3 \\
\hline Graphite & 0.0 & 0.0 & 0.0 \\
\hline Gross 'Bentonite' & -91.6 & 0.0 & 0.0 \\
\hline Treated 'Bentonite' & -7.2 & 128.3 & 18.0 \\
\hline Screened 'Bentonite' & 49.3 & -23.0 & 57.9 \\
\hline Activated 'Bentonite' & 0.0 & 0.0 & 0.0 \\
\hline Marble in plate & 4.5 & -34.8 & 2.5 \\
\hline Marble in block & -29.4 & 41.6 & -0.2 \\
\hline Polishable garnet & 0.0 & 0.0 & -61.3 \\
\hline Lapidated Stones & 0.0 & 0.0 & 0.0 \\
\hline Gold & -3.5 & -23.2 & 271.6 \\
\hline Marine waters & -70.0 & -44.9 & -69.4 \\
\hline Turmalines & -76.4 & 578.6 & 370.4 \\
\hline Tantalite & 8.0 & 73.7 & 302.3 \\
\hline Beryl & -95.7 & 6687.5 & 44.2 \\
\hline Sand & 55.1 & 71.3 & 72.4 \\
\hline Limestones & 24.5 & 78.4 & 3.6 \\
\hline 'Riolitos' & -17.2 & 57.2 & -9.6 \\
\hline Granites & -16.8 & 1.2 & -19.5 \\
\hline 'Dumortiorite’ & -16.7 & -20.0 & 0.0 \\
\hline Natural Gas & 34.3 & 94.6 & 4.1 \\
\hline TataL & & & \\
\hline Tora & -2.0 & 52.1 & 31.6 \\
\hline
\end{tabular}
production occurs in Tete province and it was interrupted during the first 6 months of the year due to lack of explosives. The explosives have now been imported from South Africa.

In the last four years the production of marble in lamina and has gone through times of instability in its levels of production as a result of the successive loss of space in the international market associated, amongst other factors, with the existence of alternative products in the market such as imported granites from South Africa. The exports of this mineral recorded successive downfalls in the region of $75 \%$ and $20 \%$ in 2002 and 2003 respectively.

In relation to small-scale production, gold production increased by $271,6 \%$ due to the efforts of licensed operators in Nampula, Zambézia, Tete e Manica.

\section{MANUFACTURING AND INDUSTRIAL PRODUCTION}

Globally the area of transformation industry, including the production of aluminium, increased significantly $(14,9 \%)$ as expected taking into account the indicators of the review of the $1^{\text {st }}$ half of 2003. Without Mozal high levels of production $(9,3 \%)$ were recorded due to the reactivation of some manufacturing units and to product expansion in some companies in which production was very low in 2002. It is worth noting that the overall industry production increased considerably in the second part of 2003 with the start of production activity in Mozal Phase II. 
The beginning of aluminium production in phase II had a multiplying effect in the other industries' activities through the celebration of new contracts for the supply of services and goods. This contributed positively for the overall performance of the transformation industry. In fact the sub-sector of metallic product industry, machines and equipment increase its levels of production $(53,3 \%)$ due mainly to the production of metallic structures for Mozal II.

\begin{tabular}{|c|c|c|c|}
\hline \multicolumn{4}{|c|}{ TRANSFORMATION INDUSTRY-Growth Rates in Volume (\%) } \\
\hline \multicolumn{4}{|l|}{ BUSINESS SECTOR } \\
\hline Designation & 2001 & 2002 & 2003 \\
\hline Food Production & 11.6 & 6.5 & 3.9 \\
\hline $\begin{array}{l}\text { Drinks and tobacco } \\
\text { production }\end{array}$ & 8.9 & 10.4 & 12.7 \\
\hline Textiles and Clothing & 55.7 & -1.3 & -7.6 \\
\hline Leather and leather articles & -22.1 & -36.2 & 33.6 \\
\hline Wood Industry & -1.0 & 0.0 & 17.9 \\
\hline Paper and graphic arts & 43.8 & 36.8 & -9.5 \\
\hline Chemical products & 3.6 & 0.8 & 14.2 \\
\hline Non-metallic minerals & -37.8 & 12.8 & 21.4 \\
\hline Base Metallurgy & 220.2 & -1.5 & 51.1 \\
\hline Aluminium & 234.7 & -0.5 & 51.6 \\
\hline Siderurgy & 0.0 & 0.0 & 0.0 \\
\hline Others & -16.7 & 63.2 & -40.5 \\
\hline $\begin{array}{l}\text { Metallic, machine and } \\
\text { equipment production }\end{array}$ & -8.5 & -3.3 & 53.3 \\
\hline Furniture and others & -63.2 & -76.4 & 161.5 \\
\hline TOTAL & 44.7 & 3.8 & 23.7 \\
\hline
\end{tabular}

In the performance of the industry without aluminium it is worth mentioning the Food, Beverages and Tobacco sectors due to their weight in the overall industrial production structure and, on the other hand, due to dynamism demonstrated in the previous years, with a multiplying effect in the performance of agricultural, transport, trading and other activities.

In the performance of the food industry we highlight the weight of wheat flour, maize flour and refined oil produced by $\mathrm{Cl}$ Matola, Socimol, Mobeira and Moagens de Moçambique, Ginwala, Fasol, $\mathrm{Cl}$ Monapo and Moçambique Industrial.

The textile and clothing industry continues to record tendencies for falling ($7,6 \%$ ). From the textile area the following factories are not operating: Texlom, Textáfrica, Texmoque and Favezal. On the clothing sector it is estimated that half of the productive complex is not operating. Factories not operating include Soberana, Investro and Ninita. In the textile industry growth expectations are dark with a tendency for a global halt. This is because the factories, which are still operational / surviving (Fábrica de Cobertores, Riopele and Baptista salomão), are gradually reducing their levels of production.

In the paper and graphic art sector performance was $-9,5 \%$. 
The chemical, rubber and plastic industry sector, although affected by strong competition, had a positive performance. The rubber industry had a positive performance motivated by regular production at Mabor.

The base metallurgic sector that includes companies such as IMA, CSM, Mozal and Mozris Metais (the last one is a new company) grew by $51,1 \%$. The aluminium production recorded growth of $51,6 \%$ motivated by Mozal phase II that widened the production capacity of aluminium in the country. Without aluminium this sector would have had a negative performance $(-40.5 \%)$.

\section{E. ELECTRICITY AND WATER}

The energy and water sector recorded a decrease of $12.6 \%$. The energy sector recorded a downfall of $14.2 \%$. This result is because of rehabilitation, modernisation and automatization works that are currently taking place at 'Hydroelectric de Cahora Bassa'. This resulted in the reduction of number of generators available for the generation of energy and therefore with a negative impact in the short-term production and in the exportation to South Africa (ESKOM) e Zimbabwe (ZESA), Botswana (BPC) and to the regional market for short-term (STEM). The production of energy for the national market recorded growth. This reflects the increase in internal demand deriving from economic growth and from the rural electrification works.

In this energy sector a study of Tariff Review, which had, as its main objective, the evaluation of the previous tariff structure and make it to the new market reality and country development challenges.

The review, which has just been completed, allows for the implementation of a sustainable tariff for the agro-industrial undertakings. This measure also takes the more sustainable tariff for the different consumers and it also ensures that EDM, E.P. becomes a financially viable company at long-term and able to obtain the necessary funding which will allow it to extend the national network of energy, to continue with rural electrification and quality energy supply to the consumers.

\section{F. CONSTRUCTION}

In the construction and fitting up_sector there was a fall of $-7,6 \%$ in the levels of construction as a result of a reduction in the level of construction expenditure of mega-projects (phase II of Mozal and the construction of the pipeline to South Africa. Mozal II is now in the operational phase.

In terms of other construction areas the road programme review is below plan. In this area activities consisted on the continuation of the rehabilitation of roads. It also consisted on routine maintenance as well as in emergency works resulting 
from damages caused by the lowering of atmospheric pressure (Delfina) and 'Japhet' cyclone and the construction and fitting of bridges.

The execution of these activities is better detailed in the sub-chapter related to Infrastructure.

It is worth highlighting the development recorded in private sector construction as a result of the economic growth And growing urbanisation in this country. In this context, apart from normal urbanisation works, the construction of Infrastructure (roads, electrification, water supply sources, and others) constitutes the pillars for the development of this activity.

\section{G. COMMERCE}

The recorded results show growth of $5.3 \%$. This dynamic results from the behaviours shown by the agricultural, fishery, transformation and extractive industry sectors. Globally, these activities recorded growth and, as a result, an increase in the flux of marketable products.

\section{H. RESTAURANTS AND HOTELS}

The restaurants and hotels activity increased their performance in 2003. This performance was positively influenced by the growing numbers of passengers, as reported in the air travel results. In fact there was an increase in the income from the tourism area and which was recorded in the balance of payments, sustained by an increase in the number of night lodgings in hotels. In terms of major events with great impact in the revenue of hotels and restaurants it is worth mentioning the African Union Summit and the Local Elections. In Maputo City, where the biggest hotel usage is recorded in the country, growth average in the number of nights lodgings in hotels during the 4th quarter is bigger than the annual average. The current pace of production growth is reflected in the expectations for returns from investors. In fact during 2003, 81 new tourism projects totalling 52 million American Dollars were approved.

\section{TRANSPORT AND COMMUNICATIONS}

This sector recorded a growth of $8.6 \%$. Road traffic (passengers and goods) contributed considerably to this result. This growth accompanies the economic growth in general and the impositions of commerce and urbanization in particular. The level of performance in passenger traffic was also positive in the other sub-areas of transport. The performance in the air travel sector is also worth noting. This performance is underlined by the opening of new entry points into Mozambique, the implementation of the civil aviation policies, the simplification of procedures, increase in the tourism activity and the increase resulting from the African Union Summit and the Local Elections. 
The communication services had a stationary tendency $(0,3 \%)$. A different pace is expected in this sector with Vodacom entering the market.

\begin{tabular}{|c|c|c|c|}
\hline \multicolumn{4}{|c|}{$\begin{array}{l}\text { TRANSPORTES E COMUNICAÇÓES - Taxas de Crescimento em } \\
\text { Volume }(\%)\end{array}$} \\
\hline & 2001 & 2002 & 2003 \\
\hline Railway & 28.1 & 5.7 & 68.8 \\
\hline Road & 24.5 & -24.3 & 11.1 \\
\hline Pipeline & 0.7 & 17.8 & -13.1 \\
\hline Maritime & 17.2 & -73.0 & 171.7 \\
\hline Air traffic & -27.9 & 4.2 & 8.7 \\
\hline Services relating with transport & 19.5 & 12.2 & 2.6 \\
\hline Communication services & 2.4 & 28.8 & 0.3 \\
\hline TOTAL & 13.6 & -8.1 & 8.6 \\
\hline
\end{tabular}

Rail traffic recorded a positive performance, especially in terms of cargo transport. The Southern region had better performance. The central region is still affected by the crisis in Zimbabwe - the country where most of the rail activities in the region are directed to.

Globally this sector recorded growth in the different kinds of transport except for the pipeline $(-13.1 \%)$. The scenario is a result of the current economic situation in Zimbabwe.

\section{V.3. MONETARY AND FOREIGN EXCHANGE SECTORS}

The monetary and exchange rate policies adopted in 2003 were underlined by the objectives incorporated in the Government Economic Programme, namely economic growth and internal and foreign stability of the national currency.

For the prosecution of these objectives the monetary policy was directed at the decceleration of monetary expansion. As a result growth in money supply decreased to $17,4 \%$ in this period, in a year which was particularly fertile in terms of the improvement in net international reserves (around USD 172 million).

\begin{tabular}{|c|c|c|}
\hline & 2002 & 2003 \\
\hline Monetary Mass (Annual balance var - \%) & 20.2 & 17.4 \\
\hline Credit to Economy (Annual balance var. - \%) & 4.8 & -1.1 \\
\hline Monetary Base (Annual balance var. - \%) & 17.4 & 22.0 \\
\hline Net International Reserves (mio USD) & 625.0 & 797.0 \\
\hline Inflation (Annual var. - \%) & 9.1 & 13.8 \\
\hline
\end{tabular}

The Bank of Mozambique continued to opt for a monetary policy based on indirect control instruments, implemented by inter-bank market, monetary and exchange operations.

In 2003 the intervention mechanisms in the Inter-Bank Monetary Market (MMI) were improved, with the adoption of a position based on daily interventions, for 
the regularization of liquidity, in accordance with the specific conditions of the bank system.

This position resulted in a substantial increase in sterilised resources in the form of Treasury Bills (BT's) and Monetary Authority Bonds (TAMs). In December 2003 bills outstanding were worth 5.365 billions of MTs, of which 1.963 billion were Treasury Bills and 3.402 billion Monetary Authority Bonds, compared to 3.315 billions of MTs in December of 2002 ( 0.526 billion of BTs and 2.789 billion TAMs).

A $17,4 \%$ growth in the Monetary Base was supported by all components, with Notes and Coins in circulation expanding 21,5\% whilst Total Deposits increased $16.7 \%$.

Resulting from exchange rate stability of the Metical against the US Dollar, deposits denominated in local currency showed more dynamic growth (23\%) compared to those in foreign currency (increase of $10 \%$ ). As a result the weight of deposits in local currency in the Monetary Base moved from about $49 \%$ in December 2002 to $52 \%$ in December 2003.

\section{Interest Rates}

The liquidity conditions in the market associated with the position taken by the Bank of Mozambique (to reduce its intervention rates in MMI) allowed for the fall in interest rates in the various products marketed in $\mathrm{MMI}$ and in the interest rates applied by credit institutions to the public.

In fact, the Permanent Permission Facility Rate from the Bank of Mozambique reduced to $18.5 \%$ in December 2003, after $22.75 \%$ in December 2002, whilst the Permanent Absorption Facility rate was at $8.25 \%$ in December 2003, after 10.25\% in December 2002.

The average rate of operations involving BTs e TAMs reduced to around $12 \%$ towards the end of 2003 , against an average of $18 \%$ in 2002 , whilst the liquidity exchange average between Credit Institutions reduced to around 10\% towards the end of December 2003 against 15\% in the same period in 2002.

Note that the average interest rates on liabilities slowed by $5.7 \mathrm{bp}$ from December 2002 until December 2003 (they stayed at 11.62\%), compared with the assets operations that slowed in the same period by $9.04 \mathrm{bp}$ (they stayed at $28.5 \%$ ).

\section{Exchange Rates}

The Metical remained stable against the US Dollar in 2003. It recorded an accumulated depreciation of only $0,6 \%$, after $2,3 \%$ in 2002 . 
In relation with the South African Rand, the national currency followed the general tendency observed in other international currency markets, accumulating a depreciation of $36,3 \%$. This behaviour incorporates not only the depreciation of the Dollar against the Rand in the international market, but also the high degree of dependence of the Mozambican economy on South African imports.

CURRENCY EXCHANGE MARKET - METICAL AGAINST AMERICAN DOLLAR

\begin{tabular}{|c|c|c|c|c|c|c|c|c|c|c|c|c|}
\hline & Jan & Feb & Mar & Apr & May & Jun & Jul & Aug & Sept & Oct & Nov & Dec \\
\hline \multicolumn{13}{|c|}{$\begin{array}{l}\text { AVERAGE RATES } \\
\text { MT/USD }\end{array}$} \\
\hline 1999 & 12366 & 12348 & 12415 & 12458 & 12496 & 12544 & 12656 & 12772 & 12864 & 12972 & 13097 & 13249 \\
\hline 2000 & 13448 & 13983 & 14933 & 15764 & 16006 & 16007 & 16085 & 16150 & 16171 & 16242 & 16513 & 16987 \\
\hline 2001 & 17323 & 17869 & 18492 & 19105 & 20081 & 21299 & 21797 & 21821 & 22065 & 22401 & 23077 & 23153 \\
\hline 2002 & 23314 & 23412 & 23513 & 23603 & 23639 & 23650 & 23708 & 23815 & 23877 & 23931 & 23836 & 23687 \\
\hline 2003 & 23801 & 23809 & 23817 & 23810 & 23816 & 23777 & 23668 & 23744 & 23735 & 23775 & 23802 & 23835 \\
\hline \multicolumn{13}{|c|}{ ACUMMULATED VARIATION (\%) } \\
\hline 2000 & $1,5 \%$ & $5,5 \%$ & $12,7 \%$ & $19,0 \%$ & $20,8 \%$ & $20,8 \%$ & $21,4 \%$ & $21,9 \%$ & $22,1 \%$ & $22,6 \%$ & $24,6 \%$ & $28,2 \%$ \\
\hline 2001 & $2,0 \%$ & $5,2 \%$ & $8,9 \%$ & $12,5 \%$ & $18,2 \%$ & $25,4 \%$ & $28,3 \%$ & $28,5 \%$ & $29,9 \%$ & $31,9 \%$ & $35,9 \%$ & $36,3 \%$ \\
\hline 2002 & $0,7 \%$ & $1,1 \%$ & $1,6 \%$ & $1,9 \%$ & $2,1 \%$ & $2,1 \%$ & $2,4 \%$ & $2,9 \%$ & $3,1 \%$ & $3,4 \%$ & $2,9 \%$ & $2,3 \%$ \\
\hline 2003 & $0,5 \%$ & $0,5 \%$ & $0,5 \%$ & $0,5 \%$ & $0,5 \%$ & $0,4 \%$ & $-0,1 \%$ & $0,2 \%$ & $0,2 \%$ & $0,4 \%$ & $0,5 \%$ & $0,6 \%$ \\
\hline \multicolumn{13}{|c|}{ HOMÓLOGIC VARIATION (\%) } \\
\hline 2000 & $8,7 \%$ & $13,2 \%$ & $20,3 \%$ & $26,5 \%$ & $28,1 \%$ & $27,6 \%$ & $27,1 \%$ & $26,4 \%$ & $25,7 \%$ & $25,2 \%$ & $26,1 \%$ & $28,2 \%$ \\
\hline 2001 & $28,8 \%$ & $27,8 \%$ & $23,8 \%$ & $21,2 \%$ & $25,5 \%$ & $33,1 \%$ & $35,5 \%$ & $35,1 \%$ & $36,4 \%$ & $37,9 \%$ & $39,8 \%$ & $36,3 \%$ \\
\hline 2002 & $34,6 \%$ & $31,0 \%$ & $27,2 \%$ & $23,5 \%$ & $17,7 \%$ & $11,0 \%$ & $8,8 \%$ & $9,1 \%$ & $8,2 \%$ & $6,8 \%$ & $3,3 \%$ & $2,3 \%$ \\
\hline 2003 & $2,1 \%$ & $1,7 \%$ & $1,3 \%$ & $0,9 \%$ & $0,7 \%$ & $0,5 \%$ & $-0,2 \%$ & $-0,3 \%$ & $-0,6 \%$ & $-0,7 \%$ & $-0,1 \%$ & $0,6 \%$ \\
\hline
\end{tabular}

\section{Credit to the Economy}

The banking system continued to record profound changes in 2003 in its credit bill, through the sanitation operations involving the major banks operating in the market or via credit recovery. As a result, the balance of Credit to Economy shows a reduction of 159.2 billions of MTs $(-1.1 \%)$ at the end of 2003.

However, if clearing the effect of clearing the credit bill that took place in this period, the results show that flw of conceded credit to the economy grew, in annual terms, by around $14.5 \%$.

The disaggregation of Credit to the Economy shows that $44.3 \%$ is credit in local currency whilst the remaining $55,7 \%$ is in foreign currency.

The breakdown of Credit to the Economy provides an indication of its sectoral composition. In this period the sectors with most outstanding credits were: Trade (15.0\%), Transformation Industry (14.2\%), Agriculture (11.7\%) and Other Sectors of the Economy (including credit to individuals at $37.2 \%$ ).

\section{Supervision and Regulation}


The development of financial markets is crucial to the creation of an environment, which is attractive to investments in Mozambique, stimulating accelerated economic growth and poverty reduction. In this context, PARPA identifies as main objectives the promotion of financial services expansion and the strengthening of bank supervision.

In 2003, the prudential management indicators show substantial improvements, and the ratio of bad debts decreased to $17 \%$, after $21 \%$ in 2002 . The ratio of solvability was well above the regulated $8 \%$.

During 2003 the Bank of Mozambique continued to adopt mechanisms for the strengthening of bank supervision and to conduct the necessary reviews in the legislation on financial regulations. These actions include: actions on financial expert inspection at BIM, the design of a reinforcement project on the institutional capacity of Banco of Mozambique, including technical assistance and covering the areas of bank supervision, payment systems and monetary policy management and the development and introduction within Bank of Mozambique of the BSA IT application for Bank supervision.

In the context of legislation and regulation review, Bank of Mozambique submitted to the competent organs for approval of the 'Credit Institutions and Financial Companies Law' (which accommodates the micro finance activity). Similarly, the Regulation of the 'Services of Credit Registration Centre' was reviewed as well as the legislation on Bankruptcy and Liquidation of Credit Institutions and Financial Corporations.

On the other hand, the implementation of plans for the recovery of bad debt associated with the privatisation of Banco Austral and the adoption of the Business Plan for BIM continued in 2003.

\section{V.4.INFLATION}

The accumulated inflation, from January to December 2003 was $13,8 \%$, against $9,1 \%$ in the same period of 2002 .

The analysis of inflation by products shows that food, beverages and tobacco group contributed $9,51 \%$ (to the overall rate), followed by the comfort and housing group with $2,71 \%$. These two groups account for virtually the totality of changes in the index during 2003. 


\begin{tabular}{|c|c|c|c|c|c|c|c|c|c|c|c|c|}
\hline & JAN & FEB & $\overline{M A R}$ & $\overline{\mathrm{APR}}$ & MAY & JUN & JUL & $\overline{A U G}$ & SEP & OCT & NOV & DEC \\
\hline \multicolumn{13}{|l|}{ INDEX: } \\
\hline 1998 & 102.4 & 104.1 & 103.2 & 102.2 & 101.7 & 100.4 & 99.1 & 98.8 & 98.0 & 97.7 & 98.9 & 100.0 \\
\hline 1999 & 102.7 & 105.0 & 103.9 & 104.7 & 104.1 & 103.8 & 103.4 & 102.7 & 102.4 & 101.2 & 100.9 & 106.2 \\
\hline 2000 & 105.8 & 113.9 & 116.5 & 118.4 & 119.3 & 117.8 & 118.6 & 117.2 & 118.0 & 118.2 & 116.8 & 118.4 \\
\hline 2001 & 117.2 & 116.9 & 117.7 & 119.0 & 121.8 & 124.4 & 127.4 & 129.6 & 130.9 & 135.9 & 140.4 & 144.3 \\
\hline 2002 & 144.1 & 146.0 & 145.0 & 145.4 & 145.6 & 147.1 & 148.6 & 149.4 & 149.6 & 150.2 & 153.0 & 157.5 \\
\hline 2003 & 157.1 & 160.7 & 164.9 & 166.9 & 169.7 & 168.3 & 168.3 & 169.4 & 170.6 & 172.3 & 173.8 & 179.2 \\
\hline \multicolumn{13}{|c|}{ MONTH ON MONTH VARIATION (\%): } \\
\hline 1998 & 1.4 & 1.6 & -0.9 & -0.9 & -0.5 & -1.3 & -1.3 & -0.3 & -0.9 & -0.3 & 1.2 & 1.2 \\
\hline 1999 & 2.7 & 2.3 & -1.1 & 0.8 & -0.5 & -0.3 & -0.4 & -0.7 & -0.3 & -1.2 & -0.3 & 5.2 \\
\hline 2000 & -0.3 & 7.6 & 2.3 & 1.6 & 0.8 & -1.2 & 0.7 & -1.2 & 0.7 & 0.2 & -1.2 & 1.4 \\
\hline 2001 & -1.0 & -0.2 & 0.7 & 1.1 & 2.4 & 2.1 & 2.4 & 1.7 & 1.0 & 3.8 & 3.3 & 2.8 \\
\hline 2002 & -0.2 & 1.3 & -0.7 & 0.3 & 0.1 & 1.1 & 1.0 & 0.6 & 0.1 & 0.4 & 1.9 & 2.9 \\
\hline 2003 & -0.3 & 2.3 & 2.6 & 1.2 & 1.6 & -0.8 & 0.0 & 0.6 & 0.7 & 1.0 & 0.9 & 3.1 \\
\hline \multicolumn{13}{|c|}{ GROWTH RATE HOMOLOGIC (\%): } \\
\hline 1998 & 4.2 & 3.6 & 2.9 & 2.9 & 3.7 & 2.4 & 1.2 & 0.1 & -0.3 & -1.2 & -0.8 & -1.0 \\
\hline 1999 & 0.3 & 0.9 & 0.7 & 2.4 & 2.4 & 3.5 & 4.3 & 3.9 & 4.5 & 3.6 & 2.1 & 6.2 \\
\hline 2000 & 3.1 & 8.4 & 12.1 & 13.1 & 14.5 & 13.4 & 14.7 & 14.1 & 15.2 & 16.8 & 15.7 & 11.4 \\
\hline 2001 & 10.7 & 2.6 & 1.0 & 0.5 & 2.1 & 5.6 & 7.4 & 10.6 & 10.9 & 15.0 & 20.2 & 21.9 \\
\hline 2002 & 22.9 & 24.9 & 23.2 & 22.2 & 19.5 & 18.3 & 16.6 & 15.2 & 14.3 & 10.5 & 8.9 & 9.1 \\
\hline 2003 & 9.0 & 10.1 & 13.7 & 14.8 & 16.5 & 14.4 & 13.2 & 13.3 & 14.0 & 14.7 & 13.6 & 13.8 \\
\hline \multicolumn{13}{|c|}{ ACCUMULATED GROWTH RATE FOR THE YEAR (\%): } \\
\hline 1998 & 1.4 & 3.1 & 2.2 & 1.3 & 0.7 & -0.6 & -1.8 & -2.1 & -0.3 & -3.3 & -2.1 & -1.0 \\
\hline 1999 & 2.7 & 5.0 & 3.9 & 4.7 & 4.1 & 3.8 & 3.4 & 2.7 & 2.4 & 1.2 & 0.9 & 6.2 \\
\hline 2000 & -0.3 & 7.2 & 9.7 & 11.4 & 12.3 & 10.9 & 11.7 & 10.4 & 11.1 & 11.3 & 9.9 & 11.4 \\
\hline 2001 & -1.0 & -1.2 & -0.6 & 0.5 & 2.9 & 5.1 & 7.7 & 9.5 & 10.6 & 14.8 & 18.6 & 21.9 \\
\hline 2002 & -0.2 & 1.2 & 0.5 & 0.7 & 0.9 & 1.9 & 3.0 & 3.5 & 3.6 & 4.0 & 6.0 & 9.1 \\
\hline 2003 & -0.3 & 2.0 & 4.7 & 6.0 & 7.7 & 6.9 & 6.9 & 7.5 & 8.3 & 9.4 & 10.4 & 13.8 \\
\hline
\end{tabular}

Source: Instituto Nacional de Estatistica

By products the following contributed positively: Peanuts, rice, wood, and potato, cooking oil, mackerel and phone calls. White maize, hairstyling services, capulana, cloroquine, glass plate, shirts for children and bottled soft drinks had a negative contribution. There is susbstantial demand in the market for these products.

\section{CONTRIBUTION FOR THE INCREASE OF INFLATION (\%)}

\begin{tabular}{|l|r|}
\hline Description & 2003 \\
\hline Food, beverages and tobacco & 9.51 \\
Clothes and shoes & -0.11 \\
Comfort and housing & 2.71 \\
Health & 0.22 \\
Transport and Communication & 0.81 \\
Education, culture and entertainment & 0.09 \\
Other goods and services & 0.58 \\
\hline & \\
\hline Total & 13.82 \\
\hline
\end{tabular}

\section{PRODUCTS WITH GREATER CONTRIBUTION IN THE INCREASE OF CPI (\%)}

\begin{tabular}{|l|r|}
\hline Description & 2003 \\
\hline Peanuts & 1.47 \\
Rice & 1.44 \\
Wood & 1.27 \\
Potato & 0.79 \\
Cooking Oil & 0.77 \\
Frozen Mackerel & 0.62 \\
Urban phone calls & 0.61 \\
Others & 7.71 \\
Sub-Total & 14.68 \\
\hline
\end{tabular}


Note that in the same period of previous year, the products which presented greater contribution for the recorded index were wood, transport tariffs (for transporting people), urban phone calls, electricity, fuel, onion and cooking oil.

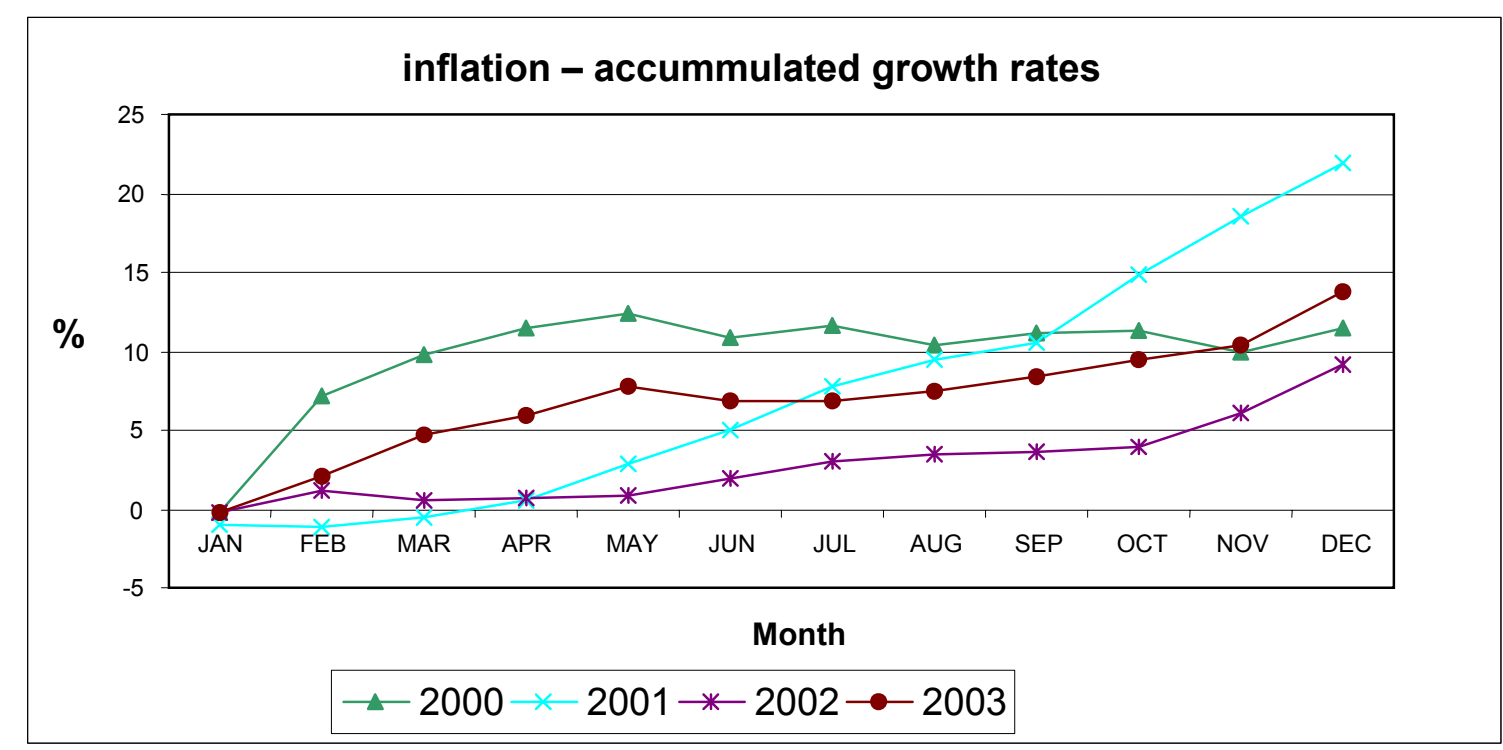

The recorded inflation is 6 percent points above the planned target around the 7 percent points compared with the previous year this is equivalent to 4.7 percent points. Amongst other factors, the following elements contributed to inflation behaviour:

- Weak level of internal production of cereals and vegetables, products with considerable weight in the CPI basket;

- Strengthening of the rand in the international markets that resulted in a depreciation of Metical.

\section{V.5.BALANCE OF PAYMENTS}

The preliminary results for 2003 indicate a notable improvement in the country's position compared to the rest of the world in the region of $97 \%$.

Selected Balance of Payments items

\begin{tabular}{lrr}
\hline & $\mathbf{2 0 0 2}$ & $\mathbf{2 0 0 3}$ \\
Exports (FOB) & 679.3 & 880.2 \\
Imports (FOB) & -1215.7 & -1228.2 \\
Revenue from Services & 339.4 & 311.6 \\
Expenditure with Services & -563.2 & -571.6 \\
Foreign Direct Investment & 347.6 & 336.7 \\
\hline
\end{tabular}


Overall, the analysis of the Balance of Payments components shows that:

- The Current Account balance improved by $27 \%$ from a deficit of USD 711.6 million in 2002, to USD 521.5 million in 2003, mainly due to movements in the Trade and Income balances;

- The Balance on Goods and Services recorded a deficit of USD 607.9 million in 2003, representing an improvement of around $29 \%$ on 2002. This improvement was determined by the increase in exports;

- The Income Balance recorded a deficit of USD 165.5 million, an improvement of $73 \%$ compared with the same period of the previous year.

- The Capital and Financial Account recorded a surplus of around USD 270.7 million, an increase of $22 \%$ compared with the same period last year;

- Direct Foreign Investment was USD 336.7 million, recording a small fall compared with 2002

\section{V.6.MACRO-ECONOMIC OUTLOOK}

The medium term economic programme aims to consolidate macroeconomic stability and resolve existing structural problems in order to guarantee a comprehensive growth process in which job creation and poverty reduction are realised.

The policies developed by the Government are consistent with the goals of the poverty reduction strategy defined in the PARPA. The Review of the PES accompanies the implementation of these policies. In particular budget allocation and policies should be compatible with the goals and priorities established in the PARPA, which might soon be reformulated and adjusted.

Looking to the medium-term, we envisage growth of about $8 \%$ in 2004 , influenced by the MOZAL II and Gas (SASOL) projects. In the following years, growth is expected to be around $6.5 \%$ and $7 \%$ per year. Inflation will fall from the levels seen towards the end of 2003 to single digit levels in 2006. Foreign assistance (granhts and concessionary lending), is expected to be US\$720 Million in 2004 , and should remain relatively constant in the following years.

The fiscal programme will continue to be strengthened in order to create conditions for the allocation of resources in priority areas and also to create incentives for an increase in credit to the private sector. The primary deficit is projected to move from $3.9 \%$ of GDP (2003) to $3.0 \%$ by 2006 . 
Fiscal revenues will continue to strengthen through improvements in fiscal administration. The fiscal programme also points to an improvement in the implementation of remuneration policies within the public sector.

These measures will create savings that can be used to increase the internal component of investment expenditure, particularly in the priority sectors.

The deficit on the external current account (after grants) will be around $2 \%$ of GDP in 2004 due to increases in Mozal II and SASOL exports, as well as a fall in imports due to the completion of the construction phases of these mega-projects. In subsequent years, the deficit is estimated to be around $6 \%$ of GDP, particularly due to the beginning of the Heavy Sands project.

The financial needs of the Country over the medium term will continue to be met through a combination of donations, concessional loans and private capital flows in the form of direct foreign investment. International reserves are predicted to be equivalent to 6 months' imports on average. 


\section{MAIN DEVELOPMENTS BY SECTOR}

\section{VI.1. SOCIAL AREA}

\section{A. EDUCATION}

Education is the major factor in the improvement of the quality of life for people through its contribution to the increase of human ability/capacity needed for the satisfaction of needs and to the reduction of poverty.

Hence, in 2003 the efforts in Education continued to be concentrated towards increasing knowledge through (1) expansion of access to all levels of education, with particular attention to the promotion of balance in terms of gender, (2) improvement in the quality of education (3) institutional development.

\section{Access Expansion}

In 2003 the number of students in the general Education increased by $9 \%$ compared with 2002. This represents an accomplishment of $97 \%$ of PES for 2003. At the primary level, the Primary Education of $\left(2^{\circ} \mathrm{Grau}\right)$ continues to record a rapid growth tendency of students $(17 \%)$ compared with the pace of growth recorded on EP1 (7\%).

\begin{tabular}{|l|c|c|c|r|r|r|c|}
\hline \multicolumn{8}{|c|}{ Number of Students. 1999 -2003} \\
\cline { 1 - 3 } Level & 1999 & 2000 & 2001 & 2002 & \multicolumn{2}{|c|}{2003} & Growth \% \\
& Actual & Actual & Actual & Actual & \multicolumn{1}{c|}{ Plan } & Actual & R03/R02 \\
\hline EP1 & $2,075,467$ & $2,289,653$ & $2,513,094$ & $2,643,126$ & $2,936,570$ & $2,825,971$ & 6.9 \\
EP2 & 187,872 & 219,325 & 265,994 & 302,912 & 359,405 & 355,618 & 17.4 \\
ESG1 & 66,924 & 78,868 & 98,095 & 116,356 & 133,861 & 141,795 & 21.9 \\
ESG2 & 8,351 & 10,071 & 11,968 & 14,019 & 17,814 & 18,291 & 30.5 \\
\hline Total & $2,338,614$ & $2,597,917$ & $2,889,151$ & $3,076,413$ & $3,447,650$ & $3,341,675$ & 8.6 \\
\hline
\end{tabular}

Source: MINED

With the aim of assessing the coverage levels attained by the education system, gross admission rates and education rates in the primary level will be analysed (pls see table below). The achievement of universal primary education is the greatest priority provided for by the government within PARPA as well as in the Strategic Plan of Ministry of Education, as per the Millennium Development Goal in the area of education. 


\begin{tabular}{|l|r|r|r|r|r|r|r|}
\hline \multicolumn{7}{|c|}{ School and Gender Coverage Indicators, 1999 - 2003 in \% } \\
\hline & \multicolumn{1}{|c|}{1999} & 2000 & \multicolumn{1}{c|}{2001} & \multicolumn{2}{|c|}{2002} & \multicolumn{2}{|c|}{2003} \\
\cline { 5 - 8 } & Actual & Actual & Actual & PARPA & Actual & PARPA & Actual \\
\hline Gross Admission Rate EP1 & 85,2 & 113,5 & 122,3 & 122,0 & 118,0 & 124,0 & 129,2 \\
Net Admission Rate EP1 & 23.7 & 29.1 & 34.5 & & 35.3 & & 44.1 \\
\hline Gross Admission Rate EP2 & 18,8 & 20,8 & 25,6 & 25,0 & 28,0 & 27,0 & 30,6 \\
\hline Gross Education Rate. EP1 & 74,4 & 90,7 & 99,5 & 102,0 & 104,0 & 104,0 & 110,3 \\
Gross Education Rate. EP2 & 21,1 & 23,2 & 27,9 & 30,0 & 31,2 & 32,0 & 36,3 \\
\hline Proportion of Girls in EP1 & 42,7 & 43,3 & 43,9 & 45,0 & 44,6 & 46,0 & 45,3 \\
Proportion of Girls in EP2 & 40,1 & 39,0 & 39,3 & 41,5 & 39,4 & 42,5 & 40,0 \\
\hline
\end{tabular}

Source: MINED

The gross admission rate in the primary level of education (EP1), an indicator that establishes the relation between new entries in standard 1 and the total population with 6 years of age (official age for entry in the education system) shows an improvement tendency in the period 1999-2003. From $85 \%$ in 1999 it went to $129 \%$ in 2003 . This achieved level was above the $5 \%$ target established in PARPA (124\%) and represented an evolution of $11 \%$ compared with 2002. Although education is fast expanding, the level of admission shows that only $44 \%$ of the population aged 6 years enrolled in schools in 2003.

In relation with EP2, the target expressed in PARPA was exceeded by $4 \%$. The significant difference in the admission rate for EP1 and EP2 results, mainly from the yet internal low efficiency of the system in the two levels.

The levels of education also show a tendency of improving in the period being analysed. The gross education rate in EP1, indicator that shows the relation between the total number of students in EP1 and the population aged 6 to 10 was $110.3 \%$ in 2003 (more than $6.3 \%$ compared with 2002), exceeding the target in PARPA of $6 \%$. In EP2 the same rate was $36 \%, 4 \%$ more than the target in PARPA.

Although EP2 is rapidly growing in terms of number of students (17\% in 2003) the coverage rates in this level continue to be low (36\% in 2003). The low schooling rates in EP2 result from the education network distortion in this level of education. However, this distortion is gradually being corrected from this year with the introduction of the new curricula for primary education which foresees that all schools must teach EP1 and EP2 simultaneously.

With the aim of expanding access to education, more attention continues to be placed in the construction of new schools and the training of teachers in the various levels of education.

As illustrated in the table below, in 2003 the total number of schools increased by $5 \%$ compared with 2002 . This corresponds to $99.8 \%$ of plan achievement. The number of schools in EP2 continues to maintain a rapid growth tendency 
compared with the other levels. It recorded in the period $1999-2003$ an expansion of more than $100 \%$.

\begin{tabular}{|c|c|c|c|c|c|c|c|}
\hline \multicolumn{8}{|c|}{ Number of Schools. $1999-2003$} \\
\hline \multirow[t]{2}{*}{ Level } & \multirow{2}{*}{$\begin{array}{c}1999 \\
\text { Actual }\end{array}$} & \multirow{2}{*}{$\begin{array}{c}2000 \\
\text { Actual }\end{array}$} & \multirow{2}{*}{$\begin{array}{c}2001 \\
\text { Actual }\end{array}$} & \multirow{2}{*}{$\begin{array}{c}2002 \\
\text { Actual }\end{array}$} & \multicolumn{2}{|c|}{2003} & \multirow{2}{*}{$\begin{array}{r}\text { Growth. \% } \\
\text { R03/R02 }\end{array}$} \\
\hline & & & & & Plan & Actual & \\
\hline EP1 & 6,692 & 7,072 & 7,496 & 7,771 & 8,084 & 8,071 & 3.9 \\
\hline EP2 & 454 & 554 & 680 & 823 & 949 & 950 & 15.4 \\
\hline ESG1 & 84 & 93 & 106 & 116 & 125 & 125 & 7.8 \\
\hline ESG2 & 18 & 20 & 23 & 27 & 29 & 29 & 7.4 \\
\hline Total & 7,248 & 7,739 & 8,305 & 8,737 & 9,187 & 9,175 & 5.0 \\
\hline
\end{tabular}

Source: MINED

In terms of training of teachers, in 20031,272 teachers were trained in the 11 Primary Teacher Training Centres (CFPPs). This represents an increase of $17 \%$ compared with 2002. In the 7 Primary Teacher Training Centres, 1,561 teachers were trained during normal working hours (see table below). Overall, without including night shifts, 2,833 primary education teachers were trained and this is well above the target set in PARPA of training 1,680 teachers per year.

\begin{tabular}{|c|c|c|c|c|c|c|c|}
\hline \multicolumn{8}{|c|}{ Training of Teachers (General Education), $1999-2003$ - Total Nº of Students } \\
\hline & \multirow{2}{*}{$\begin{array}{c}1999 \\
\text { Actual }\end{array}$} & \multirow{2}{*}{$\begin{array}{l}2000 \\
\text { Actual }\end{array}$} & \multirow{2}{*}{$\begin{array}{c}2001 \\
\text { Actual }\end{array}$} & \multirow{2}{*}{$\begin{array}{c}2002 \\
\text { Actual }\end{array}$} & \multicolumn{2}{|c|}{2003} & \multirow{2}{*}{$\begin{array}{l}\text { Growth \% } \\
\text { R03/R02 }\end{array}$} \\
\hline & & & & & Plan & Actual & \\
\hline CFPP's (Basic) & 3,836 & 4,326 & 4,534 & 4,997 & 5,042 & 5,193 & 3.9 \\
\hline Graduated & 741 & 886 & 956 & 1,089 & 1,272 & 1,272 & 16.8 \\
\hline IMAP's (Médio) - Day & 1,272 & 2,544 & 3,385 & 3,672 & 3,697 & 3,841 & 4.6 \\
\hline Graduated & 412 & 624 & 1,546 & 1,550 & 1,561 & 1,561 & 0.7 \\
\hline IMAP's (Médio) - Night & & 0 & 190 & 773 & 1,028 & 1,708 & 121.0 \\
\hline Graduated & & & & 172 & 386 & 386 & 124.4 \\
\hline
\end{tabular}

Source: MINED

As a way of elevating the participation and retention of girls in education, the distribution of food kits for girls (students) was one of the actions taken in 2003. The actions also included sensitising community leaders, parents and adults responsible for kid's education on the importance of education girls. Parallel to this gender counselling centres in schools were created.

As a result of the efforts being undertaken to promote the education of girls in the primary component, the proportion of girls in primary education is increasing although the numbers are still low. In 2003 the percentage of girls in EP1 was $45,3 \%$ and in EP2 was $40 \%$. Compared with the established targets in PARPA, the proportions achieved were slightly below plan (in EP1 there was a target of $46 \%$ and in EP2, $42.5 \%$ ).

In terms of the Millennium Development Goal of eliminating the unbalance of gender in the primary and secondary education, preferably until 2005, and for all levels of education the latest until 2015, there are good signs for the achievement of gender parity for EP1 (target of $48 \%$ ) which shows a regular tendency of growth in terms of proportion of girls. In terms of EP2, the achievement of the 
millennium goal will take place later given that the level of performance is still very low. There is also a tendency for irregular development compared with EP1.

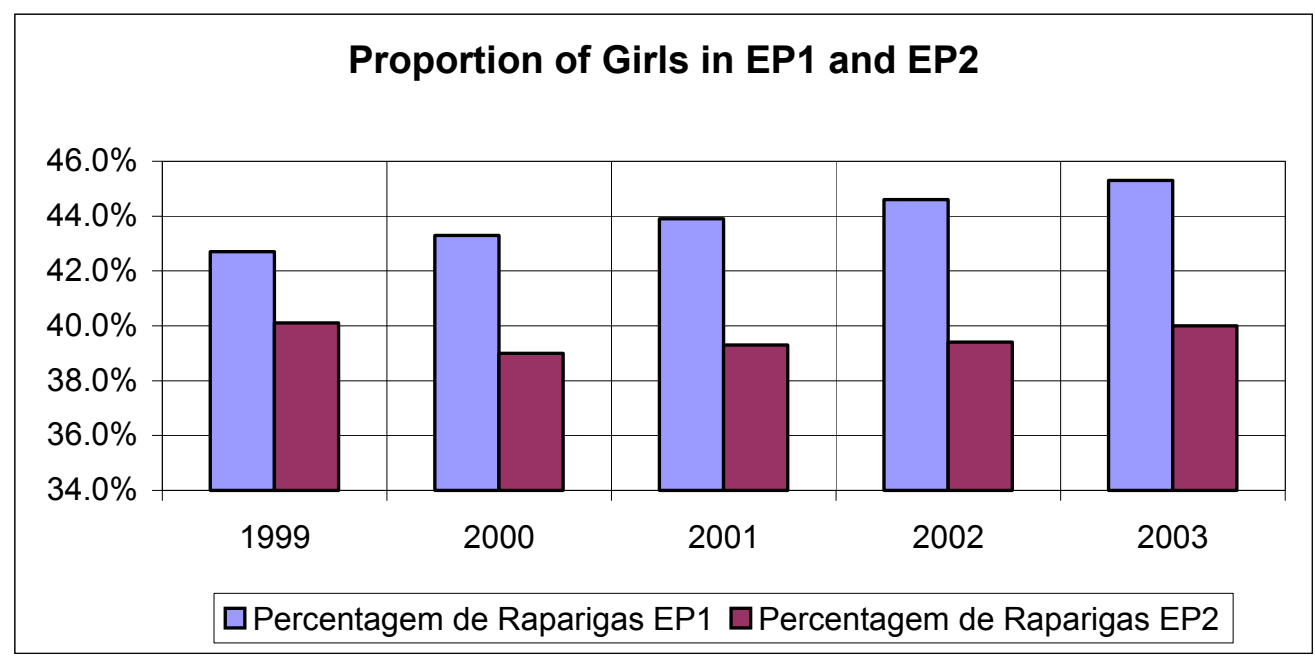

Because MINED recognises that the expansion of education is not only about building schools and training teachers, it has undertaken to use and explore the potential of Distance Education (EAD), as a valid and recognised modality of education, training, professional training and promotion of scientific knowledge and technical abilities of the citizens. Hence, in the context of creating conditions for the start of the Secondary Education Distance Learning in Maputo, the following activities were developed in 2003:

- Designing and printing of the learning modules for standard 8;

- Established five support and learning centres in the districts of Namapa, Namialo, Rapale, Mecuburi e Moma;

- Tutors and supervisors identified and trained to ensure the implementation of the programme; and

- Completed the process of enrolling and selecting students.

\section{Adult Education}

In 2003 there were identified 3,570 units of adult education operating in 133 districts. In the first and second years 438,830 adults participated. This represents a growth of $56.6 \%$ compared with 2002 . 78,972 adults, representing growth of $20.3 \%$ compared with 2002 , attended the 3 rd year.

Female participation in the 1 st and 2 nd years was $57.9 \%$, country average. In the 3rd year women's participation was at $48 \%$. 
In the 8 schools of elementary technical level currently operating, 1,250 students were registered and this corresponds to a rate of achievement against the plan. It also represents an increase of 30\% compared with 2002 .

The basic level (commercial, industrial and agricultural area) 25 schools are operational with 19,090 students. Compared with 2002 the number of students increased by $7.9 \%$.

The advanced technical education was covered in 7 schools and in which 3,278 students were registered. This represents an increase of $0.6 \%$ compared with the previous year.

\section{Improvement in the Quality of Education}

Access to education is expanding at a good pace as illustrated by the coverage rates achieved in the previous years. However, the high levels of failure recorded in the primary education, with a tendency of slowly changing in the period 19992003 and the still slow development that is observed in the success rates, illustrate that apart from access expansion to education, which is being successfully done, the efforts in improving education must continue.

\begin{tabular}{|l|c|c|c|c|c|}
\hline & 1999 & 2000 & 2001 & 2002 & 2003 \\
\hline Success Rate in Std 5 (EP1) & $65.7 \%$ & $66.6 \%$ & $64.3 \%$ & $67.7 \%$ & $70.2 \%$ \\
\hline Success Rate in Std 7 (EP2) & $54.6 \%$ & $54.2 \%$ & $59.4 \%$ & $61.0 \%$ & $62.2 \%$ \\
\hline & & & & & \\
\hline Rate of those repeating in EP1 & $23.9 \%$ & $22.8 \%$ & $23.0 \%$ & $23.3 \%$ & $21.9 \%$ \\
\hline Rate of those repeating EP2 & $24.8 \%$ & $22.7 \%$ & $22.0 \%$ & $22.0 \%$ & $19.4 \%$ \\
\hline
\end{tabular}

Source: MINED

The rates of those repeating (due to failure) in EP1 moved from $24 \%$ in 1999 to $22 \%$ in 2003 i.é a variation around $2 \%$ throughout the period. In terms of the success rates in EP1, they moved from $65.7 \%$ in 1999 to $70 \%$ in 2003 , i.é a variation of around $5 \%$ in the period being analysed.

With the aim of improving the quality of education, efforts in 2003 were placed in the revitalisation of the zones of pedagogical influence (ZIPs), in the pedagogical supervision and curricula review and in the free distribution of the school books and other support materials to the activity of teaching.

In the context of revitalisation and expansion of the zones of pedagogical influence (ZIPs), ZIPs coordinators were trained and new equipment provided. In terms of training the ZIP coordinators, the process of producing the respective modules has started.

At the same time, provincial trainers were trained totalling 128. 45 are from the South, 55 from the Central Regional and 28 from the North Region.

In the area of Pedagogic and Support supervision, pedagogic inspection and 
supervision actions were taken in various education institutions at provincial level.

In the context of the introduction of the new curricula for Basic Education, teacher-training actions took place throughout the country. The new curricula were also tested in 29 schools all over the country.

With the aim of reviewing the programmes for the 1st cycle of ESG (General Secondary Education) and concluding the analysis of the curricula for the Industrial Basic Technical Education, the following actions were developed:

- For ESG -The review of the learning programmes was completed, and

- For Technical Education - analysis of the curricula has started.

In the context of School Book Free Distribution Programme, in $200311,257,945$ schoolbooks were distributed for the primary education, of which $7,328,045$ for standards 1 and 2 and the rest for standards 3 to 7 . For the first 2 classes, the distributed books covered the needs of registered students at $98 \%$. The replacement of books was done at $60 \%$ as a way of covering for damaged books, as well as responding to the increase in number of students in this subsystem.

Total Books Distributed

\begin{tabular}{|c|c|c|r|}
\hline & $1^{\mathrm{a}}-2^{\mathrm{a}}$ & $3^{\mathrm{a}}-7^{\mathrm{a}}$ & \multicolumn{1}{c|}{ Total } \\
\hline 1999 & $5,686,000$ & $1,775,000$ & $7,461,000$ \\
2000 & $5,910,000$ & $1,780,000$ & $7,690,000$ \\
2001 & $6,450,000$ & $3,300,270$ & $9,750,270$ \\
2002 & $7,345,450$ & $2,635,700$ & $9,981,150$ \\
2003 & $7,328,045$ & $3,929,900$ & $11,257,945$ \\
\hline
\end{tabular}

Concerning the training of school headmasters, around $70 \%$ of headmasters of schools at all levels of education were covered by the training programme. These training actions extended to pedagogical and administrative deputy director.

With the aim of promoting decentralization and quality of education, the direct assistance to schools programme as launched. This programme consists of direct attribution to public primary schools (primárias do $1^{\circ} \mathrm{Grau}$ ), financial resources for the acquisition of basic school material that benefit students and teachers alike. In the first phase of the programme 8,137 EP1 public schools were covered.

\section{B. SCIENCE, TECHNOLOGY AND HIGHER EDUCATION}

In this area the development of a work force capable of responding scientifically and technologically to the great challenges of developing the country continues 
to get special attention. As a result the expansion of higher education institutions, the design of legislation with the aim of regulating the functioning and the consolidation of institutional functioning continued to be a priority.

In the area of institutional development the change to new premises enhanced institutional consolidation. It is of importance to highlight the review of the Sector Organic Statute and the Operationalisation of Organs and Regulation of Higher Education Law.

In terms of Higher Education, feasibility studies were completed for the opening of higher education institutions in the provinces of Manica, Tete and Gaza. Seminars were also organised at provincial and national levels to discuss these studies. It is also of importance to highlight the process of placing Higher Polytechnics in the provinces of Manica, Tete and Gaza and the accomplishment of supervision actions about the implementation of the Higher Education Strategic Plan in Public Sectors of Higher Education.

With the aim of providing financial support and investment in the domain of innovative initiatives for the improvement of Higher Education Quality, the Fund for Quality Improvement and Innovation (QIF) programme continued to be implemented. In 2003 various institutional and investigation projects were approved within this programme.

Still in this area it is of key importance to highlight the creation of the Health Science Higher Polytechnic Institute in Maputo City and the Military Academy in Nampula City and the allocation of a total of 101 scholarships for people from Gaza, Tete and Cabo Delgado Provinces (pls refer to table below). Scholarships were also distributed to 10 people from Nampula Province in 2003 as a reinforcement of Nisome programme.

\begin{tabular}{|l|rrrr|rc|}
\multicolumn{7}{c|}{ Scholarships by Province } \\
\cline { 2 - 5 } \multicolumn{1}{c|}{} & \multicolumn{7}{c|}{ Sex } & \multicolumn{2}{c|}{ Total } \\
\hline Provinces & $\mathrm{N}$ & $\%$ & $\mathrm{~N}$ & $\%$ & $\mathrm{~N}$ & $\%$ \\
\hline Gaza & 29 & 44.6 & 4 & 11.1 & 33 & 32.7 \\
Tete & 19 & 29.2 & 14 & 38.9 & 33 & 32.7 \\
Cabo Delgado & 17 & 26.2 & 18 & 50.0 & 35 & 34.7 \\
\hline Total & 65 & 100.0 & 36 & 100.0 & 101 & 100.0 \\
\hline
\end{tabular}

Below the numbers of people currently studying in the different Universities (these statistics are reviewed in an annual basis):

\begin{tabular}{|l|r|r|r|r|r|r|r|r|}
\hline \multicolumn{8}{|c|}{ Higher Education Public Institutions 2002-2003 } \\
\hline & \multicolumn{2}{|c|}{ Students } & \multicolumn{2}{|c|}{ New Students } & \multicolumn{2}{c|}{ Graduates (01/02) } & \multicolumn{2}{c|}{ Teachers } \\
\cline { 2 - 8 } & Women & Total & Women & Total & Women & Total & Women & Total \\
\hline UEM & 1,969 & 8,046 & 457 & 1,573 & 213 & 696 & 212 & 916 \\
UP & 751 & 3,072 & 224 & 1,155 & 77 & 212 & 65 & 245 \\
ISRI & 90 & 307 & 37 & 151 & 5 & 13 & 9 & 55
\end{tabular}




\begin{tabular}{|c|c|c|c|c|c|c|c|c|}
\hline ACIPOL & 35 & 230 & 15 & 67 & & & 3 & 42 \\
\hline Sub Total 1 & 2,845 & 11,655 & 733 & 2,946 & 295 & 921 & 289 & 1,258 \\
\hline \multicolumn{9}{|c|}{ Higher Education Private Institutions 2002-2003 } \\
\hline ISCTEM & 672 & 1,327 & 156 & 328 & & & 40 & 181 \\
\hline ISPU & 995 & 1,798 & & & & 230 & 38 & 178 \\
\hline ISUTC & 47 & 191 & 17 & 72 & & & 4 & 31 \\
\hline UCM & 718 & 1,765 & 201 & 701 & 27 & 85 & 45 & 147 \\
\hline UMBB & 112 & 453 & & & & & 2 & 50 \\
\hline Sub Total 2 & 2,544 & 5,534 & 374 & 1,101 & 27 & 315 & 129 & 587 \\
\hline Total & 5,389 & 17,189 & 1,107 & 4,047 & 322 & 1,236 & 418 & 1,845 \\
\hline
\end{tabular}

The following chart shows an example of published indicators, in the area of Higher Education, depicting the growth relation between the national population and the number of students in higher education.

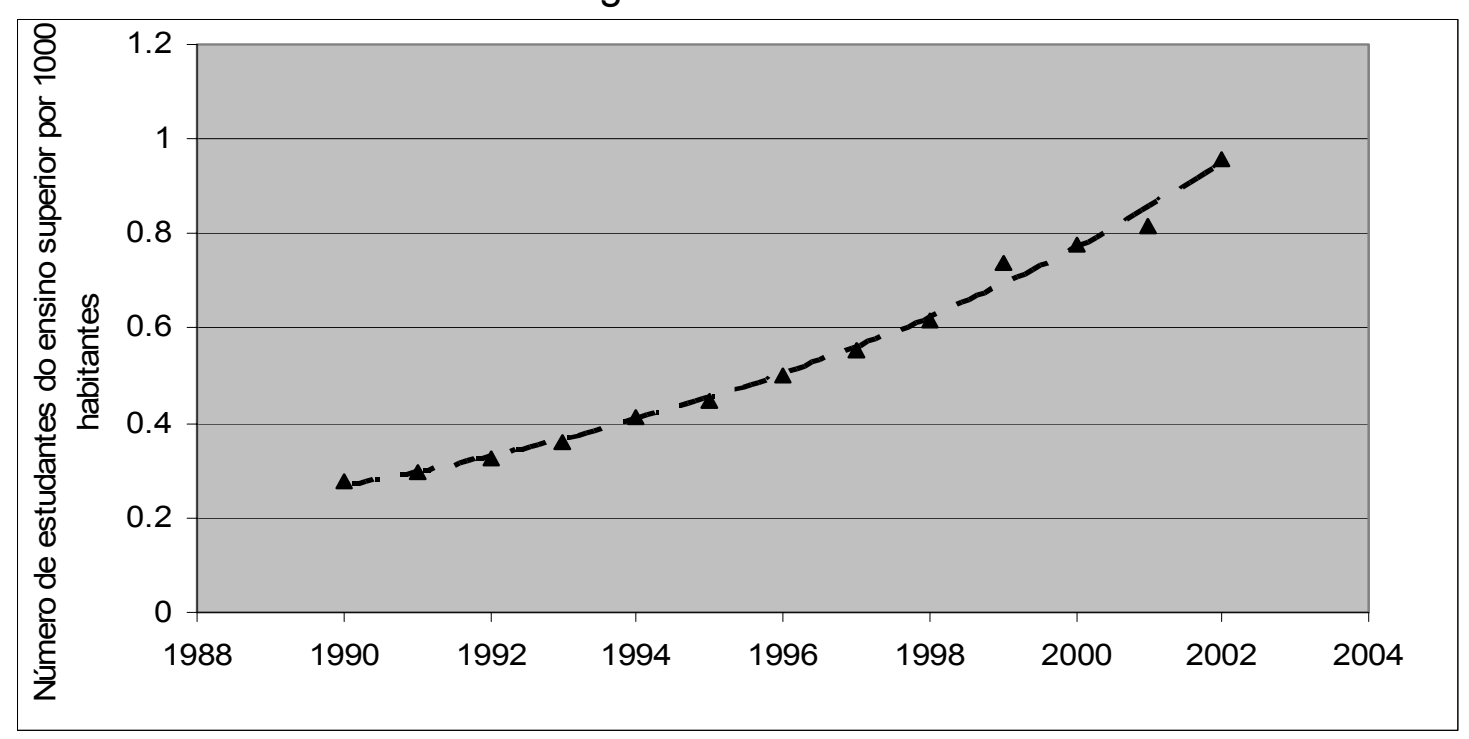

In the scope of Science and Technology, emphasis should go to the passing and dissemination of the Science and Technology Policy, the development of the Implementation Strategy and Plan for the Operationalization of the Policy and publication of the first brochure of indicators of science and technology.

The brochure of indicators presents data on the quality of human resources involved in the scientific investigation, the levels of funding per area and the scientific publications quoted in international scientific magazines. The following charts show some of the published indicators: 


\section{Level of Training of Investigators at the IIC (2002).}

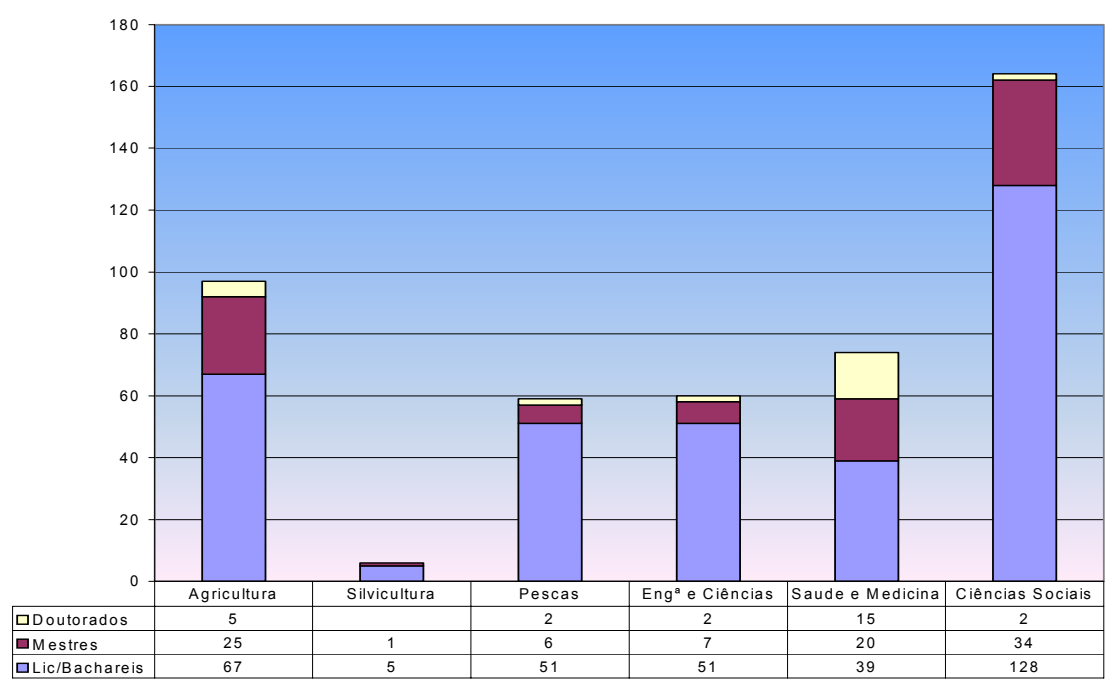

This picture shows a great concentration of investigators in the social sciences areas and that the investigators were mostly trained up to the levels of Bachelor's degree and Honours Degree, followed by Masters. The number of Doctors is still very reduced, with a small exception (relative) in the area of Health and Medical Science.

Still as an example of Science and Technology indicators, the chart below shows the origin of funds allocated for investigation, by areas. In terms of volume, it can be noted that there is modest allocation of funds for agriculture despite the importance of this area. The great allocation of funds for the area of Social Sciences is due to inclusion of great institutions such as INE. 
Funding of scientific Investigation Institutions by area

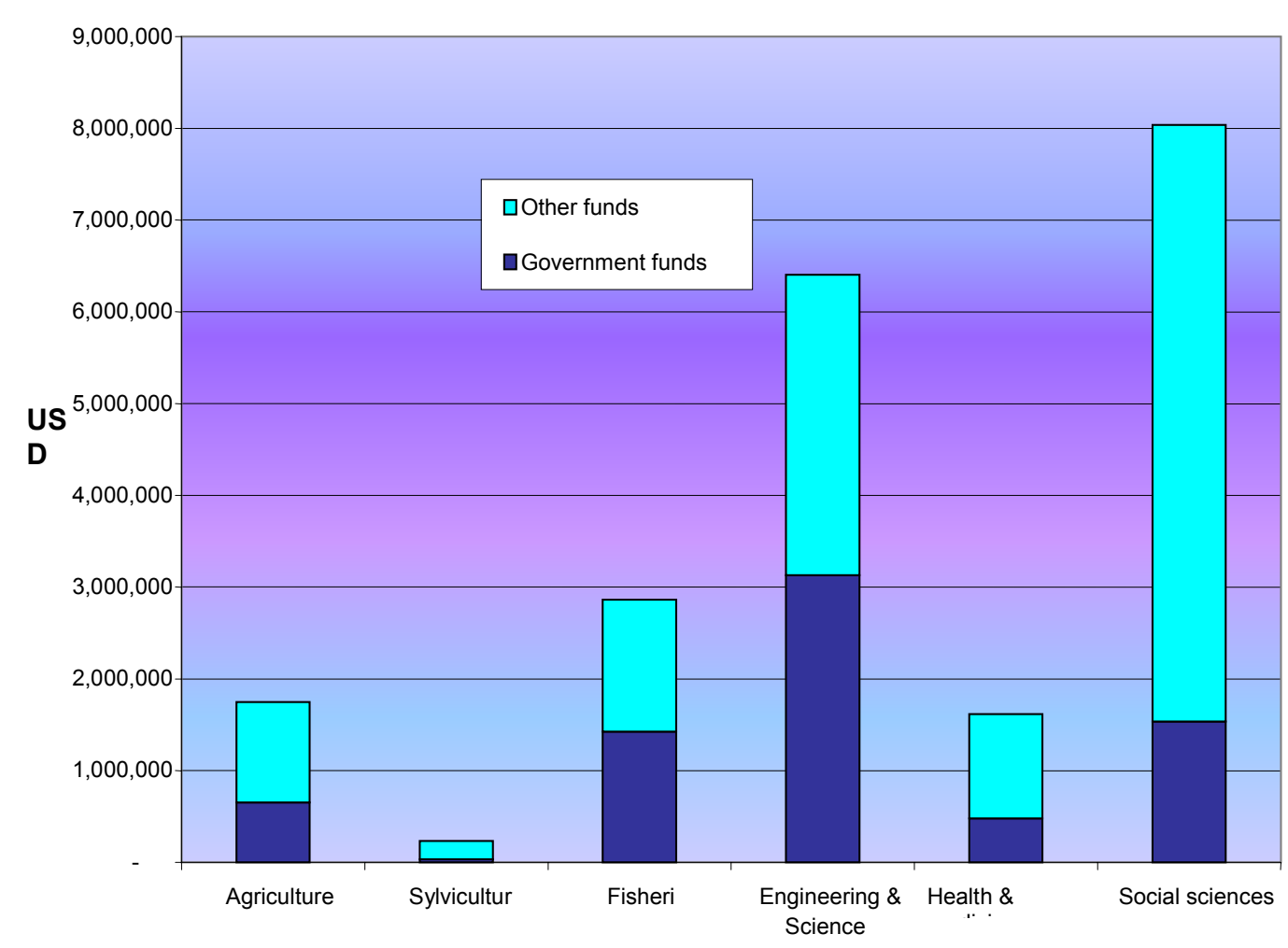

\section{HEALTH}

In the area of Health, in 2003, privileged continued to go to increasing availability of health services in order to cover the majority of the Mozambican population with priority to the groups with increased risk, less favoured geographic areas, applying as the main strategy good quality and sustainable Primary Health Care (CSP). The improvement of the health conditions of women and children is one of the objectives of the Health Sector.

In the meantime, attention was given to improving the quality of services delivered to the users, as well as to improving the living conditions of the health professionals through construction and rehabilitation of houses.

\section{Health Care Delivery}

In the scope of Delivery of Health Care, in 2003 the global volume of the activities of the National Health Services (SNS) expressed in terms of care facilities and external medical appointments grew by $2.4 \%$ and $9.9 \%$ respectively, in comparison with the year 2002 (see the chart below).

\begin{tabular}{|l|l|l|l|l|l|l|}
\hline \multicolumn{6}{|c|}{ Evolution of Overall Health Activity, 1999-2003 } \\
\hline & 1999 & 2000 & 2001 & 2002 & 2003 & Evol. \%) \\
60 &
\end{tabular}




\begin{tabular}{|c|c|c|c|c|c|c|c|}
\hline Indicators & Real & Real & Real & Real & Plan & Real & R03/R02 \\
\hline \multicolumn{8}{|l|}{ GLOBAL ACTIVITY } \\
\hline Care Facilities (Mil) & 61,121 & 61,954 & 65,739 & 65,422 & 70,022 & 66,997 & \multirow[t]{2}{*}{2.4} \\
\hline Care Facilities/Inhabitant & 3.42 & 3.62 & 3.74 & 3.62 & 3.80 & 3.61 & \\
\hline \multicolumn{8}{|c|}{ EEXTERNAL MEDICAL APPOINTMENTS } \\
\hline External Medic. Appointments (thousand) & 13,383 & 14,350 & 15,074 & 15,021 & 17,567 & 16,512 & \multirow[t]{2}{*}{9.9} \\
\hline Ext. Med. Appointments / Inhabitant & 0.82 & 0.83 & 0.85 & 0.83 & 0.94 & 0.89 & \\
\hline
\end{tabular}

Source: MISAU

*Data from 2003 adjusted from 9-month information

In the scope of the Mother to Child Health and Family Planning Program (SMI/PF), privileged continued to go to increasing accessibility and availability of essential services for women, children, students and young people, with priority going to rural areas, aiming at improving maternal health and reducing child mortality. Thus, training was conducted in the area of Obstetric Emergencies for 185 professionals, mainly in the area of Maternal Infant Health (SMI) and other experts such as general physicians, cirurgical and medical experts and various equipment was distributed for placing attention to the delivery and pre-birth care.

The main components of maternal infant health in 2003 continued to keep the trend of growing as experienced since 1999. With exception to institutional deliveries, which were below predictions, the rest of the SMI components made a positive performance in relation to PARPA targets.

\begin{tabular}{|l|c|c|c|c|c|c|c|}
\hline \multicolumn{8}{|c|}{ Evolution of the Coverage Rates SMI/Family Planning, 1999-2003 } \\
\hline \multicolumn{1}{|c|}{ Indicators } & 1999 & 2000 & 2001 & \multicolumn{2}{c|}{2002} & \multicolumn{2}{c|}{2003} \\
\cline { 5 - 9 } & Real & Real & Real & PARPA & Real & PARPA & Real \\
\hline Pre-Birth Consultations & 94 & 104.9 & 105.3 & 97 & 106.6 & 97 & 118,3 \\
Institutional Deliveries & 38 & 39.7 & 41.2 & 48 & 43 & 49 & 45.7 \\
Post Delivery Consultations & 43 & 49.5 & 50.5 & 54 & 53.8 & 56 & 56.6 \\
Family Planning (New Users) & 8 & 7 & 7.6 & 15 & 15.3 & 16 & 16.7 \\
1st Cons. Children (0-11 Months) & 123 & 154.2 & 151.9 & 97 & 148.7 & 98 & 164.9 \\
1st Cons. Children (0-4 years) & 36 & 58 & 48 & 64 & 56.1 & 66 & 65.2 \\
\hline
\end{tabular}

Source: MISAU

*Data from 2003 adjusted from 9-month information

As a result of the efforts that have been developed in the Health Sector, aiming at reducing the maternal mortality rate, the intra-hospital maternal mortality rate experience a slight decline in $2003(0.17 \%)$ in comparison with $2002(0.18 \%)$.

In the scope of the Wide Vaccinations Programmes (PAV), special attention was given to improvement of infants' health care and reduction of incidence and prevalence of the main preventable diseases through vaccination of 0-23 month old children, children at the early stage in schools and women at the fertile age (15-49 years).

Concerning 2002, the trend of PAV coverage rates was to decline due mainly to improvements on data gathering, which was possible with the inquiries in 2002. 
With exception to the level of coverage of the vaccination of children with $<1$ year against tuberculosis which overcame the PARPA target, the rest of the levels of coverage were below the targets.

\begin{tabular}{|c|c|c|c|c|c|c|c|}
\hline \multicolumn{8}{|c|}{ Evolution of the Wider Vaccination Programme Coverage Rates, 1999-2003 } \\
\hline \multirow[b]{2}{*}{ Indicators } & \multirow{2}{*}{$\begin{array}{l}1999 \\
\text { Real }\end{array}$} & \multirow{2}{*}{$\begin{array}{l}2000 \\
\text { Real }\end{array}$} & \multirow{2}{*}{$\begin{array}{l}2001 \\
\text { Real }\end{array}$} & \multicolumn{2}{|c|}{2002} & \multicolumn{2}{|c|}{2003} \\
\hline & & & & PARPA & Real & PARPA & Real \\
\hline BCG [0-11 Months] & & 108.1 & 95.1 & 98 & 107.9 & 98 & 102.5 \\
\hline VAS [9-23 Months] & 96 & 95.6 & 94.3 & 97 & 92.7 & 98 & 92.7 \\
\hline DPT/Anti-Polio e HB ( $3^{\mathrm{a}}$ Dose) $[0-11 \mathrm{M}]$ & 82 & 87.8 & 83.9 & 97 & 87 & 98 & 81.7 \\
\hline VAT- $2^{\text {nd }}$ Pregnant Women & - & - & - & & - & - & - \\
\hline VAT- $2^{\text {nd }}$ Women $15-49$ years & - & 9.9 & 7.1 & 29 & - & 31 & - \\
\hline
\end{tabular}

Source: MISAU

*Data from 2003 adjusted from 9-month information

In the scope of the Nutrition Programme, nutritional intervention actions were implemented aiming at improving the nutritional status of the populations, with priority to women at the fertile age, including pregnant women and children. Policies were also drafted for supplementation with micronutrients and on child nourishing and mother breast-feeding in the context of HIVIAIDS. Still in the scope of HIVIAIDS, a guide for nutrition was produced and distributed amongst people living with HIVIAIDS.

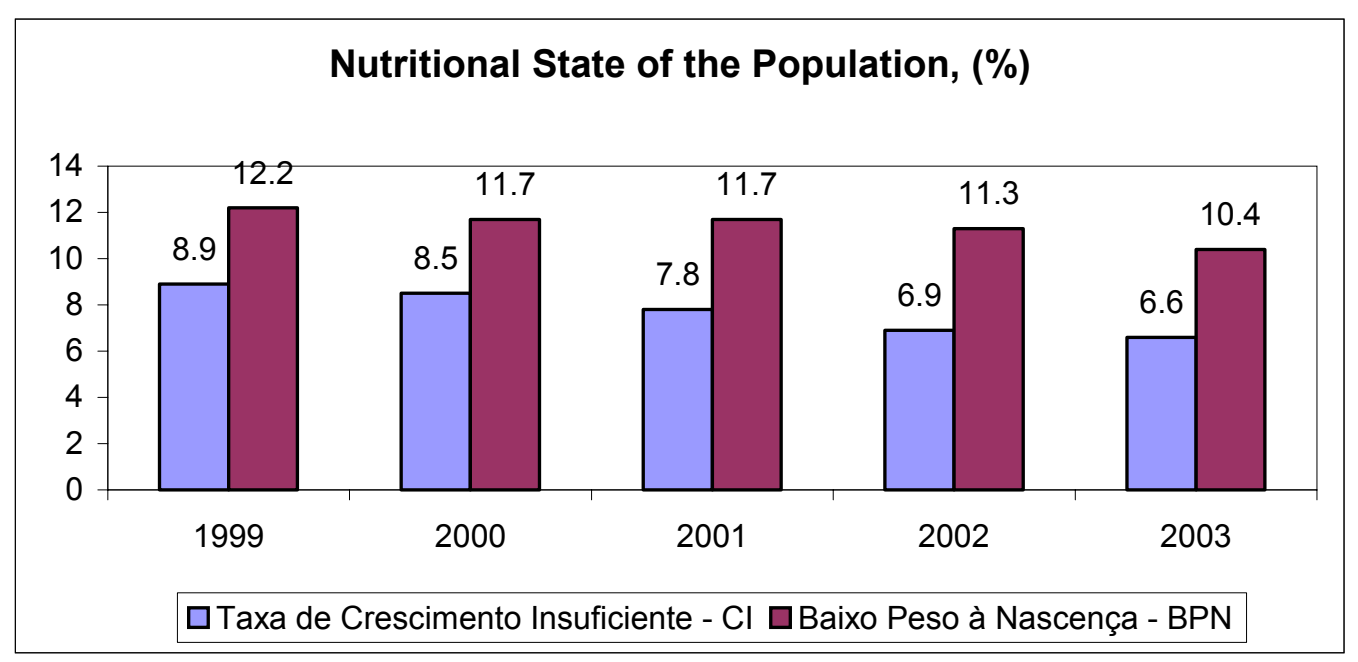

For the Low Weight at Birth indicator, which alarming level is situated above $7 \%$, there is a trend for improvement because this indicator fell from $9 \%$ to $7 \%$ during the concerned period; on the other hand, in relation to Insufficient Growth Rate which alarming level is between $16 \%$ and $30 \%$, there was a trend for improvement because it was between $12 \%$ and $10 \%$ during the concerned period.

In the scope of Epidemiological Surveillance, efforts continued to be concentrated in improving the capacity for diagnosis and early treatment of 
preventable diseases through activities of vectoral control, capacity building and refresher courses for health staff.

In 2003, throughout the Country there was notification of, 24,323 cases of Measles with 202 deaths, of which 3,567 on infants below 9 months of age with 58 deaths against 7,255 cases with 38 deaths, corresponding to $0.5 \%$ of the lethality rate notified in 2002. The significant increase experienced in 2003 on the number of cases, was due to the outbreak of measles in some provinces with major proportions in Tete, Zambezia and Sofala.

Concerning Tetanus, Diarrhoea, Meningitis, Rabies and Cholera, the cases notified do not show a significant increase. Concerning Rabies, there was an increase of approximately 400 cases between 2002 and 2003, a figure that reflects the number of suspected cases.

\begin{tabular}{|c|c|c|c|c|c|c|c|c|}
\hline \multicolumn{9}{|c|}{ Epidemiological Surveillance of Diseases of Compulsory Notification Cases and Deaths, $2000-2003$} \\
\hline & \multicolumn{4}{|c|}{$\begin{array}{c}\text { Measles (<9 Months and + } 24 \\
\text { Months) }\end{array}$} & \multicolumn{4}{|c|}{ Neonatal Tetanus } \\
\hline & 2000 & 2001 & 2002 & 2003 & 2000 & 2001 & 2002 & 2003 \\
\hline Cases & 7,713 & 7,257 & 7,255 & 24,323 & 95 & 59 & 35 & 48 \\
\hline Deaths & 28 & 8 & 38 & 202 & 32 & 20 & 9 & 12 \\
\hline \multirow[t]{3}{*}{ Lethal. Rate. \% } & 0.4 & 0.1 & 0.5 & 0.8 & 33.7 & 33.9 & 25.7 & 25.0 \\
\hline & \multicolumn{4}{|c|}{ Simple Diarrhoea and Dysentry } & \multicolumn{4}{|c|}{ Cholera } \\
\hline & 2000 & 2001 & 2002 & 2003 & 2000 & 2001 & 2002 & 2003 \\
\hline Cases & 586,953 & 561,833 & 628,212 & 594,977 & 26,405 & 9,691 & 29,447 & 14,331 \\
\hline Deaths & 356 & 501 & 449 & 384 & 164 & 118 & 330 & 111 \\
\hline \multirow[t]{3}{*}{ Lethal. Rate. \% } & 0.1 & 0.1 & 0.1 & 0.1 & 0.6 & 1.2 & 1.1 & 0.8 \\
\hline & \multicolumn{4}{|c|}{ Meningitis } & \multicolumn{4}{|c|}{ Rabies } \\
\hline & 2000 & 2001 & 2002 & 2003 & 2000 & 2001 & 2002 & 2003 \\
\hline Cases & 442 & 484 & 665 & 589 & 1,658 & 1,607 & 1,480 & 1,804 \\
\hline Deaths & 138 & 201 & 299 & 209 & 26 & 33 & 28 & 21 \\
\hline Lethal. Rate. \% & 31.2 & 41.5 & 45.0 & 35.5 & 1.6 & 2.1 & 1.9 & 1.2 \\
\hline
\end{tabular}

Malaria

In $20034,478,215$ cases of malaria were notified and 3,212 deaths, which represents a reduction of $1.6 \%$ and of $23 \%$ on the number of cases, and deaths respectively in relation to 2002 . The hospital lethality rate on adults was $6 \%$.

As the chart bellow shows, in general there is a trend of growth on the number of malaria cases and deaths recorded since 1999. This shows that the situation is alarming which might in some way compromise the Millennium Development Goals of stopping, by 2015, and start reversing the malaria incidence.

Evolution of the notification of malaria cases and deaths

\begin{tabular}{|l|r|r|r|}
\hline Year & Cases & Deaths & Let. Ra (\%) \\
\hline
\end{tabular}




\begin{tabular}{|l|l|l|l|}
\hline 1999 & $2,336,640$ & 1,520 & 0.060 \\
\hline 2000 & $3,443,172$ & 2,036 & 0.059 \\
\hline 2001 & $3,947,335$ & 3,400 & 0.086 \\
\hline 2002 & $4,554,324$ & 4,190 & 0.092 \\
\hline 2003 & $4,478,215$ & 3,212 & 0.073 \\
\hline
\end{tabular}

Source: BES (Weekly Epidemiological Bulletin)

In the scope of the ongoing efforts to fight malaria, campaigns of house fumigations were carried out throughout the Country, covering 901,468 houses and protecting some de 4,500,000 inhabitants.

Extra house fumigations were conducted in Sofala, Gaza and Maputo City with the aim of interrupting the chain of transmission of the epidemic outbreak that affected those regions in January and February 2002.

More than 300,000-treated bed nets (RMI) were distributed throughout the Country, totalling $600,000 \mathrm{RMI}$ already distributed since 1999 . The distribution of $\mathrm{RMI}$ is followed by information or demonstration on how to treat the nets.

Along that, clinical training sessions were conducted totalling to 363 in all the Provinces of the Country, in diagnosing and treating malaria, at the sanitary units, with exception to Maputo City.

\section{STD/HIVIAIDS}

The interventions to fight HIVIAIDS probably represent the most active part of the health sector in the last years, with the opening of new services, almost monthly. The present prevalence rate of HIV in adults is $14 \%$.

The notifications of HIVIAIDS cases started increasing in 1998 and in 2003; the figure was at about 12,000 new cases, with more than half of the cases being notified in Maputo City. However, the notified cases represent only $13 \%$ of the new expected cases. Under notification is high in the central region, where only $4 \%$ of the estimated cases were notified.

Blood transfusions and related products were considered to be safe. In 2003, 17 Blood Banks and more than 80 Transfusion Centres in the Country, collected more than 75,000 units of blood, which were tested for HIV, of which $10,2 \%$ were positive.

In the context of implementation of the National Strategic Plan to Fight HIVIAIDS, new services were created, specifically:

- The Counselling and Voluntary Testing Offices (GATV): During 200343 GATVs were open. In terms of volume, the GATVs assisted more than 200,000 people, of which about $26 \%$ were HIV+. 
- Three laboratories have the capacity do make CD4 tests (immunity marker) and viral charge, being two at Maputo and Beira Central Hospitals and one at the Medical Faculty of the Eduardo Mondlane University. A fourth one is to be set up at Nampula Central Hospital;

- The 13 Daily Hospitals "Hospitais de Dia" (HDD) throughout the Country, hold all the experience that exist in terms of case management, identification and treatment of opportunistic infections;

- The Youth and Adolescent Friends Services (SAAJ) which apart from HIVIAIDS, offer reproductive health services, including clinics;

- The services of Prevention of Vertical Transmission (PTV) at selected sanitary units, in general include counselling and testing of pregnant women, administration of prophylaxis with Nevirapina; and

- Different ways of Home Care (CD) to people living with HIVIAIDS.

Concerning promotion of the use of condoms, 28 million condoms were distributed in 2003 against 26 million distributed in 2002.

\section{Tuberculosis}

29,107 cases of tuberculosis were diagnosed in 2003 , of which 16,130 are new cases, against 26,117 cases during 2002 . The cure rate was at $77 \%$ in 2002 .

In the scope of the efforts being made to combat tuberculosis, training activities were developed resulting in the training of 186 clinical officials, the were supervision activities to the health personnel, and awareness actions to the sick people on the need to treat the disease.

\section{Leprosy}

The present prevalence of Leprosy in Mozambique is 3.9 per 10,000 inhabitants. The most endemic provinces are the three northern ones and Zambezia in the Central Region of the Country. The Provinces of Manica and Sofala experienced a prevalence of 2.3 and 1.4 respectively due to the recent mini-campaigns of active search to the people sick of leprosy. The rest of the provinces have figures below 1 case per 10,000 inhabitants and are regarded as lees priority, where the cure rate is $84 \%$ throughout the Country.

In the scope of the leprosy prevention and fighting programme, aiming at increasing the geographic coverage of the treatment, taking into account that Mozambique is the seventh Country in the World and second most endemic in Africa, with a prevalence rate higher than three, privilege continued to be given to integrated training of technical staff totalling 111 and specific training of 75 
technical staff, the review and updating of registration books of leprosy cases and the holding of information campaigns on the disease.

The sanitary network grows lightly in 2003, having moved from 1,221 sanitary units in 2002 to 1,230. Despite this slight growth, it should be noted that there was an intensive activity to put the sanitary network back to functioning with emphasis to the activities conducted at the following Rural Hospitals: Gurue, Mueda, Muxúngue, Mocuba, lle and Milange. 


\begin{tabular}{|c|c|c|c|c|c|c|}
\hline \multicolumn{7}{|c|}{ Evolution of the Sanitary Network, $2000-2002$} \\
\hline & \multicolumn{2}{|c|}{2000} & \multicolumn{2}{|c|}{2001} & \multicolumn{2}{|c|}{2002} \\
\hline & Total & $\%$ & Total & $\%$ & Total & $\%$ \\
\hline Sanitary Units & 1,068 & 100.0 & 1,197 & 100.0 & 1,221 & 100.0 \\
\hline Hospitals & 43 & 4.0 & 43 & 3.6 & 45 & 3.7 \\
\hline $\begin{array}{l}\text { Health Centres } \\
\text { Health Posts }\end{array}$ & $\begin{array}{l}277 \\
748\end{array}$ & $\begin{array}{l}25.9 \\
70.0\end{array}$ & $\begin{array}{l}516 \\
638\end{array}$ & $\begin{array}{l}43.1 \\
53.3\end{array}$ & $\begin{array}{l}665 \\
511\end{array}$ & $\begin{array}{l}54.5 \\
41.9\end{array}$ \\
\hline Beds (total) & 15,008 & 100.0 & 15,594 & 100.0 & 16,081 & 100.0 \\
\hline $\begin{array}{ll}\text { Maternity } & \text { Warden } \\
\text { Beds } & \end{array}$ & 4,415 & 29.4 & 4,641 & 29.8 & 4,798 & 29.8 \\
\hline Other Beds & 10,593 & 70.6 & 10,953 & 70.2 & 11,293 & 70.2 \\
\hline Source: MISAU & & & & & & \\
\hline
\end{tabular}

In terms of training, the actions were directed to improving the quality, through simplification of the selection process of candidates for courses and constant capacity building of the teachers, including financial and logistics support for the well-being and good academic conditions of the trainees.

\begin{tabular}{|l|c|c|}
\hline \multicolumn{3}{|c|}{ Training of Health Experts, $2002-2003$} \\
\hline \multicolumn{1}{|c|}{ Level } & 2002 & 2003 \\
\hline Specialized Doctors & 13 & 21 \\
Doctors & 368 & 86 \\
Basic & 483 & 749 \\
\hline \multicolumn{3}{|c|}{ Total } \\
\hline Source: MISAU
\end{tabular}

Taking into account what was predicted on the PES 2000 - 2004, out of the 72 specialised doctors that were expected to be trained 46 have already been training which corresponds to $63,9 \%$ of the plan; in relation to the medium level out of 910,740 have been trained, corresponding to $81,3 \%$; and at the basic level out of $3,010,2,019$, corresponding to $67 \%$.

\section{LABOUR}

In the area of labour, employment promotion through professional training actions, development of small projects of income generation continued to be the priority in the scope of the present efforts to reduce the levels of unemployment. Special attention was also given the construction of Infrastructure and training and expansion of the social security system.

\section{Legislative Action}


The adoption and implementation of laws and regulations of labour for the effective functioning of the labour market, continued to deserve a special attention in 2003. Hence, there is an emphasis for the ratification of the following labour convention:

- Convention on the worst forms of child labour;

- Convention on the minimum age for admission to labour; and

- Convention on the abolishment of forced labour.

\section{Employment}

By the end of 2003, unemployment recorded at the employment centres was 130,405 unemployed people, representing a growth of $5 \%$ comparatively to 2002. About $40 \%$ of the unemployed people recorded as looking for $1^{\text {st }}$ grade employment and $60 \%$ for new employment. Nampula (24\%), Sofala $(19 \%)$ and Maputo Province (13\%) are the provinces that recorded the highest numbers of unemployed people.

With a view to reducing the unemployed labour force in 2003 efforts continued to be concentrated on employment promotion through expansion of employment and professional training infra-structures, development of small projects of income generation, professional training and employment of unemployed people.

Concerning Infrastructure of employment and training, emphasis goes to the beginning of the construction of professional training centres in Pemba and Quelimane and the conclusion of the construction of the Lichinga centre.

In relation to employment generation projects, priority continued to go to the development of community level projects, which benefited a total of 15,574 members. These projects gave privilege to the promotion of the use of new variety of plants and distribution of labour instruments.

Concerning professional training, a total of 1,155 unemployed people and 133 micro and small business people benefited from training in various areas. The unemployed trained people received labour kits to start their activities.

The professional training of people with disability was promoted in order to increase the employment possibilities. Hence, a total of 48 disabled benefited from training in various areas.

The employment of candidates in the Country or abroad continued to be promoted through employment centres. During 2003, 15,331 unemployed people registered at the employment centres, of which only 1,607 were placed. The existing differences between the required qualifications and the available labour force continues to be the major stumble block in meeting the existing 
employment opportunities. Only about $23.4 \%$ of the total of the employment opportunities $(6,857$ opportunities $)$ at the centres were met.

Migratory work continues to be one of the main sources of employment for the national citizens. In 2003 this type of labour absorbed 52,369 workers for the South African mines, representing a growth of 1\% compared with 2002 .

\section{Professional Relations}

The prevention of labour conflicts, strikes and promotion of social dialogue continued to receive special attention. Thus, privilege continued to go to the dissemination of the labour legislation, awareness actions to employers and employees on the need to develop collective regulation instruments and interventions in the conciliation of labour conflicts.

\section{Social Security}

The extension of the social security system and improvement of the services rendered to the beneficiaries continued to be promoted. Thus, the Marromeu Branch was opened, the social security system started to be computerized and the provincial delegations were equipped.

During 2003, 112,374 beneficiaries and 1,383 new contributors enrolled in the system. Hence, the accumulated number on the system is 516,333 beneficiaries and 14,125 contributors.

\section{E. WOMEN AND SOCIAL WELFARE}

In this area, during 2003, attention was given to development and institutional capacity building, the elevation of the women status and promotion of security, assistance and social integration of the target groups under the situation of vulnerability, particularly children, women, elderly people and people with disability. In this context and amongst various actions that were conducted, the following can be emphasised:

In the scope of development and institutional capacity building:

- The Sector Strategic Plan continued to be drafted;

- Rehabilitation of the Matola Infantry started;

- Beginning of the construction of 49 houses for elderly people in the Districts of Buzi and Govuro;

- A tender was launched for the construction of the Institute for Visually Disabled People in Beira. 
In the scope of the elevation of the women status

- Beginning of the implementation of the National Gender Policy;

- Conclusion of the National Action Plan for the Advancement of Women;

- Capacity building for about 5,351 women in the province of Tete, in the area of women rights and ways of reducing domestic violence, premature marriages and child prostitution; and

- Implementation of micro-credit programmes which benefited about 1,902 women (1,500 in Inhambane and 402 in Tete).

In the scope of Localization and Family Re-union, 1,197 children were documented and 429 were re-unified, corresponding to an achievement above $100 \%$ of the original plan. The province that recorded the biggest number of documented children is Niassa (528).

Localization and Family Re-union

\begin{tabular}{|c|c|c|c|c|c|}
\hline \multirow[b]{2}{*}{ Indicators } & \multirow{2}{*}{$\begin{array}{c}2002 \\
\text { Actual }\end{array}$} & \multicolumn{2}{|c|}{2003} & \multirow{2}{*}{$\begin{array}{c}\text { Accompl. } \\
\text { Plan } \\
(\%)\end{array}$} & \multirow{2}{*}{$\begin{array}{c}\text { Evol. \% } \\
\text { R03/ } \\
\text { /R02 }\end{array}$} \\
\hline & & Plan & Actual & & \\
\hline Number of documented children & 772 & 330 & 1,197 & 362.7 & 55.1 \\
\hline Number of documented children & 283 & 220 & 429 & 195.0 & 51.6 \\
\hline
\end{tabular}

Source: MMCAS

In the context of Pre-School Education the following activities took place:

- In the centres under the auspices of the Ministry 1,483 children were registered corresponding to $87.2 \%$ of the original plan and representing a growth of about $4 \%$ in comparison with the number from last year;

- In the private infant centres 7,954 children were assisted throughout the country. In comparison to last year, the number of children assisted grew by about $57 \%$; and

- In the 533 community crèches in the Country, 37,410 children were accommodated with assistance from 870 animators. In relation to 2002, the number of accommodated children grew by about $61 \%$.

Pre-School Education

\begin{tabular}{|c|c|c|c|c|c|}
\hline \multirow[b]{2}{*}{ Indicators } & \multirow{2}{*}{$\begin{array}{c}2002 \\
\text { Actual }\end{array}$} & \multicolumn{2}{|c|}{2003} & \multirow{2}{*}{$\begin{array}{c}\text { Accompl. } \\
\text { Plan } \\
(\%)\end{array}$} & \multirow{2}{*}{$\begin{array}{c}\text { Evol. \% } \\
\text { R03/ } \\
\text { /R02 }\end{array}$} \\
\hline & & Plan & Actual & & \\
\hline Number of Infants Centres (State) & 15 & 15 & 15 & 100.0 & 0.0 \\
\hline Number of Accommodated Children & 1,424 & 1,700 & 1,483 & 87.2 & 4.1 \\
\hline Number of Infants Centres (Private) & 85 & 90 & 103 & 114.4 & 21.2 \\
\hline Number of Accommodated Children & 5,053 & 6,000 & 7,954 & 132.6 & 57.4 \\
\hline
\end{tabular}




\begin{tabular}{|l|r|r|r|r|r|} 
Number of Community Crèches & 373 & 400 & 533 & 133.3 & 42.9 \\
Number of Accommodated Children & 23,257 & 25,000 & 37,410 & 149.6 & 60.9 \\
Number of Animators & 636 & 650 & 870 & 133.8 & 36.8 \\
\hline
\end{tabular}

Source: MMCAS

In the scope of Assistance to Children in Difficult Situation, the following activities were conducted:

- Assistance to 10,659 children in 71 centres devoted to assisting street children, of which 4,026 children were assisted in 25 closed centres;

- 8 Crèches functioned under the auspices of MMCAS (Ministry for Women and Co-ordination of Social Welfare), which assisted 345 children, against 9 crèches that assisted 444 children in 2002;

- 14 private crèches that assisted 685 children functioned in 2003 , against the same number of crèches that accommodated 1,058 children in 2002;

- 572 children were integrated into various learning institutions in the province of Inhambane, of which 14 refugees from the Great Lakes, 24 orphans and 534 in the situation of poverty and exclusion;

- 792 children/youth were integrated in agricultural and animal farming projects and in the informal trade in the Province of Gaza;

- In the provinces of Cabo Delgado, Manica and Zambezia, about 57,809 children benefited from school material, clothes, medical and medical assistance.

Children under Difficult Situation

\begin{tabular}{|c|c|c|c|c|c|}
\hline \multirow[b]{2}{*}{ Indicators } & \multirow{2}{*}{$\begin{array}{c}2002 \\
\text { Actual }\end{array}$} & \multicolumn{2}{|c|}{2003} & \multirow{2}{*}{$\begin{array}{c}\text { Accompl. } \\
\text { Plan } \\
(\%)\end{array}$} & \multirow{2}{*}{$\begin{array}{c}\text { Evol. \% } \\
\text { R03/ } \\
\text { /R02 }\end{array}$} \\
\hline & & Plan & Actual & & \\
\hline Number of Street Centres & 78 & 80 & 71 & 88.8 & -9.0 \\
\hline Number of Accommodated Children & 4,732 & 4,600 & 10,659 & 231.7 & 125.3 \\
\hline Number of Crèches (State) & 9 & 9 & 8 & 88.9 & -11.1 \\
\hline Number of Accommodated Children & 444 & 300 & 345 & 115.0 & -22.3 \\
\hline Number of Crèches (Private) & 14 & 12 & 14 & 116.7 & 0.0 \\
\hline Number of Accommodated Children & 1,058 & 1,000 & 685 & 68.5 & -35.3 \\
\hline
\end{tabular}

Source: MMCAS

In the scope of institutional assistance to the elderly people, the following activities were conducted:

- 10 Centres for Assistance to the Elderly People operating under the auspices of the Ministry were operational and assisted 255 elderly people. Under the responsibility of private entities, 12 Centres were operational and assisted 281 elderly people; 
- At the community level 20 thousand elderly people were identified and assisted with food and other goods, throughout the country, with emphasis to the province of Manica that supported about 15,466 elderly people, MaputoProvince with 213 elderly people, Maputo-City with 4,380 elderly people, Tete 2,421 elderly people and Niassa with 325 elderly people;

- The Policy and Strategy for Assistance of the Elderly People was Disseminated in the province of Gaza;

- Beginning of the process of drafting the National Action Plan on aging in Mozambique: and

- Drafting of a manual of guidelines and procedures for assistance to the elderly people in the Elderly People Assistance Centres

Elderly People Assistance Programme

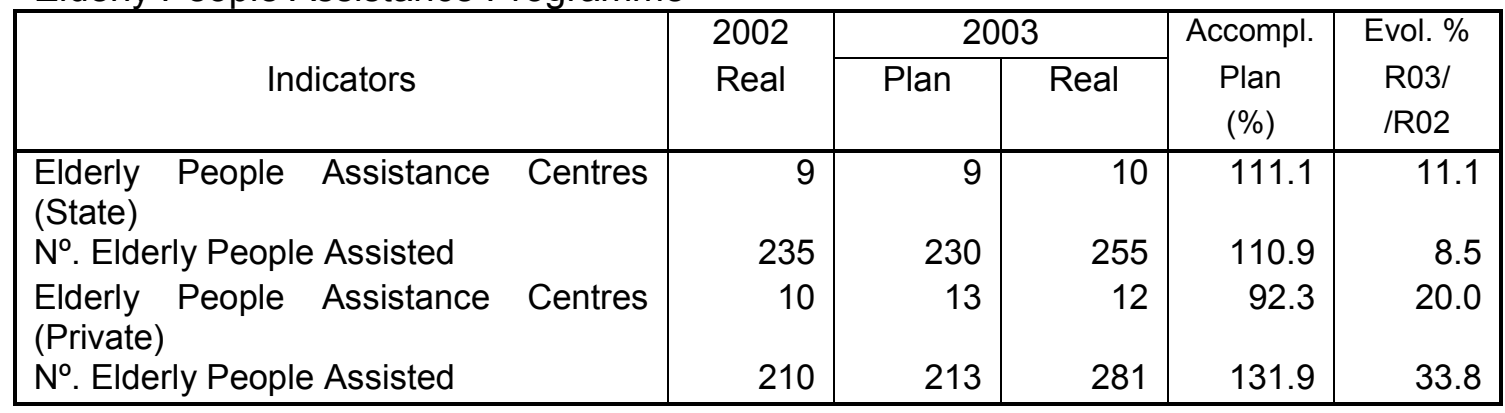

In the scope of assisting people with disability, the following activities were conducted:

- 12,800 disabled people were identified; 6,228 people were attended; and 2,165 disabled children were integrated in different normal schools, socialfamily and community programmes;

- Dissemination of the Policy on the Disabled People in all Provinces;

- Supervision visits to the Community Based Assistance Program (ABC) in the Provinces of Gaza (17 visits), Manica (12 visits), Niassa (5 visits) and Cabo Delgado (4 visits) were made.

Assistance to Disabled People

\begin{tabular}{|c|c|c|c|c|c|}
\hline \multirow[b]{2}{*}{ Indicators } & \multirow{2}{*}{$\begin{array}{c}2002 \\
\text { Actual }\end{array}$} & \multicolumn{2}{|c|}{2003} & \multirow{2}{*}{$\begin{array}{c}\text { Accompl. } \\
\text { Plan } \\
(\%)\end{array}$} & \multirow{2}{*}{$\begin{array}{c}\text { Evol. \% } \\
\text { R03/ } \\
\text { /R02 }\end{array}$} \\
\hline & & Plan & Actual & & \\
\hline Identified Disabled People & 1,498 & 3,000 & 12,800 & 426.7 & 754.5 \\
\hline
\end{tabular}




\begin{tabular}{|l|r|r|r|r|r|} 
Attended Disabled People & 355 & 1,000 & 6,228 & 622.8 & 1654.4 \\
Integrated Disabled Children & 424 & 800 & 2,165 & 270.6 & 410.6 \\
Number of Transit Centres & 6 & 6 & 8 & 133.3 & 33.3 \\
Assisted Disabled People & 302 & 400 & 290 & 72.5 & -4.0 \\
Special Schools & 3 & 3 & 3 & 100.0 & 0.0 \\
Number of Students & 284 & 300 & 308 & 102.7 & 8.4 \\
Institute of Visually Disabled People & 1 & 1 & 1 & 100.0 & 0.0 \\
Number of Students & 75 & 75 & 75 & 100.0 & 0.0 \\
\hline
\end{tabular}

Source: MMCAS

In the area of Toxic dependence, a project was drafted for public education on the dangerers of abusive use of toxic substances and lectures were held on the consumption of drugs and its effects in training/education in the province of Inhambane.

In the scope of The Food Subsidy Programme, the following activities were conducted:

- There was a review of the food subsidy programme and integration of beneficiaries with ability to work in income generating projects and community development; and

- 80.177 direct beneficiaries were assisted, corresponding to $88.1 \%$ of the plan (91.000) and about 109,675 indirect beneficiaries. In terms of category proportion, the elderly people represent $88 \%$ of the total of the groups assisted. In terms of gender, about $37 \%$ of the beneficiaries of the food subsidies are male and $63 \%$ female. 
Beneficiaries of Food Subsidies

\begin{tabular}{|c|c|c|c|}
\hline Indicators & $\begin{array}{l}2002 \\
\text { Real }\end{array}$ & $\begin{array}{l}2003 \\
\text { Real }\end{array}$ & $\begin{array}{c}\text { Evol. \% } \\
\text { R03/R02 }\end{array}$ \\
\hline Elderly People & 68,883 & 70,448 & 2.3 \\
\hline Disabled & 5,041 & 5,076 & 0.7 \\
\hline Chronically Sick People & 916 & 783 & -14.5 \\
\hline Women who are Heads of Households & 1,229 & 1,039 & -15.5 \\
\hline Women with Malnourished Children & 886 & 545 & -38.5 \\
\hline Malnourished Pregnant Women & 96 & 42 & -56.3 \\
\hline Ceasing Beneficiaries & 8,302 & 2,244 & -73.0 \\
\hline Sub-Total & 85,353 & 80,177 & -6.1 \\
\hline Indirect Beneficiaries & 108,547 & 109,675 & 1.0 \\
\hline Grand Total & 193,900 & 189,852 & -2.1 \\
\hline
\end{tabular}

Source: MMCAS

In relation to the Integrated National Program of Social Welfare, Employment and Youth under implementation in 26 rural districts and 2 urban districts at the national level, particular attention was given to the consolidation and the expansion to other beneficiaries of the income generating projects in the areas of agriculture, animal farming and trade. Thus, the number of direct beneficiaries went from 3,988 people in 2002 to 4,046 in 2003, and the indirect beneficiaries went from 12,259 to 14,825 people in 2003 . The slight growth experienced on the number of beneficiaries results from the fact that during the period under consideration, efforts were concentrated on the consolidation of projects under development.

In the scope of emergency, emphasis in the activities conducted goes to the completion of the construction of 82 improved houses and the respective handover to the victims of floods in the Province of Zambezia (Mopeia and Morrumbala) in the framework of the post floods resettlement and reconstruction plan. Emphasis also goes to the beginning of the construction of 40 conventional houses for women who are heads of households, disabled people and elderly people that were victims of floods in the Provinces of Inhambane (Govuro) and Sofala (Búzi).

In the scope of the Social Benefit for Labour Programme, some 2,118 beneficiaries were assisted, representing $43.2 \%$ of the plan.

In the scope of the Income Generation Program, some 1,002 people were integrated of which 319 are women.

In partnership with state institutions and civil society, there were Community Development activities to benefit the most vulnerable groups of population, through the implementation of different projects in the provinces of Niassa, Cabo Delgado, Nampula, Zambézia, Tete, Manica and Inhambane, more precisely in 
the areas of female education and training, health and sanitation at low cost, water supply, improvement of accessibility roads, agriculture and animal farming.

In the scope of Direct Social Support Program, various compensation means were distributed amongst disabled people under proved poverty situation, such as food, clothes, school material and construction of houses.

\section{F. EX-COMBATANTS}

The Sector for the Coordination of Former Fighters Issues, with the aim of reducing absolute poverty that affects former fighters, and taking into account the development and economic growth of the country, developed the following actions:

- Continue to register fighters applying for pensions. Currently the process of acquiring IT equipment for issuing the fighters card is under way;

- Holding of provincial seminars for the National Liberation Fighters on the Niassa, Manica-Sofala and Zambézia fronts;

- Continue to receive submissions and to register projects for the integration of fighters, which are expected to be mainly funded by the Former Fighter Integration Fund;

- Drafting of the Animal Farming Project for the Former Fighter;

- Drafting of a project for three Training Centres in Arts and Professions (North, Centre and South) for the descendants of Fighters;

- Efforts were made to register Former Fighters living abroad;

- Dissemination of the Former Fighter Statute and the respective regulation;

- Inception of the processes to pay the participation bonus in light with Law $3 / 2002$ of 17 January;

- Construction of a monument for the preservation of the Central base of Móngué, in Zambézia;

- Signing of a cooperation protocol with UEM to allow for the provision of 10 scholarships to the children of Former Fighters and for that effect efforts are being made with other higher education institutions; 
- There was an identification of graves and mass graves of Fighters and citizens that passed away while serving the Motherland and efforts are being made for the preservation of such historical places.

\section{G. CULTURE}

In the area of culture, in 2003 there was continuity on the development of actions aiming at preserving and disseminating information on the cultural heritage, promoting the development of the cultural industry and the knowledge of the national culture, paying particular attention to the valuation of the particularities and specificities of regions and of the group.

\section{Cultural Heritage}

In the scope of the current efforts aimed at drafting manuals on techniques of preventive conservation of tangible cultural heritage, work was done to gather and select the legislation, regulations and other technical documentation that is necessary for that effect.

With a view to editing a publication on traditional types of dance in the North of the Country, a research study was completed on the traditional dances in that region.

The drafting of brochures on the Inventory of National Monuments, Collections and Places and the Archaeology and National Heritage Dictionary was completed.

\section{Cultural Activities}

With a view to the holding of the I National Seminar on Cultural Associationship, seminars were held in the provinces of Tete and Sofala in the scope of the preparatory actions for the event.

Aiming at holding the II National Festival of Songs and Traditional Music, emphasis of the actions developed goes to the holding of provincial phases of the Festival.

In the scope of the Operationalization of the Project to Combat Phonogram's Forgery, the actions conducted were concentrated on the promotion of the use of the seal on imported phonograms and CDs and on inspecting shops.

There was growth in the number of cultural events held with the objective of promoting arts and organizing arts people in small cultural associations. 
With the view of ensuring good quality shows for the consumers, measures were implemented with agents, which allowed for improvements in the quality of shows in multiple artistic manifestations.

\section{H. YOUTH AND SPORTS}

In the area of Youth and Sports, in 2003 efforts were concentrated on motivating youth associateship, on the creation of employment opportunities for the youth and massification of sports.

\section{Youth}

In the scope of the dissemination of the Recommendations from the Ist National Youth Meeting held in Chókwé, awareness seminars were held for the youth throughout the Country.

With the objective of ensuring the motivation of youth associateship, in 2003 privilege continued to be given to technical and methodological support to the youth associations. Emphasis also goes to the re-edition of the National Directory of the youth associations.

The implementation of Sexual and Reproductive Health Programmes for the Youth continued. Thus, in the scope of the Program "Geração Biz" under implementation in the provinces of Zambézia, Tete, Inhambane, Gaza, Maputo and City of Maputo, 3,829 Peer Educators and 1,558 Community Leaders were trained, 139,000 adolescents were sensitised and educational theatre sessions were presented.

In the scope of the Program "Meu Futuro é Minha Escolha" My Future is My Choice, under implementation in the provinces of Manica, Sofala and Zambézia, 332 Peer Educators and 1,008 Community Leaders were trained and 14,072 youth were sensitised.

In relation to the National Programme of Integrated Social Welfare, Employment and Youth under implementation in the provinces of Maputo, Manica, Sofala, Nampula, Gaza, Inhambane, Cabo Delgado and Niassa, emphasis goes to the granting of de 39 micro credit packs to 8,831 direct beneficiaries.

With a view of ensuring the establishment of an education and training system directed at the integration of the youth into the job market and create an institutional network of support to address vocational concerns of the youth, 4 Centre for the Dissemination of Information Technologies operating in the provinces of Maputo, Sofala, Nampula and Cabo Delgado, continued to provide basic training on computers to a total of 900 youth. 
Still on the same scope, at the two Youth Centres of Vocational Training and Practice in the area of arts, 25 young trainers were trained in the provinces of Maputo and Sofala.

\section{Sports}

In terms of motivating sports membership, 1,060 new sports clubs and 25 female sports teams, were created.

In the area of massification of sports activities, recreational sports tournaments and school leave tournaments were organised at national level. With the objective of motivating sports for disabled people, sports tournaments were organized. Emphasis goes to the organization in the city of Nampula from 25 July to 02 August 2003, of the VI National Festival of School Games that was attended by 1,320 students of both sexes, in the modalities of Handball, Athletics, Basketball, Football, Volleyball and Athletics for disabled people.

The province of Gaza was the major winner of the event by winning most of the medals and trophies that were being contested for. The province of Inhambane is standing as candidate to host the VII National Festival of School Games, in 2005.

The promotion and consolidation of National Unity and the awareness of youth on the dangers of HIVIAIDS are some of the objectives that were achieved in this National Festival.

In relation to the capacity building of sports coaches and activists, training was provided throughout the country to 500 sports educators, referees and coaches and 207 teachers of physical education. Emphasis also goes to the creation of 10 new sports schools in the provinces, totalling 20 in the country, which are being attended by 5,000 player-students of various modalities.

In the scope of top competition the country managed to get good results in the modalities of women's basketball, athletics, hockey and martial arts. Hence, Mozambique became the Vice-Champion of Africa in Women's Basketball. The National Hockey Team participated at the last World Championship and managed to get results that allowed it to remain amongst the 10 best teams of the world.

The rehabilitation of sports Infrastructure continued. Thus, work was finished on the rehabilitation of 10 sports facilities, namely: (1) Magude Football Ground, (2) Maxixe Football Ground, (3) Chókwè Football Ground (4) Mahafil Football Ground, (5) Estrela Vermelha Pavillion, (6) Desportivo Pavillion, (7) Sport Quelimane e Benfica, (8) Ferroviário de Quelimane, (9) Clube Sporting de Quelimane, (10) Desportivo de Inhambane Sports Facility.

\section{ENVIRONMENT}


In the area of environment, during 2003, work continued on the development of actions aimed at ensuring sustainable development. Thus, special attention continued to be given to the institutional development, environmental development and drafting of environmental legislation.

In the scope of Institutional Development, the following activities were conducted:

- Creation of Sustainable Development Centres for the Management of Natural Resources, Coastal Management and Management of the Urban Environment;

- Conclusion of the drafting of the Environmental Strategy for the Sustainable Development of Mozambique;

- Continuation of training actions for medium level technicians on Physical and Environment planning, totalling 44 students.

In the scope of Environmental Management the construction of a sanitary landfill in Beleluane for industrial waste was completed and the following projects were implemented:

- Project of Maritime and Costal Biodiversity in Nacala, Mussoril, Palma and Mocímboa da Praia;

- Integrated Management of Lake Niassa Project;

- Urban Environmental Management Project for the Great Maputo Area;

> Rehabilitation of Hulene dumping site (City of Maputo);

> Capacity building for Community Associations for the maintenance of drainage systems (City of Maputo);

$>$ Fighting erosion (Matola and Marracuene);

- Projects for the control and fighting of land erosion;

> 17,573 trees of different types were planted throughout the country;

- Project of Urban Environmental Management in five Municipalities (Mocuba, Quelimane, Ilha de Moçambique, Pemba and Montepuez);

- Integrated Management of Hazardous Industrial Waste and Persistant Organic Pollutants

In the scope of Environmental Impact Evaluation and Environmental Promotion, the following activities were conducted: 
- Environmental Evaluation of the Heavy Sands Project of Chibuto;

- Environmental audits to projects under execution, with emphasis to the dumping site of hazardous industrial waste in Mavoco;

- 100 projects were assessed / analysed in the process of environmental licensing;

- Completion of the drafting of the strategy for environmental education; and

- Editing and distribution of magazines on environmental issues and production of radio and cinema programs on environmental issues.

In the scope of Territorial Planning, emphasis goes to:

- Studies on the mitigation of the impact of floods in the Cities of Chókwè and Xai-Xai;

- Development of capacity building courses for the technical staff of Chókwè, Xai-Xai, Nampula and Pemba Municipalities.

- Drafting of the Urbanization plans for the Municipalities of Moatize (Tete), Vila de Gorongosa and Búzi (Sofala) and the Gondola village (Manica);

- Drafting of the plan of Territorial Planning at Maputo Development Corridor;

- Produced 110 maps of regional planning.

In the scope of the Environmental Legislation, the following was done:

- Dissemination of the environmental law and regulations, at the national level;

- Approval of the Regulations of Management of hazardous Waste;

- Completion of the drafting of the regulation on the Environmental Quality Standards.

\section{VI.2. ECONOMIC SECTORS}

\section{A. AGRICULTURE}


Agriculture in Mozambique continues to face many challenges, of which emphasis goes to $i$ ) the low productivity of primary production factors, including land and the labour force, ii) climate risks and uncertainties associated with the process of agricultural production iii) food insecurity and mal-nutrition, iv) the weak investment in agriculture $v$ ) unrelated support services and food chain including lack of interlinkage amongst production, processing, trading and warehousing; and vi) week institutions of research, extension and generation of appropriate technologies to the farmers. On the other hand, the Infrastructure at the rural environment are underdeveloped, with bad roads, lack of warehousing facilities and market institutions.

On the framework of the poverty reduction strategy, the implementation of the sectoral integrated programme continued in the area of agricultural and natural resources (PROAGRI) that intend to respond to the challenges mentioned above. PARPA (integrating the basic principles of PROAGRI) identifies the following fundamental strategic objectives in the scope of the contribution of Agriculture and Rural Development to the poverty reduction: i) an increase of the production and productivity capacity in the areas of agriculture, animal breeding and forestry especially in the family sector in line with the sustainable management of natural resources (meaning a major and better usage of the production factors - seeds and land - and credit) ii) guarantee the rights of access to land and reduce bureaucracy associated to the land registration iii) promotion of the trading of agricultural and animal breeding products, and facilitation of the transporting of agricultural and animal breeding surplus and access to the markets and iv) reduction of vulnerability of the households and food insecurity. One preliminary condition for the improvement of MADER's performance is the development of the existing institutional mechanisms.

The following are the primary measures/actions that contributed to achieve the objectives mentioned above during 2003.

The agricultural extension services, animal breeding, institutional support and research promote the agricultural production and productivity through encouraging i) adoption of improved techniques, ii) the use of inputs, iii) protection of the plants and animals and iv) the post-harvest activities.

In this scope, it is a priority to increase the coverage of agricultural extension services. During 2003, the public extension services assisted 122,858 farmers (including through outsourcing) in relation to 120,959 farmers that were assisted in 2002. Precisely, the following actions were conducted:

- Work was done on the multiplication of pre-basic seeds in 47 Fields: for Maize (17), Rice (6), Black-eyed beans (5), Beans (2), Peanuts (1), Cassava (7), Sweet Potatoes (4), Cotton (1), Cashew (1), various crops on the same filed (2), Fruit trees (1). Seeds and other inputs were provided to the pilot programs, and camps for the demonstration of varieties were created. 
- Work was done on the identification of mother plants to collect vegetal material, provision of materials for the production of cashew trees, awareness campaigns on the advantages of this material,

- In the scope of aquaculture, 2.050 fish tanks were constructed and maintained, with 1,251 in Manica, 94 in Tete 18 in Nampula, 1,010 in Zambézia and 37 in Sofala, benefiting about 1,500 families.

- About 638,228 cashew plants were pulverized against odium, benefiting about 19,661 households in the provinces of Cabo Delgado, Nampula, Zambézia, Inhambane, Gaza and Maputo. Furthermore, 764,174 improved transformed trees were distributed; new plantings were made to replace the old plants.

- In the scope of the improvement of granaries and dissemination of appropriate warehousing techniques, a national strategy was drafted for the control of the main plague of cereals in the warehouses, involving the usage of control and prevention methods. Further to that, warning bulletins were produced (Monitoring of the agricultural campaign), evaluation of the vulnerability analysis and the main causes and reports including specific recommendations were produced. There was dissemination of the methods and technologies of post-harvest conservation of agricultural products (improved barns and the use of chemical products).

- $3,659,136$ poultry of the family sector were vaccinated against Newcastle $(2,967,972$ birds in 2002). 284,806 cows were vaccinated against the Mad-cow disease $(280,994$ in 2002), 488,765 cows were vaccinated against Haematic Carbuncle (371,898 in 2002), 182,476 cows were vaccinated against Symptomatic Carbuncle $(150,832$ in 2002), and $1,639,154$ cows were vaccinated against Infectious Bursitis. In Tete 1,000 dogs were vaccinated.

- 3 community chemists were set up (1 in Mecanhelas and 2 in Zambézia) and 3 private chemistries (1 in Lichinga, 1 in Sussundenga and another in Inharrime).

- In the scope of cattle repopulation, 15 cows and 30 goats were distributed in Cabo Delgado; 100 caprine were distributed in Niassa; 100 cows and 70 goats were distributed in Nampula; 297 cows and 12 goats were distributed in Tete; 7 cows were distributed in Manica; and 592 cows were distributed in Maputo.

- In the scope of the programme for the motivation of using animals for transport through the use of cows, donkeys and water buffalos, a course was held in Tete and 97 pairs of cows were distributed to the farmers and in Inhambane a centre was set up at Mangoro and they are awaiting 50 donkeys that have already been paid for.

- About 140000 producers were trained in different technological options in order to improve the living standards of the producers. 
Still in the scope of the promotion of agricultural production, it is fundamental to facilitate access to funding by farmers. Thus:

- 50,000 clients received micro-credit in 2003, the same number as in 2002.

With a view to promoting the sustainable management of Natural Resources, with the participation of local communities, private sector and other economic agents, actions were undertaken in order to:

i) promote the use of watering techniques

- 2,700 ha were identified for the rehabilitation and construction of watering systems. Out of these, works were executed in 1,200 ha, with emphasis to the construction of small scale irrigation schemes of various types and rehabilitation of 20 ha of ' 25 de Setembro' watering scheme at Boane District and 200 ha at Macuvulane at Magude District (in the Province of Maputo) and 200 ha of small watering schemes in the Provinces of Nampula, Tete, Manica, Sofala and Inhambane.

- 365 water pedestral pumps were distributed for watering purposes.

ii) stimulate the sustainable commercial management of natural resources through Administration Plans.

- The country has about 65 Administration experiences with the involvement of the communities. UPMCs were established in Cabo Delgado, Niassa, Manica, Sofala and Tete, Nampula and Maputo.

- $43 \%$ of the concessions have an approved Administration plan (14\% in 2002).

- In the scope of the dissemination of improved techniques, work was done on production techniques of coal in Goba, Licuati, Pindanyanga and Mucomboze

In order to guarantee the rights of access to land and reduce the bureaucracy associated with the registration of land, the following actions were undertaken:

- Introduction of simplified procedures for authorization to DUAT (Right for land Tenure) in October 2001. During 2003 a total of 2,534 requests were submitted in the whole Country for land tenure for 1.025.152,07 hectares, of which 1,973 requests were approved, 14 rejected, 172 under consideration, 2 cancelled and 373 awaiting a decision. The number of requests considered within the limit of 90 days was 2,462 (2,000 in 2002). This figure shows that there was $77.8 \%$ accomplishment, if we consider the processes authorized by 22 October 2003.

- A total of 532 consultations pertaining to requests for the land tenure were made in the country, for 2,549,463.25 hectares.

- Courses were given to district Administrators, District Directorates of Agriculture and Rural Development, Services of Geography and Mapping, 
Municipalities and other stakeholders in the process, about the land law and simplified process procedures for the authorisation of DUAT in seven provinces (Gaza, Inhambane, Manica, Tete, Niassa, Sofala, Zambézia, Nampula and Cabo Delgado).

- Informative material was produced and distributed, on simplified administrative and authorization procedures of the DUAT in coordination with the press.

- Technical teams of sworn land measurers were created and trained for the survey, inventory taking and mapping of the occupation and tenure of the land in the framework of the outsourcing.

Finally, in the scope of the institutional capacity building:

- Various technicians were selected and submitted to formal medium and high level training, of short and long term in the technical and administrative areas, within and outside the country in the areas of Management, Administration, Economy, Geographic Engineering.

- In the scope of decentralization of the registry services for the districts, the Matutuine District Service was created and inaugurated, in the province of Maputo. On the first phase, the following districts were selected: Matutuine (Maputo), Gorongosa (Sofala), Mucuba (Zambézia) and Mutarara (Tete).

- About 87 technicians were trained in the scope of local production of seeds. The activity had some impact in the provinces of Maputo, Gaza, Inhambane, and Sofala where the seeds produced minimized the shortage of seeds due to the effects of droughts.

- Twenty houses were built for outreaches (12 in Lichinga and 8 in Sanga).

The work of Agricultural Survey for 2003 is an integral part of the monitoring system of the results at the productive level sector. The conclusions of the above mentioned work will allow for the completion of the information presented in this "review", as well as evaluating the results obtained in other areas, such as, instigation of agricultural trade.

The sector is involved on a process of assessing the results of the implementation of PROAGRI 'l' and consultations for the drafting of a new program PROAGRI 'Il'. As a result of the analysis it was found that the sector of Agriculture has been making major progress in relation with the objective of reforms and modernization of MADER including the decentralization of material and financial resources to the provinces and district and the regulation and monitoring. However, this sector continues to face important challenges in the scope of increasing agricultural production from an improvement of the services rendered to the public (more coverage and effectiveness) as well as in the scope of improvement and sustainability of the management of natural resources. The intention is that PROAGRI II will allow for the consolidation of the results obtained in the last four years, and deal with the issues that were mentioned above, with special attention to the development of agricultural survey, instigation of agricultural trade and availability of funding. 


\section{B. INFRASTRUCTURE}

The main aim in the area of roads is to increase the coverage of access roads, with priority for those which: (i) allow that poor regions, isolated but with agricultural potential, have access to national markets; (ii) help in the expansion of markets; (iii) produce impact in the reduction of transport costs; and (iv) promote the development of the main corridors. Note that PARPA presents a target of reducing by $5 \%$ the roads, which are not good for circulation and by at least $25 \%$ reduction of bad quality roads. To manage this it is necessary to use intensive labour until the end of 2005.

The main objectives of PES 2003, in the area of roads, foresee the completion of ROCS 2 programme components, which began in 1994 and ended in June this year, and the beginning of the actions established in phase I of the third programme of roads, which started in June 2002.

The level of execution of activities that took place in the roads component is illustrated in the table below. The level of accomplishment of the targets set in the sectoral plan was not satisfactory when compared with 2002 due to irregularities in disbursements. 
Table: Rehabilitation and Maintenance of Roads

(in Kms and in percentage of accomplishment relative to the Sectoral Plan)

\begin{tabular}{|l|c|c|c|c|c|c|c|}
\hline & \multicolumn{2}{|c|}{$\mathbf{2 0 0 1}$} & \multicolumn{2}{c|}{$\mathbf{2 0 0 2}$} & \multicolumn{3}{c|}{$\mathbf{2 0 0 3}$} \\
\cline { 2 - 8 } & $\begin{array}{c}\text { Completed } \\
(\mathbf{K m})\end{array}$ & $\begin{array}{c}\text { \% Accom- } \\
\text { plishment }\end{array}$ & $\begin{array}{c}\text { Completed } \\
(\mathbf{K m})\end{array}$ & $\begin{array}{c}\text { \% Accom- } \\
\text { plishment }\end{array}$ & $\begin{array}{c}\text { Planned } \\
(\mathbf{K m})\end{array}$ & $\begin{array}{c}\text { Completed } \\
(\mathbf{K m})\end{array}$ & $\begin{array}{c}\text { \% Accom- } \\
\text { plishment }\end{array}$ \\
\hline $\begin{array}{l}\text { Rehabilitation of Primary } \\
\text { Roads }\end{array}$ & 237.0 & 68.1 & 131.8 & 40.9 & 275.0 & 63.7 & 23.2 \\
\hline $\begin{array}{l}\text { Rehabilitation of } \\
\text { Secondary Roads }\end{array}$ & 239.0 & 98.4 & 206.0 & 115.7 & 306.0 & 171.4 & 56.1 \\
\hline $\begin{array}{l}\text { Rehabilitation of Tertiary } \\
\text { Roads }\end{array}$ & 620.0 & 94.2 & 375.9 & 75.2 & 510.9 & 592.3 & 115.9 \\
\hline Total Rehab of Roads & $\mathbf{1 0 9 6 . 0}$ & $\mathbf{8 7 . 8}$ & $\mathbf{7 1 3 . 7}$ & $\mathbf{7 1 . 3}$ & $\mathbf{1 0 9 2 . 0}$ & $\mathbf{8 2 7 . 4}$ & $\mathbf{7 5 . 8}$ \\
\hline Periodic Maintenance & 190.0 & 83.7 & 843.8 & 55.9 & 1941.0 & 396.4 & 20.4 \\
\hline Routine Maintenance & $12,313.0$ & 82.1 & $11,612.5$ & 90.4 & $13,335.0$ & $10,591.6$ & 79.4 \\
\hline $\begin{array}{l}\text { Reconstruction and } \\
\text { Installation of Bridges }\end{array}$ & 4 & 66.7 & 9 & 69.2 & 15 & 15 & 100.0 \\
\hline
\end{tabular}

Source: MOPH - National Directorate of Economy. 2003.

From the balance of the implemented programmes in 2003 the following can be highlighted: completion of the roads Inchope/ Gorongosa, Gorongosa/Caia, Nampevo/Gurué and Macomia/Oasse; continution of rehabilitation works in the following roads: Nampula/Nacala, Vanduzi/Changara, Oasse/Mocimboa da Praia, Mussacama/Calaomué, Litunde/Ruaça.

According to the programme the rehabilitation works for the following roads were delayed: Maputo/Marracuene, Manhiça/Incoluane, Nhanchengue/Pambarra (Vilanculos), Chissano/Chibuto, Namacurra/Rio Ligonha, Goba-Impaputo, Nampevo/Gurué, Macomia/ Oasse and Chokwé/Lagoa nova. The delays were due late approvals of the tender and contract documents as well as unavailability of funds.

In terms of periodic maintenance the rehabilitation of the road Matola /Boane was completed. Maintenance works for the following roads did not start: Marracuene/Manhiça, Incoloane/zandamela, Zandamela/Maxixe and Muxungue/Inchope (due not only to financial constraints but also to delays in the apprvoal of the tender and contract documents).

In the context of repairs and installation of 15 bridges, 10 were rehabilitated, namely 3 bridges in Niassa Province in EN8 over the Murusso, Namatimbua and Ningare rivers, 7 bridges in Zambezia Province in EN1/225/104/232 on the rivers Nicaca, Namilate, Marata, Chinamaze, Sinonono, Nhamihungo e Sambalendo; and 5 metallic bridges were installed. This translates a level of accomplishment of $100 \%$ of the set target in the sectoral plan.

In terms of repair works for emergency damages caused by the 2000/2001 floods and the 2003 rains the following road works were completed: Maxixe-Massinga, Cuamba-Nampula, Chibuto-Guijá, Chókwe-Macarretane, 3 de FevereiroMagude, Baixa de Chicumbane, EN211-Cr. Nova Mambone and rehabilitation of the bridge over Save River and the beginning of repair works in the following roads: Ribaué-Lalaua, Liupo-Angoche, Mutarara-Rio Chire e Memba-Rio Lúrio. 
Access to potable water is one of the key vectors of Government action with the aim of improving populations' standards of living. Due to its vital importance in the promotion of social and economic development of the country, PARPA identifies, as main objectives in the water component, the following: promote the sustainable use of potable water and provision of sanitation in urban areas at low cost.

For the implementation of the first objective the following actions were taken: (i) rehabilitation of the national hydroclimatological network and the installation of the management group pertaining floods. Rehabilitation works were carried out in 32 hydroclimatological stations, of which 14 stations were hydrometric and 5 were routine maintenance, all of them in the Zambeze harbour and 18 pluviometric stations in the harbours of Zambeze, Monapo, Muirrate and Mecuburi.

In the context of international rivers management observance the following agreements were completed: Agreement for the establishment of the Commission on the Limpopo River Bank (LIMCOM) between South Africa, Botswana, Mozambique and Zimbabwe; Agreement for the establishment of a Joint Commission on Hydro resources of Common Interest between Malawi and Mozambique and the Agreement for the Funding of a Joint Study on Maputo River Bank between South Africa, Kingdom of Swaziland and Mozambique and Memorandum of Understanding for the development and implementation of The Initiative on the Management of the hydro resources of Lake Malawi/Niassa/Nyasa and Chire River between Malawi, Mozambique and Tanzania; Coordination of the Joint Study with Zimbabwe over the Pungue River.

In relation with the design of the National Strategy on Hydro Resources Management studies were made in the following sub-components: Information and Knowledge on Water, Hydro Resources Development, National Economy, Investment and Finance, Water and Environmental Issues. The process of "procurement" for the employment of a general consultant for the formulation of ENGRH is underway.

In terms of increment of potable water supply and provision of sanitation in the urban and rural areas at low cost PARPA establishes as a target to increase the coverage to $50 \%$ in the supply of water to the urban population and those populations around urban areas, through the rehabilitation of supply systems and the reduction of losses, as well as increasing the coverage to $40 \%$ of the population in the water supply to rural zones, covering 6 million people in 2004, ensuring the sustainability of the local management of Infrastructure with priority placed on the provinces of Zambézia, Nampula e Niassa. In relation to the indicators and targets used in the Millennium Development Goals - MDGs - it is of importance to note that the established targets in PARPA are, generally, consistent with the MGD's targets with the difference being a result of the time frame. 
For achieving the millennium targets (reduce to half, until 2015, the percentage of people without sustainable access to potable water and improve considerably until 2020, the life of at least 100 million inhabitants in degraded townships) the water sector strategy includes the promotion of the private sector in the provision of water and sanitation, the implementation of the rural water provision plan based on response by the interested parties, the rehabilitation and conservation of urban sanitation Infrastructure for residual and fluvial waters in the big cities.

With the aim of achieving the said targets in 2003, 1204 sources of water were constructed and/or rehabilitated. Of this number 132 were new wells, 565 bores and 505 were rehabilitated bores. This corresponds to a coverage rate of water supply in the rural areas of $39.4 \%$, increasing the percentage of total population with access to potable water to $38,5 \%$. Based in the development of the chart below, the increase of the availability of sources in provinces such as Niassa, Cabo Delgado, Sofala, Inhambane, Gaza and Maputo provided improvements in the coverage rate when compared with previous years in the provinces of Nampula e Zambézia which continue to be the ones with coverage rates below average due to the fact that these provinces present high rates of population growth.

Table: Rural Area Water Supplies Programme

\begin{tabular}{|l|c|c|c|c|c|c|c|l|l|}
\hline \multirow{2}{*}{ Province } & \multicolumn{2}{|c|}{$\mathbf{2 0 0 0}$} & \multicolumn{2}{c|}{$\mathbf{2 0 0 1}$} & \multicolumn{2}{c|}{$\mathbf{2 0 0 2}$} & \multicolumn{3}{c|}{$\mathbf{2 0 0 3}$} \\
\cline { 2 - 10 } & Sources & Cob.(\%) & Sources & Cob.(\%) & Sources & Cob.(\%) & Plan & Sources & Cob.(\%) \\
\hline Niassa & 45 & 34 & 118 & 40.7 & 126 & 44.2 & 135 & 211 & 60.0 \\
\hline Cabo Delgado & 6 & 39 & 163 & 48.0 & 94 & 48.3 & 90 & 59 & 53.8 \\
\hline Nampula & 40 & 15 & 62 & 15.1 & 107 & 16.6 & 210 & 74 & 17.1 \\
\hline Zambézia & 64 & 18 & 103 & 20.4 & 272 & 22.7 & 399 & 229 & 22.8 \\
\hline Tete & 65 & 57 & 74 & 47.3 & 126 & 47.2 & 125 & 103 & 42.4 \\
\hline Manica & 40 & 47 & 59 & 48.3 & 33 & 45.2 & 53 & 45 & 52.8 \\
\hline Sofala & 1 & 31 & 144 & 53.2 & 107 & 57.2 & 45 & 84 & 69.0 \\
\hline Inhambane & 44 & 33 & 150 & 24.1 & 169 & 28.7 & 275 & 299 & 37.6 \\
\hline Gaza & 12 & 70 & 145 & 65.3 & 30 & 64.5 & 36 & 36 & 67.1 \\
\hline Maputo & 7 & 26 & 153 & 65.8 & 38 & 58.8 & 32 & 64 & 63.0 \\
\hline Total & $\mathbf{3 3 4}$ & $\mathbf{3 6 . 5}$ & $\mathbf{1 1 7 1}$ & $\mathbf{3 5 . 0}$ & $\mathbf{1 1 0 2}$ & $\mathbf{3 6 . 3}$ & $\mathbf{1 4 0 0}$ & $\mathbf{1 2 0 4}$ & $\mathbf{3 9 . 4}$ \\
\hline
\end{tabular}

Source: MOPH, PES Review Report - 2003

In relation with the situation of coverage of basic sanitation services the results show that $32 \%$ of the population had access to adequate sanitation services.

In the area of urban sanitation, the actions are concentrated in the rehabilitation project of the sanitation system of Beira City, the design of a Sanitation Strategic Plan (to seven municipalities, Maputo, Matola, Beira, Dondo, Quelimane, Nampula and Pemba), in which a technical evaluation of the institutional and financial situation will be made with the aim of improving the drainage system as well as refuse treatment in the 4 city project, namely Inhambane, Maxixe, Xai-Xai and Chokwé. 
In terms of the activities destined to strengthen the system of improved toilets in rural zones, 13,031 were built in 2003 and this corresponds to a rate of coverage of $46.8 \%$. Apart from these activities other activities were also undertaken in the area of training of activists in the rural communities and the construction of better traditional toilets and improved toilets. These activities are mainly financed by local NGOs and by International Organizations in the form of cash and through the supply of building material. Of the various factors, which impaired the achievement of the planned goals by the sector, we can highlight the delay in making the subsidy available. This delayed the process of material acquisition, especially cement.

Table: Toilet construction, population that benefitted and coverage rate

\begin{tabular}{|c|c|c|c|c|c|c|c|c|c|c|c|c|}
\hline \multirow[b]{2}{*}{ Projects } & \multicolumn{3}{|c|}{2000} & \multicolumn{3}{|c|}{2001} & \multicolumn{3}{|c|}{2002} & \multicolumn{3}{|c|}{2003} \\
\hline & Toilet & Pop. & Covera. & Toilet & Pop. & Covera. & Toilet & Pop. & Covera. & Toilet & Pop. & Covera. \\
\hline Maputo & 7,857 & 131,957 & 70.4 & 1696 & 133,653 & 69.6 & 1,673 & 135,326 & 68.7 & 2,091 & 137,417 & 69.4 \\
\hline Matola & 880 & 1,091 & 1.3 & 490 & 1,581 & 1.9 & 197 & 1,778 & 2.1 & 222 & 2,000 & 2.3 \\
\hline Xai-Xai & 1,346 & 16,426 & 85.2 & 1665 & 18,091 & 91.6 & 802 & 18,893 & 93.3 & 610 & 19,503 & 95.7 \\
\hline Manjacaze & 83 & 1,531 & 33.8 & 115 & 1,646 & 35.5 & 111 & 1,757 & 37.0 & - & 1,757 & 36.7 \\
\hline Macia & 242 & 857 & 20.9 & 246 & 1,103 & 26.2 & 221 & 1,324 & 30.7 & - & 1,324 & 30.5 \\
\hline $\begin{array}{l}\text { Inhambane, } \\
\text { Maxixe }\end{array}$ & 1,146 & 13,511 & 7.0 & 910 & 14,421 & 49.6 & 941 & 15,362 & 51.5 & 1,292 & 16,654 & 55.5 \\
\hline Massinga & 280 & 1,154 & 33.9 & 315 & 1,469 & 42.1 & 250 & 1,719 & 48.1 & 728 & 2,447 & 68.0 \\
\hline Beira & 1,028 & 20,020 & 26.0 & 1228 & 21,248 & 26.9 & 863 & 22,111 & 27.3 & 512 & 22,623 & 27.8 \\
\hline Dondo & 211 & 1.021 & 7.4 & 216 & 1,237 & 8.7 & 433 & 1,670 & 11.5 & 115 & 1,785 & 12.2 \\
\hline Chimoio & 1,182 & 27,807 & 83.9 & 1849 & 29,656 & 87.3 & 2,408 & 32,064 & 92.0 & 1,084 & 33,184 & 94.6 \\
\hline Tete & 890 & 7,132 & 36.1 & 1205 & 8,337 & 41.1 & 1,646 & 9,983 & 48.1 & 568 & 10,551 & 50.5 \\
\hline Quelimane & 1,230 & 11,939 & 41.0 & 1495 & 13,434 & 45.0 & 1,323 & 14,757 & 48.3 & 1,380 & 16,137 & 52.5 \\
\hline Mocuba & 500 & 1,801 & 7.5 & 453 & 2,254 & 9.1 & 457 & 2,711 & 10.7 & 37 & 2,748 & 10.8 \\
\hline Nampula & 2,727 & 18,992 & 32.3 & 1782 & 20,774 & 34.5 & 2,581 & 23,355 & 37.8 & 2,727 & 26,082 & 42.0 \\
\hline Nacala & 821 & 7,492 & 45.1 & 467 & 7,959 & 46.7 & 362 & 8,321 & 47.7 & 264 & 8,585 & 38.2 \\
\hline Angoche & 192 & 482 & 2.3 & 159 & 641 & 2.9 & 203 & 844 & 43.8 & 531 & 1,375 & 7.8 \\
\hline Pemba & 384 & 12,825 & 77.9 & 793 & 13,618 & 80.7 & 473 & 14,091 & 81.5 & 412 & 14,503 & 83.4 \\
\hline Montepuez & 115 & 1,772 & 16.2 & 224 & 19,996 & 17.8 & 315 & 2,311 & 20.1 & 68 & 2,379 & 20.6 \\
\hline $\begin{array}{l}\text { Lichinga e } \\
\text { Cuamba }\end{array}$ & 795 & 6,918 & 41.6 & 748 & 7,666 & 45.0 & 840 & 8,506 & 48.7 & 390 & 8,896 & 50.6 \\
\hline Total & 21,909 & 284,728 & 42.9 & 16056 & 300,784 & 44 & 16,099 & 316,883 & 45.1 & 13,031 & 329,914 & 46.8 \\
\hline
\end{tabular}

Source: MOPH, 2003 PES Review Report

The data illustrated in the table above shows an increase in the target population coverage. The growth rate in terms of coverage of target population was $10 \%$ from 2000 to 2003. It clearly maintains a growth trend of $2-3 \%$. If this trend was maintained it would be possible to achieve more than the $50 \%$ coverage in the supply of improved toilets to populations until 2004, as established in PARPA.

The chart below shows the evolution of the coverage rate with the number built toilets in the last 4 years (2000 to 2004). 


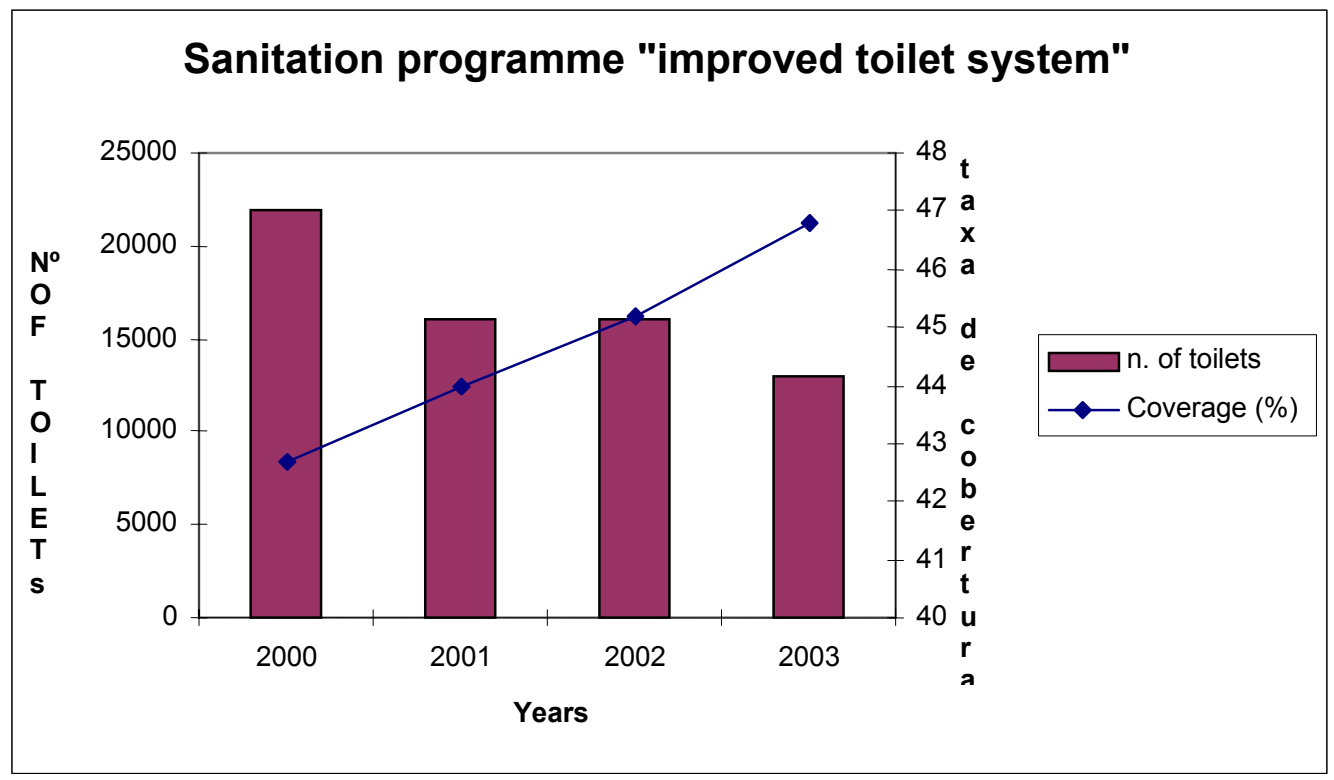

For 2003 the following can be highlighted in the area of Housing and Basic Urbanisation where the main actions are in the areas around cities and villages with the aim of ensuring infrastructered land to citizens with low income:

- The demarcation of 265 plots in Mocímboa da Praia; concession of 110 plots destined to housing, commerce and services (Wimbe Expansion I); concession of $9.600 \mathrm{~m}^{2}$ for the construction of installations for the agricultural sector and $27.000 \mathrm{~m}^{2}$ for the Education sector in Cabo Delgado; demarcation of 132 plots in Metangula; the demarcation of 98 plots in Chimoio City.

- Launch of the public tender for the concession of credit to habitation, completion and ampliation of own houses in the cities of Inhambane, Manica and Lichinga.

- Beginning of construction works of 100 houses in Cumbeza, province of Maputo.

In relation with the energy sector PARPA has, as one of the main objectives, the aim of expanding populations access to energetic sources, reducing the environmental impact caused by the use of non-renewable sources. As main actions to the accomplishment of these objectives in 2003 the electrification of the district capitals of Eráti, Mongicual, Zumbo, Chifunde, Macanga, Meluco and Mabote, were completed. Currently generators are being installed in Ngaúma, Mecula, Majune, Metarica, Massangena, and Chicualacula districts.

Public tenders were launched for the construction of electrical networks and supply of generators in 2004 for the districts of Muidumbe e Pemba-Metuge and Muanza. The process for the rehabilitation and extension of the Quissanga electric network is underway. 
The supply of electrical energy to these districts motivated the existence of new activities such as: millers, restaurants, tourism, installation of freezers for the conservation of fish and iron workshops.

In 2003 the process of electrifying administrative locations of Larde, Aúbe and Namige (Nampula) were initiated. Tenders were launched and the selection process of contractors for the electrification of (Inhambane), Rotanda (Manica) and Mocumbura (Tete) is underway.

\section{Review of Rural electrification}

\begin{tabular}{|l|c|c|c|}
\hline \multirow{2}{*}{ Province } & \multicolumn{3}{|c|}{ 2003 Review } \\
\cline { 2 - 4 } & $\begin{array}{l}\text { Number } \\
\text { electrified } \\
\text { districts }\end{array}$ & $\begin{array}{l}\text { olectrification } \\
\text { currently } \\
\text { underway }\end{array}$ & $\begin{array}{l}\mathbf{N}^{\circ} \text { of non- } \\
\text { electrified } \\
\text { Districts }\end{array}$ \\
\hline Niassa & 11 & 4 & 0 \\
\hline Cabo Delgado & 14 & 0 & 2 \\
\hline Nampula & 19 & 0 & 0 \\
\hline Zambézia & 16 & 0 & 0 \\
\hline Tete & 12 & 0 & 0 \\
\hline Manica & 9 & 0 & 0 \\
\hline Sofala & 10 & 1 & 1 \\
\hline Inhambane & 12 & 0 & 0 \\
\hline Gaza & 7 & 2 & 1 \\
\hline Maputo & 7 & 0 & 0 \\
\hline Total & 117 & $\mathbf{7}$ & $\mathbf{4}$ \\
\hline
\end{tabular}

Parallel to the installation of isolated systems, national networks of electric energy are underway for Gorongosa, Morrongulo, Eduardo Mondlane, Zonguene, Chidenguele e Macaneta. Inchope's Administrative Post was completed.

The construction of the $110 \mathrm{Kv}$ line (Nampula-Monapo-Nacala) is underway. The deforestation on path of the line has been concluded and 29 towers from a total of 607 have been erected.

The topographic survey of the $110 \mathrm{Kv}$ line between Nampula-Chiúre-Pemba has been concluded and the deforestation works have been completed. The totality of the path is now being inspected for the detection and removal of mines.

Construction works of a $110 \mathrm{kV}$ line between Gurué-Cuamba-Lichinga are underway (topographic survey, deforestation and inspection of path line). The construction of Cuamba sub-station was completed. The construction of Niassa sub-station is underway. A 1250KVA Generator was installed in Lichinga to increase electric energy supply. 
In the context of the promotion of Mephanda Nkuwa hydroelectric project the actions towards its construction continued through participation in conferences, contacts with potential investors and financial institutions. The promotion exercise will culminate with a process of defining the criteria and procedures for pre-qualification of candidates that show interest in setting up the company for the implementation and exploration of "Project Company", entity which will have all the responsibility of developing the project, starting from searching for funding, construction and operation of the dam, within the prescribed concession period, to be negotiated with the Government of Mozambique.

\section{TRANSPORT AND COMMUNICATION}

The rehabilitation and development of the transport system is vital for the development of agricultural production of the family sector, for the generation of revenue in foreign currency and to stimulate the regional development along the transport corridors. In this sector from the policies implemented the following can be highlighted:

- An addendum to the contract was negotiated and signed for the supply and re-installation of the land stations in Vilanculos and Inhambane.

- The infrastructure works in civil construction in Marromeu are underway. Inspection of Malema works is expected to take place.

- The contract for the supply of transmission equipment within the scope of the Massingir integrated project was completed.

- The processors of contracting a consultant for the assessment of the postal services, designed by the reform Strategic Plans to be implemented for the restructuring and Operationalization of 'Correios de Moçambique' is underway.

- In terms of corridor development, concessions for the private management of sub-systems of the rail-port area within the sector are underway. The global production of the rendered services is showing that the impact is very positive.

- In relation with the development corridors (Maputo, Limpopo, Beira and Nacala), the following studies were conducted: agro-industry, mineral resources processing and tourism for the identification of new initiatives and opportunities for investment, as well as project studies in the corridor areas. In February this year, an investor conference on the Nacala corridor, partners' seminar for the Beira and Limpopo Corridors were organised. 
- In April 2003, the formal hand-over of the Maputo port for management by the 'Sociedade de Desenvolvimento do Porto de Maputo, S.A.R.L' was completed. Currently the concession of the Ressano Garcia rail line and the north's rail-port system is being prepared.

- Resource mobilization actions with the aim of dredging the ports of Maputo and Beira are taking place.

- In the south works for the rehabilitation of the Limpopo line are underway; in the central region the rehabilitation of the line between Dondo/Muanza (in the Sena Line) and in the north the rehabilitation of the line between Cuamba/Lichinga.

- The process for the creation of the National Maritime Institute, as well as the process of acquiring two patrolling boats in the context of maritime inspection.

- In the Maputo port all the 'mooring buoys of North bar, south bar' were maintained. The work consisted of replacing some of the metallic buoys and the respective parts.

- The topographic data compilation of the Maputo Port was completed. Same work is underway for the Beira Port.

- A new map was produced for the Quelimane port.

- The 'marigraph or tide gauge Pressure' in the Inhambane port is currently being tested. With the aim of improving the quality of data, a course for observers of 'marégrafos' was conducted and dedicated people were placed in the stations.

- Regular inspections to national and international vessels that use our ports were conducted and this helped improve security to navigation.

- In terms of the restructuring of the aviation sector the following points are worth mentioning: the implantation of the Mozambique Civil Aviation Institute (IACM); the continuation of the actions towards transforming the Nacala Air Base in an International Civil Airport and the concession of the Maputo International Airport; the privatisation of LAM.

- New entry points into the country were opened (Beira, Vilanculos, Nampula e Pemba).

\section{PRIVATE SECTOR DEVELOPMENT ASSISTANCE}


The strategy for the reduction of poverty and for economic growth set in PARPA was conceived in the assumption that the private initiative of Particulars, families and enterprises is the key to development and that the State has the role of providing the basic conditions for the flourishing of those initiatives through the supplying of Infrastructure, the development of know how, the improvement of public sector efficiency and of the State regulating role. Additionally we can mention the propositions that reiterate the prosecution of policies aimed at the maintaining social stability and macroeconomic policies important for the creation of an adequate atmosphere for such initiatives and the expansion of private investment.

Apart from the activities that were done in the above areas, described in details in the sub-sections of this document, we also mention some additional actions important for the development of enterprises and to the promotion of employment.

Among the actions aimed at guarantying an efficient employment market, we highlight the normative action with the beginning on one hand of the review of the labour law and the elaboration of an organic law for the labour courts on the other hand. On the scope of the review of the labour law, the Decree 57/2003 that regulates the legal regime for expatriate work was approved.

Also under way is the reform of the commercial registration that stipulates a single balcony in the process of constitution of commercial societies. Its conclusion will be in March 2004.

We also approved the Licensing Regulation for industrial sites and the elaboration of the proposal for the review of the Decree number 43/98, on commercial licensing. We are currently working on process of its harmonization.

A new Law regulation on Investments is in the final stage of editing. However, there still a need to incorporate some key aspects in order to reduce the necessary time for the implementation of projects approved within the Investment Law. Basically it is intended that CPI becomes an in facto 'one stop shop', ie, the approval of projects should simultaneously mean its licensing.

This process includes the areas of investment reserved to the public sector which may be leased to the private sector, the enlargement of competencies to decision making on investment projects, specially at the level of provincial governors and taking into account some legal dispositions approved in recent years and the reformulation of procedures and deadlines for decision making on investment projects submitted under de investment law.

\section{E. MINERAL RESOURCES}


In the mining sector the activities that were done made possible the increase of production and the reduction of poverty, through the promotion of mineral activity and the reinforcement of mineral inspection. So, in 2003 , the main activities that were done are the following:

- Conclusion of prospecting and Geological research in selected zones, in Espungabera-Manica, as well as Geological cartography works of Greenstones in the northern provinces of Mozambique.

- Field work was carried out in the southern part of Niassa Province. From this work the following was compiled: itinerary map; geographic map and description of mineral outcropping; sampling map of rocks; and the compiling of a final report on geological and geo-chemical studies done in the district of Lago in the years 1999, 2000 e 2001 (namely the photo-geological map; the geographic location of geo-chemical sample maps, a map of mineral occurrences in the area of study; the map of selected tendencies for the prospecting and research work and the processing of data and laboratorial analysis).

- Reactivação dos projectos mineiros de minérios de tântalo em Muiane e Morrua, tendo já sido feita a importação de equipamento e se registado a reparação de infraestruturas, nomeadamente estrada e pone que permitiraram o reinício da produção na mina de Morrua;

- Conclusão da organização do Cadastro Mineiro, incluindo a sua informatização e ligação do sistema entre as Direcções Provinciais e o órgão central; em relação a reposição da rede geodésica foi feita a actualização e expansão dos 30 pontos com alta precisão da rede geodésica; Relativamente a colecção e sistematização de dados, foi feito em $80 \%$ o trabalho de colecção e sistematização de dados sobre as licenças existentes com base num banco de dados concebido.

- The Pilot Centre implementation project in the Manica District covering in this first stage about 20 arts; areas designed for the implementation of the mining cards (senhas) were identified and demarcated and the extension of support services to small scale mining. Technical support to the local mining operators associations, with strong involvement of the local comunity leaders and governments was provided.

- The elaboration and updating of the regulation of the Mining Law (Environmental regulation for the mining activity and technical safety regulation for mining works in the open air and underground) was completed.

- The regulation of oil operations was completed.

- The economic feasibility study of the Moma Heavy sands was completed and the respective project licensing agreement was signed. The status of Industrial Free Zone was approved for the area where the processing operations of heavy sands concentrate will be located. We are currently in the 
process of gathering financing and have already gathered USD 130 millions of USD 230 millions needed for the project.

- In relation with the Moebase Heavy Sands project, a survey programme in the old dunes "Decksands" for the increase of reserves outside the partial protection zones (sea coasts) was carried out.

- The technical-economical feasibilty study of the Chibuto Heavy Sands project and the bankable document were completed. Technological trials were carried out and the project implementation agreement was signed.

- The construction of the Temane - South Africa gas pipeline was completed. Various hydrostatic tests of the Processing Centre equipment (CPE) and of the gas pipeline were carried out. The supplying of gas to South Africa will begin in the first quarter of 2004 .

- In the Zambeze block, the Malaysian Company PETRONAS Made geological and geophysical studies of the available data and processed $1905 \mathrm{~km}$ of seismic lines. In the end of 2003, $3000 \mathrm{Kms}$ of seismic 2D were acquired and processed. The next phase will be of digging a survey well.

- In the Inhaminga block, a Survey and production contract was signed in 2003 for the Inhaminga block with DNO company (England) and with WILRUSCO from the United States of America)

- In the area of promotion of coal production, currently Chipanga Mining Company 11 does the production in small quantities for the supplying of the internal and regional market. The production resumed in 1999 and since then until $2003,132.547,7$ tons of coal was extracted.

Subsequent to the two consultative conferences with the pre-qualified consortiums for the concession of the Sena Railway, on one hand and with the potential investors/concessionaires of the Moatize Coal project in the other hand, the Government signed an agreement with IFC for the elaboration of an optional Strategy for the development of the Moatize Coal project proposal. The option to be adopted and approved will guide the government in the preparation of a bidding document for the concession of the project.

- As a way of ensuring the marketing of gold and other minerals, licences have been issued for that purpose. Both the Mining Promotion Fund and other authorised operators have been buying the gold that is extracted by local gold prospectors with the aim of increasing the rates of production. In parallel to the purchase of gold, the Mining Promotion Fund has been working together with local gold prospector so that these can organise themselves into associations. In 2003, $62.8 \mathrm{kgs}$ of gold were extracted. This figure is equivalent to an increase of $271.6 \%$ compared to 2002 .

- The production of graffiti is presently paralysed due to production high costs and its low prices in the international market. The study done by the company indicates as a pre-condition for the resumption of production, the increase of 
graffiti prices in the international market and an additional investment of around USD 8.5 million, to be done by a strategic industrial partner. Its reactivation is dependent on the supply of electricity from Cahora Bassa.

- $20 \%$ of MARMONTE SARL social capital reserved to the GTT's was attributed by the Prime Minister decision of August 8 2001. Up to now, it is not yet possible to evaluate its social impact, since the public writ allocating the $20 \%$ of the MARMONTE SARL shares to the GTT's has not been signed.

\section{F. FISHERIES}

In this sector, the actions that were executed were oriented to improving the internal supply of fish, life conditions of the fishing communities, of the inspection service networks and capacitating in specialised labs. Thus, the main actions of the implemented policies were:

- Signing of a fishing agreement with the European Union that sets the principles, rules and procedures in matters of scientific, financial, technical and economic co-operation in the area of fishing.

- Signing of an agreement with BADEA and the BID for the concession of credit for the rehabilitation of a Fishing Port in Beira.

- The acquisition of the necessary equipment for the functioning of the inspection system.

- Approval of a new general regulation of sea fishing.

- Conclusion of construction of an inspection lab in Quelimane.

- Capacitating activities of local fisherman in matters of co-management in the provinces of Maputo and Inhambane, and follow-up actions in the associative groups in Maputo, Cabo Delgado, Nampula and Sofala;

- The introduction of new technologies of fishing, processing and conservation adequate to local conditions and the diversification of production in the provinces of Inhambane, Sofala, Nampula, Zambézia, Niassa and Maputo Bay.

- The continuation of monitoring actions and evaluation of the state of fishing of prawns in the Sofala region.

- In the domain of aquaculture experiments aimed at installing the Fishing Investigation Institute, and a lab for seaweed were made.

- A micro-credit line for the promotion of artesan aquaculture was opened on an experimental basis in Macanga in the province of Tete. 
- The continuity of statistical information gathering of artesan fishing with incidence in the provinces of Nampula, Zambézia, Sofala, Inhambane and Maputo;

\section{G. MANUFACTURING AND INDUSTRIAL PRODUCTION}

Dentre as várias acções importa destacar o seguinte:

- The process of designing a Strategy for the Export of Wood Processed Products is under way;

- The process of reformulating the strategy for the textile and clothing sector is underway;

- Terms of Reference for the Metalo-Mechanic sector Strategy were designed;

- Data on Agricultural product prices and of consumption in different domestic and international markets were gathered and disseminated to national producers;

- The programme to facilitate credit to rural commerce in the provinces of Niassa, Nampula and Zambézia was implemented;

- The regulation on Customs Regime for the Transforming Industry on goods for industrial use that can benefit from tax exemption was approved.

- The Institute of Industrial Propriety was created.

- The regulation of the Licensing of Industrial Sites was approved.

- The Policy and Quality Strategy was approved.

- The proposal for the review of Decree number 43/98 on commercial licensing was approved. Presently work is taking place on its harmonization.

- The mechanisms of access to preferential markets in the south, centre and north zones were published and monitored.

- Foram assinados acordos comerciais bilaterais com o Zimbabwe e Vietname, estando em curso o processo da sua ratificação com vista a sua implementação;

- The process of restructuring ICM and Trade Fund is under way;

\section{H. TOURISM}


In this sector the main objectives were the promotion and valorisation of our cultural and landscape heritage and of conservation areas for tourism purposes. In this area we highlight the following:

- Measures were adopted with the aim of decentralizing, within the provinces, the process of inspections of hotels and restaurants up to three star hotels aiming to simplify the conditions for their licensing;

- Three regional seminars (North, Centre and South) and one national seminar for tourism inspectors were organised. The current status of inspectors and coordination work with other inspection groups in the areas of health, maritime security and environment to strengthen the inspection in the area of tourism were discussed. In order to raise the levels of inspections, human and financial resources were supplied;

- Local committees of tourism in the provinces Cabo Delgado, Zambézia, Sofala, Inhambane, Gaza and Maputo were created;

- Seminars and courses for capacity building in the areas of tourist resources sustainable management were organised;

- The National Seminar for consulting the civil society on the draft project on the Main Tourism Law was organised;

- The Policy and Strategy of the Tourism sector was revised;

- The decree which updates the amounts for the exploration of wild fauna was approved.

\section{VI.3. GOOD GOVERNANCE, LEGAL SYSTEM, DECENTRALISATION \& DECONCENTRATION}

Good governance is one of the main pre-conditions for the success of the strategy to eliminate poverty. PARPA includes policies to promote good governance such as: decentralization and de-concentration, reform of public administrations to better answer the citizens needs, the reinforcement of the legal and judicial system capacity and efficiency, the improvement of public security and development of a programme focused in the reduction of corruption at all levels.

In 2003, MAE had follow-up activities of the Municipal elections process that culminated in the voting on the November 19 in 33 Municipalities with the involvement of all provincial governments.

Concerning the assistance and follow-up of municipalities for their sustainable development and consolidation the following actions were done: (i) seminar of presentation of a directory of the main actions in the 33 municipalities in the first mandates (ii) elaboration of an assistance guide to the 33 municipalities for the preparation of a special report of the end of mandates; (iii) assistance visits to the 33 municipalities to prepare the local elections; (iv) realisation of a diagnostic of 
the profile for the municipal staff that resulted in the approval of instruments for the management of human resources; ( $v$ ) elaboration of a support manual in the areas of management of human resources, finances, assets and management of urban soils.

\section{A. PUBLIC SECTOR REFORM, DECENTRALISATION AND DECONCENTRATION}

The reform of the Public Sector involves all the components of decentralization and rationalisation of structures and processes of service delivery, improvement of formulation and monitoring of public policies, improvement of public sector employees, improvement of Financial management and presentation of accounts and corruption fighting.

This section presents the main activities done in each of those areas regarding not only the activities mentioned in the plan of the Technical Unity of the Reform of Public Sector (UTRESP) but also the activities of other institutions that contribute for the same objectives.

On the scope of decentralization and deconcentration, PARPA sets as main objectives the capacitating of Local authorities of the State at the District and provincial levels of a better dynamism and capabilities. During 2003, we highlight the following activities:

- The law number 8/2003 that sets the principles and norms of organisation, competencies and functioning of the Local State authorities in the provincial, district, localities and administrative Posts levels was approved by Parliament;

- Extension of the participatory district planning to 21 districts.

Concerning the rationalisation of structures and processes of service delivery all the ministries are involved in the process of doing functional analysis. The Ministry of Planning and Finances (MPF), of Industry and Commerce (MIC), of Agriculture and rural Development (MADER) and of State Administration (MAE) have already submitted the diagnosis, analysis and proposal plan of restructuring to UTRESP. On the other hand, preliminaries reports of the Ministries of Youth and Sports, of Culture, of Old Independence Fighters, of Tourism, of Science and technology and of Labour have been submitted to UTRESP. The Ministries of public Works and of Justice have already contacted UTRESP for assistance in the respective analysis.

With the aim of improving process of formulation and monitoring of public policies, a preliminary report of analysis of decision process of the Council of Ministers (CM) was produced, the relationship between the secretariat of $\mathrm{CM}$ and the ministries and the monitoring process, evaluation and presentation of financial accounts related to the production of public policies. 
Concerning the Upgrading of public sector staff and the administrative modernisation aimed at achieving the final objective of quality improvement of the services delivered to the citizens, the draft project of Reviewing the General Status of State Employees was concluded and a study envisaging the definition o a new salary policy is under way. This study will supply the instruments needed to transform de system of Personal Information into a more dynamic instrument (through its decentralization). The Beira IFAPA was installed and the Maputo IFAPA was strengthened. Assistance was given to various sectors of State Institutions and individual citizens on the interpretation of the General Status of State Employees, of the System of Careers and remuneration and of the Decrees number $64-65 / 98$ on the promotion and progression. Various sectors were given assistance in the elaboration of regulations of career qualifiers of the special and specific regime and an updating of the list of district administrators and heads of administrative posts and superior technicians by career and academic background. Concerning the review of the pensions system of the public sector, a bid for the selection of organizations that give technical assistance was launched.

Apart from the mentioned activities of Reform to the Public Sector and of the support to the Municipalities, the Ministry of Public Administration carried out the following actions:

- The registration of institutes and other similar institutions for analysis purposes related to the review of the Decree number 4/81, on the Norms of Organisation and Management of State Central apparatus (NODAEC) was done;

- The III National Meeting of Municipalities took place;

- In the context of implementation of Municipal Development Project, Infrastructure in the cities of Maputo, Beira, Quelimane, Nampula and Pemba were built and/or rehabilitated;

- The process of implementation of the Decree number $15 / 2000$, of $20^{\text {th }}$ June, on community authorities in all the provinces and the systematization of data on the process was monitored. Proposals on the Technical Assistance Guidance and the provincial report development on monitoring were also designed;

- The review of ciphers for the operators of district administration radios was undertaken. In the district of Montepuez, a course on ciphers for radio operators of the central and southern districts of Cabo Delgado, and in the Mueda district for the radio operators of the northern zone was carried out;

- Regional courses (north, centre and south zones) of capacity building for district Administrators in all the country were organized and Modular courses in the provinces of Inhambane, Manica, Zambézia, Nampula, Sofala, Maputo - City, Gaza, Tete Cabo Delgado, Niassa and Maputo Province were implemented; 
- The Decree number 30/2001 of October 15 , on the operating manuals of the Public Administration services, was communicated;

- The activities for the assessment of the proposals for the review of the administrative division presented by the Provincial Governments are under way;

- The financial management system of the Municipalities of Mandlakazi, Chibuto, Manhiça and Dondo was monitored.

In the context of the improvement of financial management and presentation of financial accounts the highlight was the creation of "a single treasury account" (Conta Única do Tesouro), the reinforcement of financial planning through the Fiscal scenario at medium term, the implementation e-SISTAFE, the reform of State procurement and the reinforcement of internal and foreign audits.

In 2003, the Physical Treasury Single Account was implanted from the consolidation of the entire treasury accounts of revenues and expenditures in all the Commercial banks under the management of Bank of Mozambique.

In the area of strengthening financial and budgeting planning systems the design of a thorough study on the experience with the Fiscal Scenario at Medium Term (CFMP) in Mozambique can be highlighted. It included recommendations for the strengthening and greater integration of this instrument with PES and OE in order to improve the efficiency in the distribution of resourcesin the public sector. With the same objective the introduction of an integrated financial management in a training system (e.SISTAFE) WITHIN THE Government is expected. During 2003 the network for the beginning, in 2004, of the implantation of e-SISTAFE system in MPF and MINED as pilot projects was set up.

Related with the reform of State procurement, a consultant was selected within the scope of international technical assistance to the National Direction of Patrimony with the aim of designing a legal document on public work contracts.

In terms of the Fight against Corruption, a Base National Survey on Governance and Corruption was launched on November 27, 2003, directed to households, enterprises and civil servants. The survey will last for 9 months and it is aimed at consulting the society about governance and corruption, and it will be an instrument for the design of policies and strategies for the fight against corruption. The co-ordination will be done by UTRESP, with the assistance from a technical commission (created by the government), made up by representatives of the ministries, parliament, judicial system, private sector and civil society. A private company was selected, in a public bid, for its execution. The analytical report from the survey should be ready by June 2004 .

Finally, related with the management of the Public Sector reform, UTRESP continued to provide technical assistance in the implementation of components and started the setting up process of establishing a monitoring and evaluation 
system that aims at monitoring all the activities of the Reform, those financed by UTRESP and those to be implemented in the sectors with direct financing.

\section{B. JUSTICE AND PUBLIC ORDER}

PARPA highlights the need for the State to ensure justice for the citizens and other social actors and the internal public order. These demands bring challenges for the transforming, capacity building and improvement of the legal and judicial system and of the Public Order forces.

The Justice Sector, with the aim to ensuring good governance, legality and justice, completed the following actions:

- In the scope of the legal reform

- The draft project of the Legal Reform Policy and Strategy was designed and submitted to the Inter-ministerial commission of Legal Reform (CIREL);

- Family Law was approved;

- The legislation on the simplification of procedures for Registration and Notary acts was published;

- The draft projects of the Civil registration codes, Notary and Civil Process were concluded and submitted to CIREL;

- A preliminary report of the reform of Penal code was concluded and submitted to CIREL;

- The reform of the law of successions and the review of the is under way and the Organic Status of the Institute for sponsorship and Judicial Support (IPAJ) is under way;

- On the other hand, the Maputo City Attorney's General office was rehabilitated to adequately accommodate not only the Attorney General's office but also to serve as the Central Office for the Anti-Corruption Unit and office for the inspection unit of the Attorney's office. An extension of the anti-corruption unit was set up in Nampula. Conditions for a similar delegation in Beira in 2004 have been created.

- The implementation of some activities of the Operative Plan of the Integrated Strategic Plan of the Justice Sector was initiated. These activities had some financial constraints whose solution will be found in the dialogue between the main actors.

- The research work that will culminate in the design of a consolidated document with a long-term vision for the Justice sector continues. 
- The key indicators of performance for the Justice Ministry were identified for the next 3 years and a monitoring system of the Operative Plan in the Justice Ministry started functioning.

- In the scope of consolidating Community Courts.

- The design of a proposal for the reform of Law 4/92 is underway;

- 120 community judges were trained in Tete in matters pertaining human rights and applicable legislation to community courts;

- In terms of training and capacity building aimed at increasing the levels of professional performance,

- 169 magistrates (judges and from the Attorney General's Office) representing $87 \%$ of the original plan;

- 217 justice officers were trained (officers from customs courts and diligence officers) - representing $110 \%$ of plan.

- 32 Trainers were trained in different areas. This number represents $213 \%$ of plan.

- The process of computing the Institute for Judicial Sponsorship and Assistance (IPAJ) has been initiated;

- In terms of modernizing the services of the Civil Registration and Notary an intranet system was installed in the Maputo Building Registration Office (Registo Predial) and the deeds and proxy extracts are done using computers in all the Notaries in Maputo City. Similarly, works on the Notary' delegation in were completed and construction has begun the Civil Registration Office in Mopeia;

- With the aim of improving prison services, within the scope of prison policy implementation:

- The Technical Unit for the Unification of the Prison System started to operate;

- The following Infrastructure and equipment construction and rehabilitation activities were carried out:

- The construction of an open prison centre in Matutuine District through the self-construction pilot project is under way;

- The chimoio Agricultural penitenciary was initiated;

- A study of the sanitation system at Maputo Central Prison is under way;

- A joint commission involving the Ministries of National Defense and Interior that is identifying the needs in terms of security, first at Maputo Central prison, was created; 
- The construction of the wall at the Female Reclusion Centre in Dlavela has begun. A female pavillion was built in the production centre of Chidzolomondo (Tete).

- The process of setting up computer systems in the prisons in the provinces of Cabo Delgado, Nampula, Sofala and Inhambane has been initiated;

- In the scope of prisoner training, a proposal for the regulation of schools in Correctional Services was designed and actions were started in the areas of adult education in the Maputo Central Prison. Apart from this, various activities were organised for the education of prisoners in the prevention of DTS/AIDS in various prison centres of the country.

In terms of Public Order, one of the main objectives is the increase in the Police capacity to prevent and chase crime. In 2003 , the following actions aided this objective:

- Construction of the Immigration Services border control building in Chicualacuala (Gaza Province); construction of the police stations in Polana Caniço (Maputo City); and completion of works at the Distrital Command Centre in Montepuez (Cabo Delgado Province); and construction of the District Command Centre building in Massagena;

- The process of extending the IT network to the Immigration Services Offices in the Provinces was started;

- Rehabilitation of the Provincial Command Centres of Maputo-City, Zambézia, Sofala and Inhambane; rehabilitation of the District Command Centres of Morrumbene, Maxixe, Mocuba, Manica, Dondo, Nhamatanda and Nacala Porto; rehabilitation of Police stations in the cities of Maputo, Nampula and Beira; rehabilitation of two barracks for FIR (Special Interventio Force). Rehabilitation of the Ministry's Head Offices and of the Fire Fighters office;

- Training of 142 senior and basic investigators in issues pertaining criminal investigation; Refresher training and capacity building provided for 700 police members in aspects related with traffic, quick intervention and protection; 96 immigration inspectors were also trained; 30 police officers were trained in aspects related with Financial management; 870 guards and 60 agents were trained for maritime and fluvial and dwellings (lakes).

\section{VI.4. FOREIGN RELATIONS AND DEFENSE}

The Foreign Relations Sector placed emphasis in the implementation of the foreign policyc and international cooperation, projecting the good image and prestige of the country abroad. The activities also centred around the protection of country's interests and of the citizens as well as the attraction of investments, 
capital, technology and 'know how' with the end aim of reducing absolute poverty and consolidating peace and harmony. In this context the following activities took place:

- Organisation of the II Ordinary Summit of Heads of State and Government of the African Union;

- Identification of programmes and regional projects within the context of NEPAD. The conceptual debate was completed. Continuation of the completion process of sectoral implementation plans, clarification and communication/publishing of the vision and involvement of development partners;

- In the context of SADC the design of a Regional Development Indicative Strategic Plan (RISDP) for Cooperation in the areas of Politics, Defense and Security (SIPO) was completed. For the political component as part of Mozambique's presidency activities of this organ; The signing of the Mutual Defense Pact, the implementation in the third year of the commercial Protocol and the adoption of guidelines for the negotiations of the Economic Partnership agreement with the European Union;

- Continuation of the process of accompanying of activities of associations of mozambicans outside the country, namely South Africa, Zimbabwe, Zimbabwe, Malawi, Suazilândia, Angola, Quénia, Tanzania - Zanzibar, Zâmbia, EUA and Portugal;

- In terms of request for asylum/refugee status in the Country, the Maratane Centre was created. This centre accommodated from June to December 4,495 people of which $80 \%$ from from the refugee camps of Tanzania, Zambia and Malawi. The others are from countries currently in conflict;

- Identification of existing agreements with the aim of updating the data base of International Law Committments by the Mozambican State;

- In terms of participation in the prevention, management and resolution of conflicts, there was continuation of observing electoral processes in Ruanda, peace processes in Ivory Coast, Burundi and Democratic Republic of Congo as well as in the period post the Coup de Etait in the Central African Republic, S. Tomé e Príncipe and Guiné Bissau, the war in Liberia, the atempt to overthrow the government in Mauritania and the political crisis in Zimbabwe;

- In the area of Bilateral Relationship, the country strengtned the economic relations with african countries. Joint Cooperation Commission sessions with Morocco, Algeria dn South Africa can be highlighted.

- Signing, with South Africa, of a memorandum of agreement on the initiative for the development of energy in the North of Mozambique. In this aspect the supply of 50 megawatts of additional energy constitutes a point to be highlighted;

- With Morocco the results are translated in the granting of 20 scholarships for studying in higher, technical and professional education. 
The Defense Sector completed the following actions:

- Approval of Presidential Decree $N^{0} 4 / 2003$, of 27th December, on the responsibilities and competencies of the Ministry of National Defense;

- Approval of Decree $n^{\circ} 48 / 2003$, dated 24th December on the Organic Structure of the Mozambique Armed Defense Forces;

- Approval of Decree $n^{\circ}$ 63/2003 dated 24th December on medical and medicinal assistance;

- Approval of Decree $n^{\circ} 62 / 2003$ dated 24th December on the creation of the Military Academy.

- Design and appreciation, by the National Council of Defense and Security of the Honorary and Condecorations Titles Project:

- Continuation of the process of establishing the Military Academy in Nampula;

- The programmes for the creation of a Practical School for Sergeants and the restructuring and operationalisation of the Mozambique Navy Schools was initiated;

- Participation in the peace process in Burundi under the auspices of the African Union, with an Armed Force Contingent of the Mozambique Defense Force. The Group consists of 228 soldiers stationed in that country since September 2003;

- Participation with Military Observers in the Republics of East Timor and Democratic Congo, since 2000 and 2002 respectively.

- In the area of demining more than $800.000 \mathrm{~m}^{2}$ were demined in the north, centre and south regions andd this allowed the rehabilitation of the road between Niassa and Cabo Delgado, and the construction of a new water treatment and supply station in Dondo. This station is to supply Beira City, Dondo and Mafambisse with water. The demining has also created conditions for agricultural and other social related activities;

- Organisation and implementation of executive courses on Defense Management attended by military and civil personnel, including paramilitary institutions and Parliament;

- In the scope of recruitment and renovation of the military force around 2,000 new recruits were incorporated in two phases. Of this number 34 recruits are female and this required an extra effort for the creation of special and adequate conditions for the girls in the training camps;

- Completion and equipping of the Military Residential Block in the Albasine area and start of phase II of the project consisting of the construction of social Infrastructure, with great impact on the military social group;

- Rehabilitation of various military Infrastructure; currently the rehabilitation of the 'Quartel General' in Maputo is underway, as well as the 
rehabilitation of Manhiça Military Training Camp, Tete Brigade Barracks, Maputo Military Hospital, Montepuez Training Centre, Logistics Training Centre, Mavalane Air Base, and equipment and war material deposits in Maputo, Beira and Nacala.

- Participation in Regional Forums within the scope of SADC (Inter-State Committee on Defense and Security). Amongst other aspects the following can be highlighted: the role the sector had at regional level in the coordination and design of an Indicative Strategic Plan of the Organ (SIPO), later approved by the SADC Organ; and participation in the SADC Mutual Defense Pact;

- In the scope of exercising the presidency and later the integration InterState Committee Troika on Defense and Security (CIEDS) the following can be highlighted: participation in the efforts to coordinate SADC's View Point in relation with Peace and Security Council of the African Union and of the African Alert Force;

- The beginning of activities in Maputo of the CPLP Strategic Analysis Centre;

- Participation in joint military force exercises aimed at peace operations and humanitarian actions. The organization and execution in Maputo of the "felino" military exercice within the scope of CPLP can be highlighted in this area;

\section{BUDGET EXECUTION}

The budget policy in 2003 had a number of main aspects:

- Continue to work towards maintaining a sustainable economic and social development based in strict and rational use of public resources and in the maintenance of social effort for the prosecution of the strategy for the reduction of poverty

- The implementation of SISTAFE constitutes to be a fundamental step towards fiscal discipline and greater transparency and efficiency in the use of State resources in order to ensure that public expenditure is more efficient in acheiving poverty reduction and in creating the conditions for sustainable economic growth.

- Make efforts to reinforce the collection of State revenues in the scope of reforms of the State financial administration. Thus the government has been implementing taxation reforms concerning taxation of domestic and international commercial activity, aimed at the enlargement of the tax base and achievement of better performance in revenue collection.

- Promote social justice and integrate a series of fundamental initiatives for the national development and the reduction of poverty. 
The performance of this policy shows that in general the objectives of the budget are being met.

To achieve these objectives, a number of measures and actions were implemented. Of these the following can be highlighted:

- The introduction from $1^{\text {st }}$ January 2003 of new taxes on income namely the tax on income of individuals and company income tax. These taxes replace the previous 5 taxes namely: industrial contribution, tax on work revenue - section $\mathrm{A}$, tax on revenue - section $\mathrm{B}$, complementary tax and the Urban building contribution

- The introduction from January, 1 st 2003 of a tax on vehicles that replaces the Compensation Tax and the Manifest of Automobile Vehicles that covers cars, motorcycles, aeroplanes and recreation boats, using objective and simplified criteria for its calculation

- The introduction of revised stamp duty tax rates

- The computation of management control information concerning the taxation of domestic economic activity, in the context of the modernisation of the tax system and its administration

- Improvements in the operation of units devoted to large tax payers, namely special Finance Institutions (Repartições de Finanças Especiais) from 2002

- Continuation of actions with the objective of improving the inspection and auditing of taxes and duties

- The training and continued capacity-building of staff in order to have a more dynamic follow-up of tax reforms under way

- Approval of new Customs Guidelines in order to elicit greater trust from economic agents and thus enlarge the tax base. The minimum rate of customs duties is now $25 \%$ instead of the previous $30 \%$

- Abolition of the Pre-Declaration process in the import of goods

- Actions to strengthen the Tax Administration in the implementation stage of the Plan for the Installation of a Tributary Authority.

- Introduction in the main financial institutions (Repartições de Finanças) of a revenue collection computing system aimed at ensuring better controls.

- Review and re-edition of the customs legislation, namely the regulation of customs transits; customs storehouses; storehouses for oil products; international terminals for goods; customs regime for industrial free zones; activities around the dispatch of goods; pre-embark inspection (the SASOL special case); extension of special regime for industries using sugar and the regulation of temporary import of vehicles 
- Redefinition of the strategy to fight corruption and smuggling, through a system of intelligence and close collaboration with the Police of the Republic of Mozambique and Border Guards;

- There was a seminar on a strategy in the Post-HIPC strategy of Mozambique with the involvement of all the main sectors of PARPA and in which various scenarios were formulated on the country's debt. This seminar was preceded by work on updating data related with the foreign debt.

\section{VII.1. REVENUE COLLECTION}

The following table shows revenue collected in 2003:

\begin{tabular}{|c|c|c|c|c|c|c|}
\hline State revenue $-10^{9} \mathrm{MT}$ & $\begin{array}{r}\text { Law } \\
2003 \\
\end{array}$ & $\begin{array}{r}\text { Act } \\
2002 \\
\end{array}$ & 2003 & $\begin{array}{l}\% \text { of } \\
2002 \\
\end{array}$ & 2003 & $\begin{array}{c}\begin{array}{c}\text { Variation in pp } \\
\text { of GDP }\end{array} \\
\end{array}$ \\
\hline FISCAL REVENUE & 14,191 & 10,629 & 13,629 & $12.5 \%$ & $13.3 \%$ & $0.8 \%$ \\
\hline Income taxes & 2,588 & 2,116 & 3,235 & $2.5 \%$ & $3.1 \%$ & $0.7 \%$ \\
\hline Taxes on goods and services & 9,086 & 8,255 & 10,028 & $9.7 \%$ & $9.8 \%$ & $0.1 \%$ \\
\hline of which: taxes of external commerce & 2,165 & 1,851 & 2,229 & $2.2 \%$ & $2.2 \%$ & $0.0 \%$ \\
\hline Other taxes & 2,518 & 258 & 366 & $0.3 \%$ & $0.4 \%$ & $0.1 \%$ \\
\hline NON-FISCAL REVENUES & 1,168 & 1,428 & 1,085 & $1.7 \%$ & $1.1 \%$ & $-0.6 \%$ \\
\hline TOTAL & 15,359 & 12,057 & 14,714 & $14.2 \%$ & $14.3 \%$ & $0.2 \%$ \\
\hline
\end{tabular}

In 2003, the revenue was 14.714 billion representing $14.3 \%$ of the GDP. The revenue collected in 2003 represents a nominal growth of $22.0 \%$ and a real growth of $7.6 \%$ compared to the collection of revenue in 2002 . This volume of revenue collection for 2003 corresponds to $96 \%$ of what was programmed by the Government.

Of the total amount collected, the biggest contribution is from fiscal revenues. However, around $68 \%$ of the revenue resulted from taxation on goods and services while the revenue collected from income tax contributed with approximately $22 \%$ of the total revenue collected. Note that the revenue from income tax grew in real terms by $34.8 \%$ compared to previous year. This clearly shows the positive results of the introduction of new taxes such as IRPS and IRPC.

\section{VII.2. CURRENT EXPENDITURE}

In general, the level of expenditure in 2003 fell within what was planned, with the exception of expenditure on personnel and debt charges. 


\begin{tabular}{|c|c|c|c|c|c|c|}
\hline Current expenditure $-10^{y} \mathrm{MT}$ & $\begin{array}{r}\text { Law } \\
2003\end{array}$ & $\begin{array}{r}\text { Act } \\
2002\end{array}$ & 2003 & $\begin{array}{r}\% \text { of } \\
2002\end{array}$ & 2003 & $\begin{array}{c}\text { Variation in pp } \\
\text { of GDP }\end{array}$ \\
\hline Compensation to employees & 7,579 & 6,206 & 7,734 & $7.3 \%$ & $7.5 \%$ & $0.2 \%$ \\
\hline Goods and services & 4,359 & 3,163 & 4,039 & $3.7 \%$ & $3.9 \%$ & $0.2 \%$ \\
\hline of which: other expenditures & 396 & 363 & 822 & $0.4 \%$ & $0.8 \%$ & $0.4 \%$ \\
\hline Debt interest & 1,176 & 1,274 & 1,319 & $1.5 \%$ & $1.3 \%$ & $-0.2 \%$ \\
\hline Transfer payments & 3,304 & 2,826 & 3,250 & $3.3 \%$ & $3.2 \%$ & $-0.2 \%$ \\
\hline TOTAL & 16,287 & 13,469 & 16,342 & $15.8 \%$ & $15.9 \%$ & $0.1 \%$ \\
\hline TOTAL EXCL. DEBT INTEREST & 15,111 & 12,195 & 15,023 & $14.3 \%$ & $14.6 \%$ & $0.3 \%$ \\
\hline
\end{tabular}

Current expenditures excluding debt charges are 15.023 billion representing $14.6 \%$ of GDP. This item represents a nominal growth of $23.2 \%$ and a real growth of $8.6 \%$ in current expenditure excluding debt charges. Within current expenditure, the biggest burden continues to be in the area of personnel which accounts for $47 \%$ of the total. However, it should be noted that other current expenditures show an accelerated growth in 2003 mainly due to the expenditures incurred under the Local Elections of November 19.

\begin{tabular}{|c|c|c|c|c|c|c|}
\hline Investment expenditure $-10^{9} \mathrm{MT}$ & \begin{tabular}{r|} 
Law \\
2003 \\
\end{tabular} & $\begin{array}{r}\mathrm{Ac} \\
2002 \\
\end{array}$ & 2003 & $\begin{array}{l}\% \text { of } \\
2002\end{array}$ & 2003 & $\begin{array}{c}\text { Variation in } p p \\
\text { of GDP }\end{array}$ \\
\hline Financed internally & 3,760 & 3,167 & 3,662 & $3.7 \%$ & $3.6 \%$ & $-0.2 \%$ \\
\hline Financed externally & 10,153 & 8,982 & 9,704 & $10.5 \%$ & $9.4 \%$ & $-1.1 \%$ \\
\hline Grants & 7,125 & 6,348 & 6,671 & $7.5 \%$ & $6.5 \%$ & $-1.0 \%$ \\
\hline Borrowing & 3,028 & 2,634 & 3,033 & $3.1 \%$ & $3.0 \%$ & $-0.1 \%$ \\
\hline TOTAL & 13,912 & 12,149 & 13,366 & $14.3 \%$ & $13.0 \%$ & $-1.3 \%$ \\
\hline
\end{tabular}

Investment (capital) expenditure in 2003 was MT 13.366 billion of which $27.4 \%$ was financed internally, and $72.6 \%$ from external sources. Within these investment programme expenditures, used in the fight against poverty, the largest single source of funding is (external) grants, which grew by $5.1 \%$.

\begin{tabular}{|c|c|c|c|c|c|c|}
\hline Summary fiscal Map - $10^{9} \mathrm{MT}$ & \begin{tabular}{r|} 
Law \\
2003 \\
\end{tabular} & $\begin{array}{r}\mathrm{AC} \\
2002 \\
\end{array}$ & 2003 & $\begin{array}{l}\% \text { of } \\
2002 \\
\end{array}$ & 2003 & $\begin{array}{c}\begin{array}{c}\text { Variation in } p p \\
\text { of GDP }\end{array} \\
\end{array}$ \\
\hline REVENUE & 15,359 & 12,057 & 14,714 & $14.2 \%$ & $14.3 \%$ & $0.2 \%$ \\
\hline CURRENT EXPENDITURE & 16,287 & 13,469 & 16,342 & $15.8 \%$ & $15.9 \%$ & $0.1 \%$ \\
\hline INVESTMENT EXPENDITURE & 13,912 & 12,149 & 13,366 & $14.3 \%$ & $13.0 \%$ & $-1.3 \%$ \\
\hline NET FINANCING & 34 & 3,414 & 481 & $4.0 \%$ & $0.5 \%$ & $-3.5 \%$ \\
\hline OTHER REVENUE (-)/SPENDING(+) & 0 & -210 & 252 & $-0.2 \%$ & $0.2 \%$ & $0.5 \%$ \\
\hline EXPENDITURE TOTAL & 30,200 & 25,408 & 29,960 & $29.8 \%$ & $29.2 \%$ & $-0.7 \%$ \\
\hline EXPENDITURE TOTAL INCL. NET FINANCINC & 30,234 & 28,822 & 30,441 & $33.8 \%$ & $29.6 \%$ & $-4.2 \%$ \\
\hline CURRENT BALANCE & -928 & $-1,412$ & $-1,628$ & $-1.7 \%$ & $-1.6 \%$ & $0.1 \%$ \\
\hline OVERALL DEFICIT BEFORE GRANTS & $-14,875$ & $-16,765$ & $-15,726$ & $-19.7 \%$ & $-15.3 \%$ & $4.4 \%$ \\
\hline GRANTS & 11,072 & 10,020 & 10,841 & $11.8 \%$ & $10.6 \%$ & $-1.2 \%$ \\
\hline OVERALL DEFICIT AFTER GRANTS & $-3,803$ & $-6,745$ & $-4,886$ & $-7.9 \%$ & $-4.8 \%$ & $3.2 \%$ \\
\hline CENTR. BANK HIPC TRANSFERS & 348 & 538 & 237 & $0.6 \%$ & $0.2 \%$ & $-0.4 \%$ \\
\hline BORROWING & 4,471 & 5,401 & 4,741 & $6.3 \%$ & $4.6 \%$ & $-1.7 \%$ \\
\hline Disbursements & 5,408 & 5,886 & 5,332 & $6.9 \%$ & $5.2 \%$ & $-1.7 \%$ \\
\hline Amortization & -937 & -485 & -591 & $-0.6 \%$ & $-0.6 \%$ & $0.0 \%$ \\
\hline NET INTERNAL CREDIT & $-1,016$ & 806 & -92 & $0.9 \%$ & $-0.1 \%$ & $-1.0 \%$ \\
\hline
\end{tabular}


In real terms revenue grew by $7.6 \%$ while expenditure grew by $4.0 \%$. This indicates greater efficiency in the State's collection of revenues and also their greater coverage of State expenditures, thereby reducing foreign dependence. Thus it can be noted that there are some improvements in terms of the overall deficit before and after grants. Reviewing net internal credit, it can be noted the State met its objectives to the point of having saved MT 403 billion. 


\section{VII.3. EXPENDITURE IN PARPA PRIORITY AREAS}

The following table shows the global expenditure in the Main sectors of PARPA.

\begin{tabular}{|c|c|c|c|c|c|}
\hline & 2001 & 2002 & 2003 & 2003 & 2004 \\
\hline & CGE & CGE & Lei & RE & Law \\
\hline \multicolumn{6}{|l|}{ TOTAL EXPENDITURE IN PRIORITY SECTORS } \\
\hline In \% GDP & 19.4 & 19.4 & 18.0 & 17.7 & 17.3 \\
\hline In \% Total Expenditure & 64.3 & 62.0 & 63.2 & 61.2 & 62.6 \\
\hline in \% Total Expenditure, exl. debt interest & 65.8 & 65.3 & 65.7 & 64.1 & 65.0 \\
\hline \multicolumn{6}{|l|}{$\begin{array}{l}\text { TOTAL EXPENDITURE IN PRIORITY SECTORS } \\
\text { IN \% TOTAL EXPENDITURE (EXL. DEBT INTEREST) }\end{array}$} \\
\hline EDUCATION & 23.3 & 18.0 & 17.8 & 18.5 & 21.3 \\
\hline ENSINO GERAL (Primary and Secondary Education) & 18.5 & 15.4 & 14.1 & 15.1 & 17.4 \\
\hline ENSINO SUPERIOR (Higher Education) & 4.8 & 2.6 & 3.7 & 3.4 & 3.9 \\
\hline HEALTH & 9.9 & 12.6 & 14.9 & 13.6 & 11.1 \\
\hline HIVIAIDS & 0.5 & 0.8 & 0.3 & 0.2 & 0.7 \\
\hline INFRASTRUCTURE & 17.4 & 16.5 & 11.8 & 11.5 & 13.8 \\
\hline ROADS & 9.0 & 7.9 & 7.7 & 7.3 & 6.4 \\
\hline WATER AND OTHER PUBLIC WORKS & 8.4 & 8.5 & 4.1 & 4.1 & 7.4 \\
\hline AGRICULTURE AND RURAL DEVELOPMENT & 3.4 & 5.3 & 6.9 & 6.6 & 6.3 \\
\hline GOVERNANCE, SECURITY AND THE JUDICIAL SYSTEM & 7.7 & 8.1 & 8.9 & 8.5 & 9.7 \\
\hline SECURITY AND PUBLIC ORDER & 5.0 & 5.4 & 4.7 & 4.8 & 4.9 \\
\hline GOVERNANCE & 1.2 & 1.0 & 1.9 & 1.9 & 2.5 \\
\hline JUDICIAL SYSTEM & 1.5 & 1.7 & 2.3 & 1.7 & 2.3 \\
\hline OTHER PRIORITY SECTORS & 3.6 & 4.1 & 5.1 & 5.1 & 2.1 \\
\hline WELFARE & 0.9 & 0.9 & 1.1 & 1.1 & 0.8 \\
\hline LABOUR AND EMPLOYMENT & 0.4 & 0.5 & 0.5 & 0.4 & 0.4 \\
\hline ENERGY AND MINERAL RESOURCES & 2.3 & 2.7 & 3.6 & 3.6 & 0.9 \\
\hline
\end{tabular}

The expenditures in the main sectors of PARPA are at $61.2 \%$ of the total expenditure (current + Investment). If the public debt interest is removed from the total expenditure, the expenditures in the main sectors will be above $64.1 \%$. As the table above shows, greater part of the resources in the priority sectors is absorbed by Education, Health and Infrastructure.

From the 2003 accounts and comparing with the previous year, the education, Health, Agriculture, Governance and other priority sectors had an execution above the execution of 2002.

Despite that PARPA 2001-2005 refers that the expenditures in the main areas should total $74 \%$ in 2005 , the budget exercise show that the expenditures in the PARPA main sectors will not go beyond $67 \%$ of total expenditure excluding the interests of the public debt. Further to that, the PARPA 2001-2005 paper itself, on table 7.4. "Expenditure evolution in the priority sectors, $1999-2005$ ", refers to this percentage that should reach about $65 \%$ in 2005.

This matter was considered when discussing the ad-hoc report on PARPA implementation in 2002, in the following terms: "Taking into account the limitations on revenue, the provision of more resources to the priority sectors would have a negative impact on the performance of other sectors which, despite of not being priority are important to the development of the country. In this context, to increase the efficiency becomes the top priority in the management of public expenditure".

The following table shows the budget execution of expenditure in PARPA priority sectors: 
TOTAL SPENDING ON PRIORITY PARPA AREAS

(in billions of Meticais, unless otherwise stated)

\begin{tabular}{|c|c|c|c|}
\hline & \begin{tabular}{|l|}
2003 \\
Law \\
\end{tabular} & \begin{tabular}{|l}
2003 \\
RE \\
\end{tabular} & $\begin{array}{c}\text { Execution } \\
\text { Rate }\end{array}$ \\
\hline TOTAL EXPENDITURE IN PRIORITY SECTORS & $19,262.1$ & $18,196.6$ & $94 \%$ \\
\hline EDUCATION & $5,212.8$ & $5,264.1$ & $101 \%$ \\
\hline ENSINO GERAL (Primary and Secondary Education) & $4,123.6$ & $4,290.9$ & $104 \%$ \\
\hline ENSINO SUPERIOR (Higher Education) & $1,089.2$ & 973.2 & $89 \%$ \\
\hline HEALTH & $4,377.3$ & $3,866.2$ & $88 \%$ \\
\hline HIVIAIDS & 87.2 & 60.9 & $70 \%$ \\
\hline INFRASTRUCTURE & $3,458.7$ & $3,257.1$ & $94 \%$ \\
\hline ROADS & $2,250.8$ & $2,082.9$ & $93 \%$ \\
\hline WATER AND OTHER PUBLIC WORKS & $1,207.9$ & $1,174.2$ & $97 \%$ \\
\hline AGRICULTURE AND RURAL DEVELOPMENT & $2,015.5$ & $1,883.2$ & $93 \%$ \\
\hline GOVERNANCE, SECURITY AND THE JUDICIAL SYSTEM & $2,611.3$ & $2,411.0$ & $92 \%$ \\
\hline SECURITY AND PUBLIC ORDER & $1,379.5$ & $1,366.6$ & $99 \%$ \\
\hline GOVERNANCE & 559.9 & 552.7 & $99 \%$ \\
\hline JUDICIAL SYSTEM & 671.9 & 491.6 & $73 \%$ \\
\hline OTHER PRIORITY SECTORS & $1,499.3$ & $1,454.1$ & $97 \%$ \\
\hline WELFARE & 310.3 & 307.6 & $99 \%$ \\
\hline LABOUR AND EMPLOYMENT & 137.0 & 126.3 & $92 \%$ \\
\hline ENERGY AND MINERAL RESOURCES & $1,051.9$ & $1,020.1$ & $97 \%$ \\
\hline
\end{tabular}

RE: Relatório de Execução

When compared with the initial programme provided for by the Budget Law of 2003 , in general, expenditure in the priority sectors was at $94 \%$.

The Education sector is the one representing a budget execution above $100 \%$. During the 2003 exercise and due to the importance of this sector, there was a need to reinforce the item of expenditure on personnel that cover essentially expenditures for teachers' salaries. In relation to other sectors, in general they have a satisfactory budget execution for the fulfilment of the policy objectives set planed for 2003, even with the level of execution for payment of interests of public debt being above the planned.

\section{Recurrent Expenses}

The priority sectors absorbed 7.794 billion in 2003 corresponding to $51.9 \%$ of the total reccurent expenditure excluding the public debt interests. This amount represents a nominal increase of $18.4 \%$ compared with the execution experienced in 2002.

The major burden in current expenditure in the priority sectors continues to be on the sectors of Education, Health, Governance, Safety and Judicial System. In 2002, Education and Health represented $68 \%$ of current expenditure within the areas for fundamental actions. This figure corresponds to the same situation expenditure in the previous year. In this item of expenditure, the government effort is noticeable in channelling more resources to the priority sectors of PARPA with a view on reccurent expenditure. 


\begin{tabular}{|c|c|c|c|c|}
\hline RECURRENT SPENDING & 2001 & 2002 & 2003 & 2004 \\
\hline & CGE & CGE & RE & Law \\
\hline TOTAL EXPENDITURE IN PRIORITY SECTORS & $5,264.2$ & $6,580.5$ & $7,794.3$ & $9,730.4$ \\
\hline In \% GDP & 7.4 & 7.7 & 7.6 & 8.0 \\
\hline In \% Total Expenditure & 50.6 & 48.7 & 47.7 & 50.5 \\
\hline in \% Total Expenditure, exl. debt interest & 53.0 & 53.7 & 51.9 & 53.9 \\
\hline \multicolumn{5}{|l|}{$\begin{array}{l}\text { TOTAL EXPENDITURE IN PRIORITY SECTORS } \\
\text { IN \% TOTAL EXPENDITURE (EXL. DEBT INTEREST) }\end{array}$} \\
\hline EDUCATION & $24.7 \%$ & $25.2 \%$ & $25.8 \%$ & $25.8 \%$ \\
\hline ENSINO GERAL (Primary and Secondary Education) & $21.5 \%$ & $22.0 \%$ & $22.5 \%$ & $22.0 \%$ \\
\hline ENSINO SUPERIOR (Higher Education) & $3.2 \%$ & $3.2 \%$ & $3.3 \%$ & $3.9 \%$ \\
\hline HEALTH & $10.6 \%$ & $10.7 \%$ & $9.5 \%$ & $11.4 \%$ \\
\hline HIVIAIDS & $0.0 \%$ & $0.0 \%$ & $0.2 \%$ & $0.2 \%$ \\
\hline INFRASTRUCTURE & $0.6 \%$ & $1.3 \%$ & $1.1 \%$ & $0.4 \%$ \\
\hline ROADS & $0.0 \%$ & $0.0 \%$ & $0.0 \%$ & $0.0 \%$ \\
\hline WATER AND OTHER PUBLIC WORKS & $0.6 \%$ & $1.3 \%$ & $1.1 \%$ & $0.4 \%$ \\
\hline AGRICULTURE AND RURAL DEVELOPMENT & $1.8 \%$ & $1.8 \%$ & $1.4 \%$ & $2.1 \%$ \\
\hline GOVERNANCE, SECURITY AND THE JUDICIAL SYSTEM & $13.2 \%$ & $12.9 \%$ & $12.2 \%$ & $12.3 \%$ \\
\hline SECURITY AND PUBLIC ORDER & $9.9 \%$ & $9.5 \%$ & $8.7 \%$ & $8.2 \%$ \\
\hline GOVERNANCE & $0.9 \%$ & $1.0 \%$ & $1.0 \%$ & $0.9 \%$ \\
\hline JUDICIAL SYSTEM & $2.3 \%$ & $2.5 \%$ & $2.6 \%$ & $3.1 \%$ \\
\hline OTHER PRIORITY SECTORS & $2.1 \%$ & $1.8 \%$ & $1.8 \%$ & $1.8 \%$ \\
\hline WELFARE & $1.0 \%$ & $0.9 \%$ & $0.8 \%$ & $0.8 \%$ \\
\hline LABOUR AND EMPLOYMENT & $0.7 \%$ & $0.6 \%$ & $0.5 \%$ & $0.5 \%$ \\
\hline ENERGY AND MINERAL RESOURCES & $0.5 \%$ & $0.3 \%$ & $0.4 \%$ & $0.4 \%$ \\
\hline
\end{tabular}

\section{Investment Expenditure}

The expenditure on investment in the priority sectors of PARPA was at 10.402 billion that corresponds to $77.8 \%$ of the total investment expenditure. This expenditure amount represents $19 \%$ of nominal growth of expenditure investment as compared to 2002.

The sectors of Infrastructure, Agriculture and Rural Development, Education and Health are the one that presents the highest level of absorption of investment resources. Adding these sectors, they represent $83 \%$ of total expenditures of the PARPA sectors and $64 \%$ of total investment expenditure. 


\begin{tabular}{|c|c|c|c|c|}
\hline INVESTMENT EXPENDITURE & 2001 & 2002 & 2003 & 2004 \\
\hline & CGE & CGE & RE & Law \\
\hline TOTAL DA DESPESA NOS SECTORES PRIORITÁRIOS & $8,510.0$ & $8,742.5$ & $10,402.3$ & $11,297.3$ \\
\hline In \% GDP & 12.0 & 10.3 & 10.1 & 9.3 \\
\hline In \% Total Investment Expenditure & 77.3 & 78.1 & 77.8 & 78.8 \\
\hline EDUCATION & $22.0 \%$ & $10.2 \%$ & $10.4 \%$ & $15.5 \%$ \\
\hline ENSINO GERAL (Primary and Secondary Education) & $15.8 \%$ & $8.2 \%$ & $6.8 \%$ & $11.6 \%$ \\
\hline ENSINO SUPERIOR (Higher Education) & $6.2 \%$ & $2.0 \%$ & $3.6 \%$ & $3.9 \%$ \\
\hline HEALTH & $9.3 \%$ & $14.6 \%$ & $18.3 \%$ & $10.9 \%$ \\
\hline HIVIAIDS & $1.0 \%$ & $1.6 \%$ & $0.3 \%$ & $1.4 \%$ \\
\hline INFRASTRUCTURE & $32.6 \%$ & $33.0 \%$ & $23.1 \%$ & $30.7 \%$ \\
\hline ROADS & $17.1 \%$ & $16.6 \%$ & $15.6 \%$ & $14.4 \%$ \\
\hline WATER AND OTHER PUBLIC WORKS & $15.5 \%$ & $16.4 \%$ & $7.6 \%$ & $16.3 \%$ \\
\hline AGRICULTURE AND RURAL DEVELOPMENT & $4.8 \%$ & $9.0 \%$ & $12.5 \%$ & $11.6 \%$ \\
\hline GOVERNANCE, SECURITY AND THE JUDICIAL SYSTEM & $2.8 \%$ & $2.9 \%$ & $4.3 \%$ & $6.4 \%$ \\
\hline SECURITY AND PUBLIC ORDER & $0.5 \%$ & $0.9 \%$ & $0.5 \%$ & $0.7 \%$ \\
\hline GOVERNANCE & $1.4 \%$ & $1.0 \%$ & $3.1 \%$ & $4.5 \%$ \\
\hline JUDICIAL SYSTEM & $0.8 \%$ & $0.9 \%$ & $0.8 \%$ & $1.2 \%$ \\
\hline OTHER PRIORITY SECTORS & $4.9 \%$ & $6.7 \%$ & $8.9 \%$ & $2.4 \%$ \\
\hline WELFARE & $0.9 \%$ & $0.9 \%$ & $1.4 \%$ & $0.6 \%$ \\
\hline LABOUR AND EMPLOYMENT & $0.1 \%$ & $0.5 \%$ & $0.3 \%$ & $0.2 \%$ \\
\hline ENERGY AND MINERAL RESOURCES & $3.9 \%$ & $5.4 \%$ & $7.2 \%$ & $1.6 \%$ \\
\hline
\end{tabular}

\section{a) Internally Financed Component of Investment}

The investment expenditure with internal financing in the main sectors of PARPA was 2.054 billion MTs that represents $56.1 \%$ of all investment expenditure which is financed internally. Compared with the 2002 budget performance, it can be noted in this component of expenditure an effort to keep the growing flows of resources in these main sectors of PARPA.

\begin{tabular}{|c|c|c|c|c|}
\hline \multirow[t]{2}{*}{ INTERNALLY FINANCED INVESTMENT EXPENDITURE } & 2001 & 2002 & 2003 & 2004 \\
\hline & CGE & CGE & RE & Plan \\
\hline TOTAL EXPENDITURE IN PRIORITY SECTORS & $1,700.9$ & $1,695.8$ & $2,054.3$ & $2,500.2$ \\
\hline In \% GDP & 2.4 & 2.0 & 2.0 & 2.1 \\
\hline In \% Total Investment Expenditure (internal) & 55.0 & 52.0 & 56.1 & 60.6 \\
\hline \multicolumn{5}{|l|}{$\begin{array}{l}\text { TOTAL EXPENDITURE IN PRIORITY SECTORS } \\
\text { AS \% OF TOTAL INVESTMENT, FINANCED INTERNALLY }\end{array}$} \\
\hline EDUCATION & $6.4 \%$ & $7.0 \%$ & $8.1 \%$ & $10.8 \%$ \\
\hline ENSINO GERAL (Primary and Secondary Education) & $4.5 \%$ & $5.0 \%$ & $6.8 \%$ & $8.5 \%$ \\
\hline ENSINO SUPERIOR (Higher Education) & $1.9 \%$ & $2.0 \%$ & $1.3 \%$ & $2.3 \%$ \\
\hline HEALTH & $5.9 \%$ & $3.5 \%$ & $4.5 \%$ & $4.8 \%$ \\
\hline HIVIAIDS & $1.8 \%$ & $2.1 \%$ & $1.0 \%$ & $1.5 \%$ \\
\hline INFRASTRUCTURE & $27.7 \%$ & $27.5 \%$ & $25.6 \%$ & $27.8 \%$ \\
\hline ROADS & $23.1 \%$ & $19.3 \%$ & $20.1 \%$ & $20.3 \%$ \\
\hline WATER AND OTHER PUBLIC WORKS & $4.7 \%$ & $8.1 \%$ & $5.5 \%$ & $7.5 \%$ \\
\hline AGRICULTURE AND RURAL DEVELOPMENT & $2.6 \%$ & $2.9 \%$ & $4.8 \%$ & $3.3 \%$ \\
\hline GOVERNANCE, SECURITY AND THE JUDICIAL SYSTEM & $7.6 \%$ & $6.6 \%$ & $9.6 \%$ & $9.6 \%$ \\
\hline SECURITY AND PUBLIC ORDER & $1.9 \%$ & $1.7 \%$ & $1.7 \%$ & $2.4 \%$ \\
\hline GOVERNANCE & $2.8 \%$ & $2.3 \%$ & $5.2 \%$ & $3.3 \%$ \\
\hline JUDICIAL SYSTEM & $2.9 \%$ & $2.6 \%$ & $2.7 \%$ & $3.9 \%$ \\
\hline OTHER PRIORITY SECTORS & $2.9 \%$ & $2.3 \%$ & $2.5 \%$ & $2.8 \%$ \\
\hline WELFARE & $0.9 \%$ & $0.6 \%$ & $0.7 \%$ & $0.6 \%$ \\
\hline LABOUR AND EMPLOYMENT & $0.2 \%$ & $0.1 \%$ & $0.2 \%$ & $0.4 \%$ \\
\hline ENERGY AND MINERAL RESOURCES & $1.8 \%$ & $1.5 \%$ & $1.6 \%$ & $1.8 \%$ \\
\hline
\end{tabular}

b) Externally Financed Component of Investment. 
The investment expenditure with foreign financing was of 9.707 thousand million representing $86 \%$ of the foreign investment expenditure. Compared with the previous year it can be noted that the investment expenditure has been growing a lot although the foreign resources for investment projects fell from 2002 to 2003.

\begin{tabular}{|c|c|c|c|c|}
\hline \multirow[t]{2}{*}{ EXTERNALLY FINANCED INVESTMENT EXPENDITURE } & \multirow{2}{*}{$\begin{array}{l}2001 \\
\text { CGE } \\
\end{array}$} & \multirow{2}{*}{2002} & \multirow{2}{*}{$\begin{array}{c}2003 \\
\text { RE } \\
\end{array}$} & \multirow{2}{*}{$\begin{array}{l}2004 \\
\text { Plan } \\
\end{array}$} \\
\hline & & & & \\
\hline TOTAL EXPENDITURE IN PRIORITY SECTORS & $6,809.1$ & $6,945.8$ & $8,348.0$ & $8,481.7$ \\
\hline In \% GDP & 7.8 & 8.2 & 8.1 & 7.0 \\
\hline In \% Total Investment Expenditure (external) & 86.0 & 87.5 & 86.0 & 83.1 \\
\hline \multicolumn{5}{|l|}{$\begin{array}{l}\text { TOTAL EXPENDITURE IN PRIORITY SECTORS } \\
\text { AS \% OF TOTAL INVESTMENT, FINANCED EXTERNALLY }\end{array}$} \\
\hline EDUCATION & 28.0 & 11.5 & 11.3 & 17.4 \\
\hline ENSINO GERAL (Primary and Secondary Education) & 20.2 & 9.5 & 6.9 & 12.9 \\
\hline ENSINO SUPERIOR (Higher Education) & 7.8 & 2.0 & 4.4 & 4.5 \\
\hline HEALTH & 10.7 & 19.2 & 23.5 & 13.3 \\
\hline HIVIAIDS & 0.7 & 1.4 & 0.0 & 1.4 \\
\hline INFRASTRUCTURE & 34.4 & 35.3 & 22.2 & 31.9 \\
\hline ROADS & 14.7 & 15.5 & 13.8 & 12.1 \\
\hline WATER AND OTHER PUBLIC WORKS & 19.7 & 19.8 & 8.3 & 19.8 \\
\hline AGRICULTURE AND RURAL DEVELOPMENT & 5.7 & 11.5 & 15.4 & 14.9 \\
\hline GOVERNANCE, SECURITY AND THE JUDICIAL SYSTEM & 0.9 & 1.4 & 2.3 & 5.1 \\
\hline SECURITY AND PUBLIC ORDER & 0.0 & 0.6 & 0.0 & 0.0 \\
\hline GOVERNANCE & 0.9 & 0.5 & 2.3 & 5.0 \\
\hline JUDICIAL SYSTEM & 0.0 & 0.3 & 0.1 & 0.1 \\
\hline OTHER PRIORITY SECTORS & 5.6 & 8.6 & 11.3 & 2.2 \\
\hline WELFARE & 0.9 & 1.0 & 1.6 & 0.6 \\
\hline LABOUR AND EMPLOYMENT & 0.0 & 0.6 & 0.4 & 0.1 \\
\hline ENERGY AND MINERAL RESOURCES & 4.7 & 7.0 & 9.3 & 1.5 \\
\hline
\end{tabular}

It should be remembered that for the elaboration of these tables (CGE, RE) the distribution of resources in the main sectors has as base on one hand the data of execution registered and on the other hand the estimates of the execution of expenditure in particular concerning the foreign donations for projects of investment. Thus, for current expenditures and for investment expenditure with internal financing the data is easily gathered by the public accountancy and is in the budget execution reports and in the State General Report. In the case of investment expenditure with foreign sources that go for investment projects it is done an estimate taking into consideration the structure of the programmed expenditures.

As it can be observed in the following graph, 2003 was characterised by a good improvement in the effective realisation of expenditures. Both for the current expenditure as well for the investment expenditure the performance is above $90 \%$.

In the current expenditures of the main sectors of PARPA there was an increase in the execution of two percentage points in 2003 compared to 2002.

On the other hand, the investment expenditure in 2003 gained a better efficiency in the usage of resources. From 2002 to 2003, the execution of investment expenditures in the main sectors of PARPA had a big increase of 8.6 percentage points. 
Execution Rate of State Budget in the main sectors of PARPA

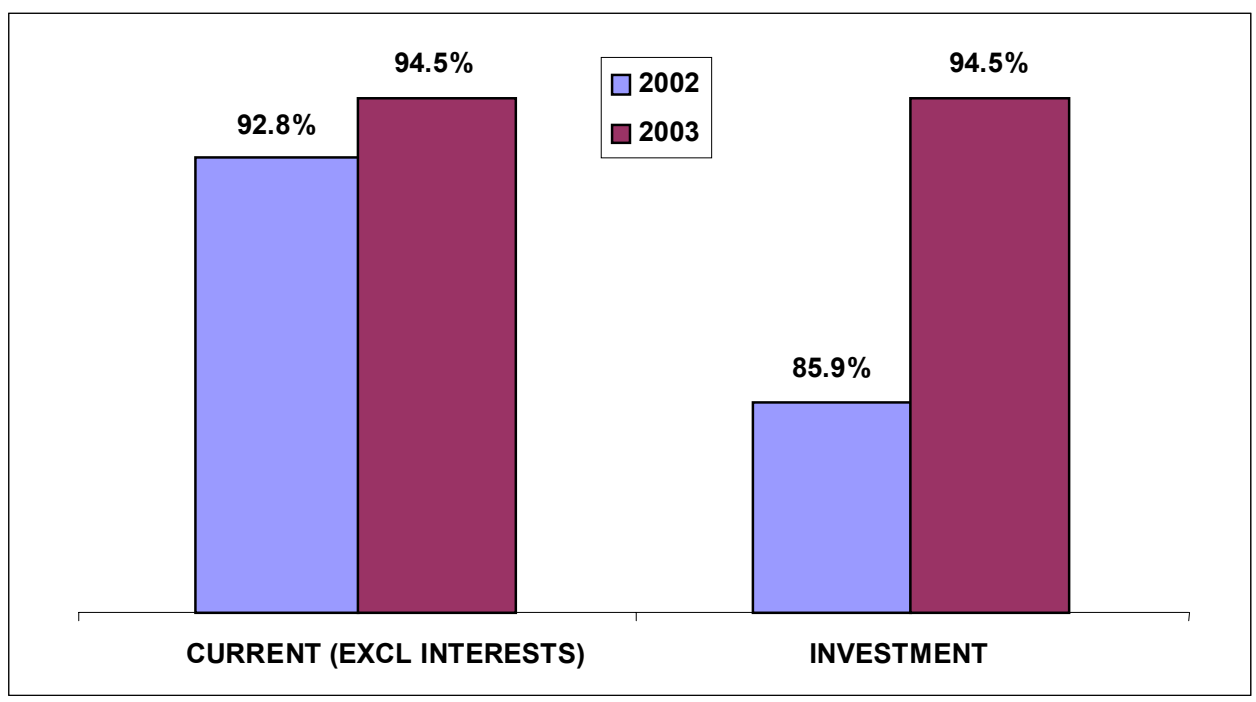

\section{FINAL CONSIDERATIONS}

The Review of the Economic and Social Plan in 2003 represents a new perspective that meets the challenges of integration of planning instruments and monitoring. This review was done through a process of consultations with the sectors and will serve as base for assessment by internal and foreign partners of the Government performance in the scope of Poverty observatory an international co-operation. Apart from giving performance results in 2003 concerning the objectives and targets set in PES and in PARPA, the document includes new chapters that enable the evaluation of the stage the country is living in terms of fighting poverty and the commitment signed by the country in the international forums.

In a context where the world economy registered a small recovery and the regional economy showed tendencies to de-accelerate, Mozambique kept a macro-economic stability that has been having in the last years. Thus, the economic growth rate kept at the same level registered in 2002 with a light tendency to fall. We highlight in these results the increase of agricultural production, in the mining sector and in transports. In spite of the de-acceleration of monetary offer in the economy, the inflation rate grew due to the strengthening of the South African rand.

The national social and demographic panorama was characterised by a reduction of poverty compared to 96/97, especially in the rural areas and in the north and central regions of the country. However, the HIV-AIDS impact shows a worrying scenario due to the high rates of prevalence of the disease. 
Analysing the evolution of the main social indicators since 2000, the fulfilment of the most part of PARPA targets and Millennium Development seem achievable although the challenges are enormous. In the scope of Education, the main sectarian indicators show a positive tendency. That is the result of the efforts to increase the access in all levels of education with special attention to girls, continuing with the challenge to improve the quality according to PARPA targets. In that direction, the curricular reform may contribute for such improvement. In the Health sector the evolution is positive, showing the analysis of its main targets real possibilities of achieving the Millennium Development targets. In the Infrastructure sector the level of execution of the programme of roads in 2003 poses huge challenges in order to meet the target of reducing to less than $5 \%$ the non-passable roads and to less than $25 \%$ the roads in poor quality until 2005 . The Agriculture sector shows a high growth, recording a meaningful recovery in the production of some crops such as tobacco and vegetables. Mozambique is engaged in improving the provision of public services through a Reform of the Public sector with emphasis in an improved State financial administration; the fight against corruption and in the decentralization/de-concentration, having given some meaningful steps in 2003. Envisaging the improvement of the atmosphere of businesses the Government made a review of the legislative package in particular in the area of investments, in the industrial, commercial and in the justice sectors.

The referred activities had a direct relation with a priority in affecting public resources to areas considered as strategic in the fight against poverty according to PARPA. The analysis of budget execution reflects a substantial improvement in the rates of execution in 2002 (current/investment/provinces). 


\section{ANNEX 1 - MEDIUM TERM MACROECONOMIC FRAMEWORK}

\begin{tabular}{|c|c|c|c|c|c|c|c|}
\hline \multirow[b]{3}{*}{ National income and prices } & \multirow{2}{*}{$\begin{array}{c}2001 \\
\text { Actual }\end{array}$} & \multirow{2}{*}{$\begin{array}{c}2002 \\
\text { Prel. }\end{array}$} & \multicolumn{2}{|c|}{2003} & \multirow{2}{*}{$\begin{array}{l}2004 \\
\text { Prog. }\end{array}$} & \multirow{2}{*}{$\begin{array}{r}2005 \\
\text { Proj. }\end{array}$} & \multirow{2}{*}{$\begin{array}{r}2006 \\
\text { Proj. }\end{array}$} \\
\hline & & & Prog. & Estimated & & & \\
\hline & \multicolumn{7}{|c|}{ (Annual percentage change, unless otherwise specified) } \\
\hline Nominal GDP (in billions of meticais) & 71,135 & 85,206 & 102,749 & 102,753 & 125,776 & 144,771 & 165,447 \\
\hline Nominal GDP (in billions of U.S. dollars) & 3.4 & 3.6 & 4.2 & 4.3 & 5.2 & 5.7 & 6.2 \\
\hline Real GDP growth & 13.0 & 7.4 & 7.0 & 7.1 & 8.4 & 6.8 & 6.5 \\
\hline GDP per capita (in U.S. dollars) & 195 & 199 & 217 & 233 & 274 & 294 & 311 \\
\hline Consumer price index (annual average) & 9.0 & 16.8 & 12.7 & 13.5 & 12.9 & 7.8 & 7.3 \\
\hline Consumer price index (end of period) & 21.9 & 9.1 & 10.8 & 13.8 & 11.0 & 8.5 & 7.0 \\
\hline \multicolumn{8}{|l|}{ External sector } \\
\hline Merchandise exports & 93.2 & -3.4 & 22.5 & 29.6 & 42.8 & 4.3 & 2.3 \\
\hline Merchandise imports & -8.6 & 26.3 & 29.4 & 9.8 & -6.1 & 18.5 & 3.4 \\
\hline Terms of trade & -1.6 & 8.7. & $\ldots$ & 4.5 & 0.5 & 4.4 & 4.0 \\
\hline Nominal effective exchange rate (end of period) $1 /$ & -23.4 & -10.7 & $\ldots$ & -10.9 & $\ldots$ & $\ldots$ & $\ldots$ \\
\hline Real effective exchange rate (end of period) $1 /$ & -9.3 & -6.4 & $\cdots$ & -3.7 & $\cdots$ & $\cdots$ & $\cdots$ \\
\hline & \multicolumn{7}{|c|}{ (In percent of GDP) } \\
\hline External current account, after grants & -14.5 & -13.1 & -22.2 & -8.6 & -2.1 & -6.4 & -6.3 \\
\hline \multicolumn{8}{|l|}{ Government budget } \\
\hline Total revenue & 13.3 & 14.2 & 14.3 & 14.3 & 14.6 & 15.0 & 15.2 \\
\hline Tax revenue & 11.8 & 12.5 & 13.2 & 13.3 & 13.5 & 13.8 & 14.0 \\
\hline Nontax revenue & 1.5 & 1.7 & 1.1 & 1.1 & 1.0 & 1.1 & 1.2 \\
\hline Total expenditure and net lending (incl. residual) & 34.7 & 33.8 & 28.7 & 29.6 & 27.7 & 27.1 & 26.2 \\
\hline Current expenditure & 14.5 & 15.8 & 16.0 & 15.9 & 15.6 & 15.4 & 15.0 \\
\hline Compensation to employees & 7.0 & 7.3 & 7.6 & 7.5 & 7.3 & 7.1 & 7.0 \\
\hline Goods and services & 3.8 & 3.7 & 3.9 & 3.9 & 4.0 & 4.0 & 4.0 \\
\hline Interest on public debt & 0.7 & 1.5 & 1.1 & 1.3 & 1.2 & 1.3 & 0.9 \\
\hline Transfer payments & 3.1 & 3.3 & 3.3 & 3.2 & 3.1 & 3.1 & 3.1 \\
\hline Capital expenditure & 16.6 & 14.3 & 12.7 & 13.0 & 12.0 & 11.6 & 11.1 \\
\hline Net lending & 3.4 & 4.0 & 0.0 & 0.5 & 0.1 & 0.1 & 0.1 \\
\hline Overall balance, before grants & -21.4 & -19.7 & -14.4 & -15.4 & -13.2 & -12.1 & -11.0 \\
\hline Total grants & 14.8 & 11.8 & 10.5 & 10.6 & 9.1 & 8.0 & 7.4 \\
\hline Overall balance, after grants & -6.6 & -7.9 & -3.9 & -4.8 & -4.0 & -4.1 & -3.6 \\
\hline Central bank transfer of HIPC assist. by the IMF & 0.7 & 0.6 & 0.3 & 0.2 & 0.3 & 0.3 & 0.3 \\
\hline Net external borrowing & 3.9 & 6.3 & 4.2 & 4.6 & 3.8 & 3.7 & 3.4 \\
\hline Net domestic financing & 1.9 & 0.9 & -0.6 & 0.0 & -0.1 & 0.1 & -0.1 \\
\hline \multicolumn{8}{|l|}{ Memorandum items: } \\
\hline Domestic primary balance & -8.5 & -5.9 & -3.7 & -3.9 & -3.3 & -3.1 & -3.0 \\
\hline Excluding bank restructuring & -6.3 & -3.6 & -3.7 & -3.9 & -3.3 & -3.1 & -3.0 \\
\hline
\end{tabular}




\begin{tabular}{rrrrrrr}
2001 & 2002 & \multicolumn{2}{c}{2003} & 2004 & 2005 & 2006 \\
\cline { 3 - 7 } Actual & Prel. & Prog. & Estimated & Prog. & Proj. & Proj. \\
\hline \multicolumn{7}{c}{ (In percent of exports of goods and nonfactor services) } \\
109.8 & 96.1 & 87.7 & 91.5 & 85.1 & 80.4 & 78.9 \\
& & & & & & \\
5.8 & 8.5 & 7.6 & 8.1 & 7.8 & 7.2 & 7.1 \\
3.6 & 5.6 & 5.2 & 5.6 & 5.6 & 5.2 & 5.3 \\
3.5 & 4.5 & 4.2 & 4.5 & 4.8 & 4.6 & 4.7 \\
& (In millions of U.S. dollars, unless otherwise specified) & & \\
-497 & -470 & -943 & -373 & -110 & -366 & -392 \\
-421 & 94 & 45 & 172 & 0 & 0 & 0 \\
531 & 625 & 670 & 797 & 797 & 797 & 797 \\
727 & 825 & 845 & 1,007 & 990 & 966 & 936 \\
5.8 & 6.1 & 4.9 & 6.9 & 7.0 & 5.9 & 5.5 \\
\hline
\end{tabular}

Net present value of total public external debt outstanding 2/

External debt service (nonfinancial public sector)

Scheduled, after original HIPC Initiative assistance

Scheduled, after enhanced HIPC Initiative assistance

Scheduled, after additional bilateral assistance

External current account, after grants

Overall balance of payments

Net international reserves (end of period)

Gross international reserves (end of period)

In months of imports of goods and nonfactor services

Sources: Mozambican authorities; and IMF estimates and projections.

2/ Public and publicly guaranteed, in percent of the three-year average of exports. The data for 1999-2000 include the impact of total debt relief granted

under the original HIPC Initiative. Data for 2001-03 include the impact of total debt relief under the enhanced HIPC initiative, additional bilateral

assistance, and new borrowing. 